CARLOS TAVEIRA AMÂNCIO

PRODUÇÃO E CARACTERIZAÇÃO DE VIDROS DE TELURETO TRIDOPADOS COM ÍONS DE TERRAS RARAS E NANOPARTÍCULAS METÁLICAS PARA USO EM DISPLAYS COLORIDOS

SÃO PAULO 
CARLOS TAVEIRA AMÂNCIO

\section{PRODUÇÃO E CARACTERIZAÇÃO DE VIDROS DE TELURETO TRIDOPADOS COM ÍONS DE TERRAS RARAS E NANOPARTÍCULAS METÁLICAS PARA USO EM DISPLAYS COLORIDOS}

Dissertação apresentada à Escola Politécnica da Universidade de São Paulo para a obtenção do título de Mestre em Engenharia.

Área de concentração:

Microeletrônica

Orientador:

Prof. Dra. Luciana Reyes Pires Kassab

SÃO PAULO

2011 


\section{FICHA CATALOGRÁFICA}

Amâncio, Carlos Taveira

Produção e caracterização de vidros de teluretos dopados com íons de terras raras e nanopartículas metálicas para uso em displays coloridos / C.T. Amâncio. -- São Paulo, 2011.

$114 \mathrm{p}$.

Dissertação (Mestrado) - Escola Politécnica da Universidade de São Paulo. Departamento de Engenharia de Sistemas Eletrônicos.

1. Nanopartículas (Aplicações) 2. Vidro 3. Terras raras (Propriedades eletromagnéticas) I. Universidade de São Paulo. Escola Politécnica. Departamento de Engenharia de Sistemas Eletrônicos II. t. 
Dedico este trabalho aos meus queridos pais, e aos meus amigos. 


\section{AGRADECIMENTOS}

À Prof. Dra. Luciana Reyes Pires Kassab, pela orientação, apoio, amizade demonstrados ao longo do trabalho.

Ao Prof. Dr. Niklaus Ursus Wetter e ao aluno Jonas Jakutis Neto pela colaboração na realização das medidas preliminares de luminescência.

À Sra. Simone Perche do Laboratório de Microscopia Eletrônica do IFUSP pela persistência e paciência na realização e análise das medidas de Microscopia Eletrônica de Transmissão.

Ao Prof. Dr. José Roberto Martinelli do Centro de Ciências e Tecnologia dos Materiais - CCTM do IPEN-SP, pela colaboração na análise das medidas de Microscopia Eletrônica de Transmissão.

À FATEC-SP, pelo espaço oferecido pelo Laboratório de Tecnologia em Materiais Fotônicos e Optoeletrônicos do Departamento de Ensino Geral para produção e caracterização das amostras.

À rede Nanofoton e ao Instituto Nacional de Fotônica, ambos do CNPq pelos recursos para compra de materiais de consumo e permanentes necessários para produção e caracterização das amostras.

Aos amigos que ainda estão e aos que passaram pelo laboratório pela amizade e apoio em todos os momentos.

À Ambriex S/A pela compreensão durante a realização do trabalho.

À minha família, especialmente aos meus pais, por terem me proporcionado o aprendizado, amizade e, sobretudo, o amor.

A todos os que, de alguma forma, foram importantes para a realização deste trabalho. 
"Muito útil é conhecer a verdadeira e memorável origem das invenções"

Leibnitz 


\section{RESUMO}

Neste trabalho são apresentados estudos de produção e caracterização de amostras vítreas de $\mathrm{TeO}_{2}-\mathrm{PbO}-\mathrm{GeO}_{2}$ dopadas com íons de érbio, túlio e itérbio preparadas com diferentes nanoparticulas metálicas para aplicações em dispositivos como displays coloridos. Este sistema vítreo apresenta uma larga janela de transmissão no visível e no infravermelho (350 - $6500 \mathrm{~nm}$ ), alta solubilidade para os íons de terras raras, baixa energia de fônon (em torno de $700 \mathrm{~cm}^{-1}$ ) e considerável estabilidade química, mecânica e térmica, que são fatores indispensáveis para produção de displays ou dispositivos utilizados para iluminação.

Este trabalho pode ser dividido em três partes, sendo iniciado com o estudo da fotoluminescência de vidros de telureto com dopante érbio, seguido do estudo da codopagem com érbio e itérbio. Na segunda parte é estudada a interferência das nanopartículas metálicas na luminescência das amostras codopadas com érbio e itérbio e, finalmente, na terceira parte, são estudadas amostras tridopadas com érbio, túlio e itérbio com e sem nanopartículas metálicas.

Através das medidas de absorção óptica e medidas de emissão, foi observada a incorporação dos íons de terras raras na forma trivalente e por meio das medidas de microscopia eletrônica de transmissão de elétrons foi analisada a nucleação das nanopartículas metálicas.

Dentre as amostras codopadas, produzidas com diferentes nanopartículas metálicas, destaca-se a amostra com nucleação de prata para a qual foi observado aumento da luminescência de conversão ascendente do érbio de aproximadamente $50 \%$.

As amostras tridopadas mostraram-se promissoras para aplicações com displays coloridos.

Palavras-chave: Nanopartículas metálicas, íons de terras raras, érbio, túlio, itérbio, vidros. 


\begin{abstract}
This works presents studies of the production and the characterization of $\mathrm{TeO}_{2}$ $-\mathrm{PbO}-\mathrm{GeO}_{2}$ doped with erbium, thulium and ytterbium ions and also prepared with different metallic nanoparticles for applications in displays. This glass system presents a broad transmission window in the visible and infrared (350 - $6500 \mathrm{~nm})$, high solubility for rare earth ions, low phonon energy (about $700 \mathrm{~cm}^{-1}$ ) and considerable chemical, mechanical and thermal, stabilities which are importamt factors for the production of displays or devices used for illumination.

This work can be divided in three parts, and starts with the study of the photoluminescence of teluritte glasses doped with erbium followed by the study of erbium and ytterbium codoped glasses. The second part presents the influence of metallic nanoparticles on the luminescence of samples codoped with erbium and ytterbium and, finally, in the third part, the study of samples doped with erbium, thulium and ytterbium with and without metallic nanoparticles.

The incorporation of rare earth ions in the trivalent form was determined by means of optical absorption and emission measurements and, by using the transmission electron microscopy technique to the nucleation of metallic nanoparticles.

Among the codoped samples, produced with different metallic nanoparticles, we remark the sample produced with silver nanoparticles that presented enhancement of erbium upconversion luminescence of approximately $50 \%$.

Samples doped with erbium, thulium and ytterbium showed possible applications for full color displays.
\end{abstract}

Keywords: Mettalic nanoparticles, rare earth ions, erbium, thulium, ytterbium, glasses. 


\section{LISTA DE ILUSTRAÇÕES}

Figura 1 - Imagem de MET e histograma da amostra T1 com NPs de prata tratada por 57 horas

Figura 2 - Imagem de TEM e histograma da amostra T1 com NPs de ouro com tamanho médio de $4 \mathrm{~nm}$..... 24

Figura 3 - Imagem de TEM e histograma da amostra T1 dopada com íons de $\mathrm{Pr}^{3+} \mathrm{e}$ NPs de prata e tratada termicamente por 7 horas. .25

Figura 4 - Gravação na amostra Q1. 27

Figura 5 - Micrografias das amostras GP dopadas com $\mathrm{Tm}^{3+}$ contendo NPs de prata, tratadas por (a)72 horas não-contínuas e (b) 72 horas contínuas 28

Figura 6 - Espectro de emissão de amostras de germanato de mesma composição, tratadas em diferentes temperaturas. 28

Figura 7 - Resfriamento de um líquido e a ordenação das moléculas no estado sólido

Figura 8 - Formação dos cristais e vidros

Figura 9 - Estrutura de um vidro bidimensional (a) arranjo formado por Si-O e (b) estrutura de um vidro binário Si-O-Na.

Figura 10 - Estruturas básicas presentes em vidros de teluretos com número de coordenação 4, 3+1 e 3, respectivamente em (a), (b) e (c) 34

Figura 11 - Formação da estrutura $\mathrm{TeO}_{3+1}$ a partir de uma estrutura $\mathrm{TeO}_{4} \ldots \ldots \ldots \ldots . . .35$

Figura 12 - Formação da estrutura $\mathrm{TeO}_{3}$ a partir da estrutura $\mathrm{TeO}_{3+1} \ldots \ldots \ldots \ldots \ldots \ldots \ldots . . . .36$

Figura 13 - Mecanismo de conversão ascendente (a) Absorção de Estado Excitado,

(b) Conversão Ascendente por Transferência de Energia, (c) Sensibilização

Cooperativa e (d) Emissão Cooperativa. 40

Figura 14 - Representação do íon ativador na matriz hospedeira. .41

Figura 15 - Diagrama de energia $\mathrm{Er}^{3+}$ 44

Figura 16 - Diagrama de energia simplificado do $\mathrm{Er}^{3+}$, mostrando os processos de conversão ascendente por (a) absorção do estado excitado e (b) transferência de energia .

Figura 17 - Diagrama simplificado do $\mathrm{Er}^{3+}$, mostrando possíveis emissões, quando excitado em 1,48 um 
Figura 18 - Diagrama simplificado dos níveis de energia dos íons $\mathrm{Tm}^{3+}$ com a representação das emissões possíveis no visível.

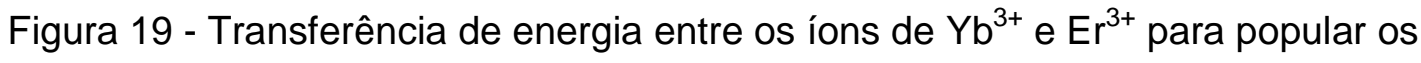
níveis emissores de radiação do visível e do vermelho.

Figura 20 - Diagrama dos processos de transferência de energia entre as TRs. As linhas sólidas representam os processos de absorção e emissão; as pontilhadas as transferências de energia; as linhas distorcidas os processos não radiativos.

Figura 21 - Esquema para a oscilação plasmônica de uma esfera, mostrando o deslocamento da nuvem dos elétrons livres em relação ao núcleo 51

Figura 22 - Espectro de absorção de NPs de ouro com diferentes tamanhos. 52

Figura 23 - Representação das distâncias entre NPs e íons de TRs. .53

Figura 24 - Diagrama das etapas de produção do vidro e nucleação das NPs metálicas. .54

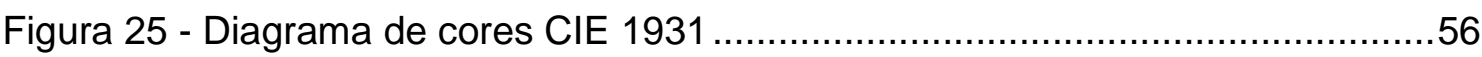

Figura 26 - Diagrama de cores CIE 1931 com eixo de intensidade .......................57

Figura 27 - Diagrama de cores CIE 1931 com eixo de intensidade ......................58

Figura 28 - Espectro de atenuação de filtro ópticos utilizado em um sistema RGB de emissão 58

Figura 29 - Espectro de emissão dos sistemas T1 (A) e T3 (B) ............................60

Figura 30- Fluxograma das etapas usadas para produção das amostras................64

Figura 31 - Arranjo experimental para medidas de absorção óptica. .65

Figura 32 - Arranjo experimental das medidas de emissão realizadas nas amostras 66

Figura 33 - Curva de cores do padrão CIE para os vetores $x(\lambda), y(\lambda)$ e $z(\lambda)$..........69

Figura 34 - Diagrama de cores CIE...................................................... 70

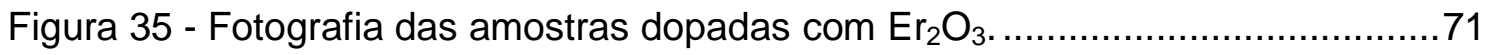

Figura 36 - Espectro de absorção óptica das amostras T1 dopadas apenas com $\mathrm{Er}_{2} \mathrm{O}_{3}$ 72

Figura 37 - Espectros de emissão no visível das amostras $\mathrm{T} 1$ dopadas com $\mathrm{Er}_{2} \mathrm{O}_{3} .72$ Figura 38 - Espectro de absorção óptica das amostras $\mathrm{T} 1$ codopadas com $\mathrm{Er}_{2} \mathrm{O}_{3} \mathrm{e}$ $\mathrm{Yb}_{2} \mathrm{O}_{3}$. 73

Figura 39 - Espectros de emissão no visível da amostra $\mathrm{T} 1$ codopada com $\mathrm{Er}_{2} \mathrm{O}_{3} \mathrm{e}$ $\mathrm{Yb}_{2} \mathrm{O}_{3}$. 
Figura 40 - Integral da intensidade de emissão em função da concentração de $\mathrm{Yb}_{2} \mathrm{O}_{3}$.

Figura 41 - Intensidade de conversão ascendente em função da potência de excitação da amostra preparada com $0,5 \% \mathrm{Er}_{2} \mathrm{O}_{3}-3,0 \% \mathrm{Yb}_{2} \mathrm{O}_{3}$. 76

Figura 42 - Espectro de absorção óptica das amostras $\mathrm{T} 1$ codopadas com 0,5\% $\mathrm{Er}_{2} \mathrm{O}_{3}, 2,0 \% \mathrm{Yb}_{2} \mathrm{O}_{3}$ e com 1,0\% $\mathrm{Au}_{2} \mathrm{O}_{3}$, para vários períodos de tratamento térmico.

Figura 43 - Espectro de absorção óptica das amostras T1 codopadas com 0,5\% $\mathrm{Er}_{2} \mathrm{O}_{3}, 2,0 \% \mathrm{Yb}_{2} \mathrm{O}_{3}$ e com 1,0\% $\mathrm{Ag}_{2} \mathrm{O}$, para vários períodos de tratamento térmico. 78 Figura 44 - Espectro de absorção óptica das amostras T1 codopadas com 0,5\% $\mathrm{Er}_{2} \mathrm{O}_{3} 3,0 \% \mathrm{Yb}_{2} \mathrm{O}_{3}$ e com 1,0\% $\mathrm{AgNO}_{3}$, para vários períodos de tratamento térmico.

Figura 45 - Espectros de emissão no visível da amostra codopada com $0,5 \% \mathrm{Er}_{2} \mathrm{O}_{3} \mathrm{e}$ $2,0 \% \mathrm{Yb}_{2} \mathrm{O}_{3}$ e $1,0 \% \mathrm{Ag}_{2} \mathrm{O}$.

Figura 46 - Espectros de emissão no visível da amostra codopada com $05 \% \mathrm{Er}_{2} \mathrm{O}_{3} \mathrm{e}$ $3,0 \% \mathrm{Yb}_{2} \mathrm{O}_{3}$ e $1,0 \% \mathrm{Ag}_{2} \mathrm{O}$ 79

Figura 47 - Intensidade de conversão ascendente em função da potência de excitação para as amostras com 0,5\% $\mathrm{Er}_{2} \mathrm{O}_{3}$ e 2,0\% e 3,0\% $\mathrm{Yb}_{2} \mathrm{O}_{3}-1,0 \% \mathrm{Ag}_{2} \mathrm{O}$ de período de nucleação 72 horas.

Figura 48 - Espectros de emissão no visível da amostra codopada com $05 \% \mathrm{Er}_{2} \mathrm{O}_{3} \mathrm{e}$ $2,0 \% \mathrm{Yb}_{2} \mathrm{O}_{3}$ e $1,0 \% \mathrm{AgNO}_{3}$. 80

Figura 49 - Espectros de emissão no visível da amostra codopada com $05 \% \mathrm{Er}_{2} \mathrm{O}_{3} \mathrm{e}$ $3,0 \% \mathrm{Yb}_{2} \mathrm{O}_{3}$ e $1,0 \% \mathrm{AgNO}_{3}$

Figura 50 - Intensidade de conversão ascendente em função da potência de excitação para as amostras com 0,5\% $\mathrm{Er}_{2} \mathrm{O}_{3}$ e 2,0\% e 3,0\% $\mathrm{Yb}_{2} \mathrm{O}_{3}-1,0 \% \mathrm{AgNO}_{3}$ de período de nucleação 72 horas.

Figura 51 - Diagrama CIE e fotografia da amostra $\mathrm{T} 1$ 0,5\% $\mathrm{Er}_{2} \mathrm{O}_{3}-3,0 \% \mathrm{Yb}_{2} \mathrm{O}_{3^{-}}$

$1,0 \% \mathrm{AgNO}_{3}$ de período de nucleação 72 horas.

Figura 52 - Espectros de emissão no visível da amostra codopada com $05 \% \mathrm{Er}_{2} \mathrm{O}_{3} \mathrm{e}$ $2,0 \% \mathrm{Yb}_{2} \mathrm{O}_{3}$ e $1,0 \% \mathrm{Au}_{2} \mathrm{O}_{3}$.

Figura 53 - Espectros de emissão no visível da amostra codopada com $05 \% \mathrm{Er}_{2} \mathrm{O}_{3} \mathrm{e}$ $3,0 \% \mathrm{Yb}_{2} \mathrm{O}_{3}$ e $1,0 \% \mathrm{Au}_{2} \mathrm{O}_{3}$. 
Figura 54 - Intensidade de conversão ascendente em função da potência de excitação para as amostras com 0,5\% $\mathrm{Er}_{2} \mathrm{O}_{3}$ e 2,0\% e 3,0\% $\mathrm{Yb}_{2} \mathrm{O}_{3}-1,0 \% \mathrm{Au}_{2} \mathrm{O}_{3}$ de período de nucleação 72 horas.

Figura 55 - Micrografia e EDX das amostras $\mathrm{T} 1$ com $0,5 \% \mathrm{Er}_{2} \mathrm{O}_{3}-3,0 \% \mathrm{Yb}_{2} \mathrm{O}_{3}-$ $1,0 \% \mathrm{AgNO}_{3}$ para período de nucleação de 72 horas.

Figura 56 - Micrografia e EDX das amostras $\mathrm{T} 1$ com $0,5 \% \mathrm{Er}_{2} \mathrm{O}_{3}-2,0 \% \mathrm{Yb}_{2} \mathrm{O}_{3}-$ $1,0 \% \mathrm{Au}_{2} \mathrm{O}_{3}$ para período de nucleação de 72 horas.

Figura 57 - Espectro de absorção óptica das amostras $\mathrm{T} 1$ tridopadas com $\mathrm{Er}_{2} \mathrm{O}_{3}$,

$\mathrm{Tm}_{2} \mathrm{O}_{3}$ e $\mathrm{Yb}_{2} \mathrm{O}_{3}$.

Figura 58 - Espectro de absorção óptica das amostras $\mathrm{T} 1$ tridopadas com $\mathrm{Er}_{2} \mathrm{O}_{3}$,

$\mathrm{Tm}_{2} \mathrm{O}_{3}$ e $\mathrm{Yb}_{2} \mathrm{O}_{3}$.

Figura 59 - Espectros de emissão no visível da amostra T1 tridopada do Grupo A sobre potência de excitação de $181,6 \mathrm{~mW}$.

Figura 60 - Diagrama CIE das T1 tridopada do Grupo A sobre potência de excitação de $181,6 \mathrm{~mW}$ e fotografia da amostra $0,5 \% \mathrm{Er}_{2} \mathrm{O}_{3}-0,5 \% \mathrm{Tm}_{2} \mathrm{O}_{3}-3,0 \% \mathrm{Yb}_{2} \mathrm{O}_{3} \mathrm{e}$ $0,5 \% \mathrm{Er}_{2} \mathrm{O}_{3}-0,25 \% \mathrm{Tm}_{2} \mathrm{O}_{3}-2,0 \% \mathrm{Yb}_{2} \mathrm{O}_{3}$.

Figura 61 - Espectros de emissão no visível da amostra $\mathrm{T} 1$ - 0,5\% $\mathrm{Er}_{2} \mathrm{O}_{3}-0,5 \%$

$\mathrm{Tm}_{2} \mathrm{O}_{3}-3,0 \% \mathrm{Yb}_{2} \mathrm{O}_{3}$, com diferente potência de excitação.

Figura 62 - Diagrama de cromaticidade das $\mathrm{T1}$ - 0,5\% $\mathrm{Er}_{2} \mathrm{O}_{3}-0,5 \% \mathrm{Tm}_{2} \mathrm{O}_{3}-3,0 \%$

$\mathrm{Yb}_{2} \mathrm{O}_{3}$, com diferente potência de excitação.

Figura 63 - Intensidade de conversão ascendente em função da potência de excitação da amostra $0,5 \% \mathrm{Er}_{2} \mathrm{O}_{3}-0,5 \% \mathrm{Tm}_{2} \mathrm{O}_{3}-3,0 \% \mathrm{Yb}_{2} \mathrm{O}_{3}$.

Figura 64 - Espectros de emissão no visível da amostra do Grupo B com potência de excitação de 181,6 mW.

Figura 65 - Diagrama de CIE e fotografia das amostras do Grupo B com potência de excitação de 181,6 mW.

Figura 66 - Integral da intensidade de emissão em função da concentração de Yb2O3 das amostras do Grupo B .93

Figura 67 - Espectros de emissão no visível da amostra tridopadas do (Grupo C) com potência de excitação $181,6 \mathrm{~mW}$.

Figura 68 - Diagrama de CIE das amostras do Grupo $\mathrm{C}$ com potência de excitação de $181,6 \mathrm{~mW}$ e fotografia da amostra $2,0 \% \mathrm{Er}_{2} \mathrm{O}_{3}-1,0 \% \mathrm{Tm}_{2} \mathrm{O}_{3}-3,0 \% \mathrm{Yb}_{2} \mathrm{O}_{3}$. 
Figura 69 - Espectros de emissão no visível da amostra T1 tridopada com $2,0 \% \mathrm{Er}_{2} \mathrm{O}_{3}-3,0 \% \mathrm{Yb}_{2} \mathrm{O}_{3}$ com diferentes concentrações de $\mathrm{Tm}_{2} \mathrm{O}_{3}$ e potência de excitação.

Figura 70 - Diagrama de cromaticidade da amostra T1 tridopada com 2,0\% $\mathrm{Er}_{2} \mathrm{O}_{3}$ $3,0 \% \mathrm{Yb}_{2} \mathrm{O}_{3}$ com diferentes concentrações de $\mathrm{Tm}_{2} \mathrm{O}_{3}$ e potências de excitação. 95

Figura 71 - Intensidade de conversão ascendente em função da potência de excitação da amostra com 2,0\% $\mathrm{Er}_{2} \mathrm{O}_{3}-1,0 \% \mathrm{Tm}_{2} \mathrm{O}_{3}-3,0 \% \mathrm{Yb}_{2} \mathrm{O}_{3}$.

Figura 72 - Espectros de emissão no visível da amostra T1 tridopada com $0,5 \% \mathrm{Er}_{2} \mathrm{O}_{3}-0,15 \% \mathrm{Tm}_{2} \mathrm{O}_{3}-3,0 \% \mathrm{Yb}_{2} \mathrm{O}_{3}$ com diferentes potências de excitação.

Figura 73 - Diagrama de CIE com o padrões de cromaticidade RGB e a gama obtida de cores obtida do amostra $0,5 \% \mathrm{Er}_{2} \mathrm{O}_{3}-0,25 \% \mathrm{Tm}_{2} \mathrm{O}_{3}-3,0 \% \mathrm{Yb}_{2} \mathrm{O}_{3}$.

Figura 74 - Espectro de absorção óptica das amostras T1 tridopadas com $0,5 \% \mathrm{Er}_{2} \mathrm{O}_{3}-0,25 \% \mathrm{Tm}_{2} \mathrm{O}_{3}-3,0 \% \mathrm{Yb}_{2} \mathrm{O}_{3}-3,0 \% \mathrm{AgNO}_{3}$ para vários períodos de tratamento térmico.

Figura 75 - Espectros de emissão no visível da amostra $\mathrm{T} 1$ com $0,5 \% \mathrm{Er}_{2} \mathrm{O}_{3}$ -

$0,25 \% \mathrm{Tm}_{2} \mathrm{O}_{3}-3,0 \% \mathrm{Yb}_{2} \mathrm{O}_{3}-3,0 \% \mathrm{AgNO}_{3}$ para potencia de 181,6 $\mathrm{mW}$.

Figura 76 - Espectros de emissão no visível da amostra $\mathrm{T} 1 \mathrm{com} 0,5 \% \mathrm{Er}_{2} \mathrm{O}_{3}$ -

$0,25 \% \mathrm{Tm}_{2} \mathrm{O}_{3}-3,0 \% \mathrm{Yb}_{2} \mathrm{O}_{3}-3,0 \% \mathrm{AgNO}_{3}$ para potencia de 108,2 $\mathrm{mW}$.

Figura 77 - Diagrama de cromaticidade e fotografia da amostra T1 tridopada com $0,5 \% \mathrm{Er}_{2} \mathrm{O}_{3}-0,25 \% \mathrm{Tm}_{2} \mathrm{O}_{3}-3,0 \% \mathrm{Yb}_{2} \mathrm{O}_{3}-3,0 \% \mathrm{AgNO}_{3}$ para potência de excitação de $181,6 \mathrm{~mW}$ e para diferentes períodos de nucleação.

Figura 78 - Intensidade de conversão ascendente em função da potência de excitação da amostra $0,5 \% \mathrm{Er}_{2} \mathrm{O}_{3}-0,25 \% \mathrm{Tm}_{2} \mathrm{O}_{3}-3,0 \% \mathrm{Yb}_{2} \mathrm{O}_{3}-3,0 \% \mathrm{AgNO}_{3}$ para período de nucleação de 72 horas. 102

Figura 79 - Micrografia das amostras $\mathrm{T} 1$ com $0,5 \% \mathrm{Er}_{2} \mathrm{O}_{3}-0,25 \% \mathrm{Tm}_{2} \mathrm{O}_{3}-3,0 \% \mathrm{Yb}_{2} \mathrm{O}_{3}$ 3,0\%AgNO3 para período de nucleação de 72 horas. 102

Figura 80 - Espectros de emissão no visível da amostra $\mathrm{T} 1 \mathrm{com} 2,0 \% \mathrm{Er}_{2} \mathrm{O}_{3}$ -

$0,25 \% \mathrm{Tm}_{2} \mathrm{O}_{3}-3,0 \% \mathrm{Yb}_{2} \mathrm{O}_{3}-3,0 \% \mathrm{AgNO}_{3}$ para potência de 108,2 mW. 103

Figura 81 - Diagrama de cromaticidade da amostra $\mathrm{T} 1 \mathrm{com} 2,0 \% \mathrm{Er}_{2} \mathrm{O}_{3}-0,25 \% \mathrm{Tm}_{2} \mathrm{O}_{3}-$ $3,0 \% \mathrm{Yb}_{2} \mathrm{O}_{3}-3,0 \% \mathrm{AgNO}_{3}$ para potência de excitação de $181,6 \mathrm{~mW}$ e para diferentes períodos de nucleação. 103

Figura 82 - Micrografia das amostras $\mathrm{T} 1$ com 2,0\% $\mathrm{Er}_{2} \mathrm{O}_{3}-0,25 \% \mathrm{Tm}_{2} \mathrm{O}_{3}-3,0 \% \mathrm{Yb}_{2} \mathrm{O}_{3}-$ $3,0 \% \mathrm{AgNO}_{3}$ para período de nucleação de 72 horas. 



\section{LISTA DE TABELAS}

Tabela 1 - Composições e índices de refração dos vidros de telureto.

Tabela 2 - Parâmetros termo ópticos dos vidros de teluretos produzidos pelo grupo

Tabela 3 - Parâmetros termo ópticos de vidros de telureto reportados na literatura . .26

Tabela 4 - Amostras $\mathrm{T} 1$ dopadas com $\mathrm{Er}^{3+}$ e codopadas $\mathrm{Er}^{3+} / \mathrm{Yb}^{3+}$. 61

Tabela 5 - Amostras $\mathrm{T} 1$ codopadas com $\mathrm{Er}^{3+} \mathrm{Mb}^{3+}$ e com NPs metálicas. 61

Tabela 6 - Amostras $\mathrm{T} 1$ com diferente concentração de $\mathrm{Er}_{2} \mathrm{O}_{3}, \mathrm{Tm}_{2} \mathrm{O}_{3}$ e $\mathrm{Yb}_{2} \mathrm{O}_{3} \ldots \ldots 61$

Tabela 7 - Grupo A de amostras tridopadas.......................................................62

Tabela 8 - Grupo B de amostras tridopadas.......................................................

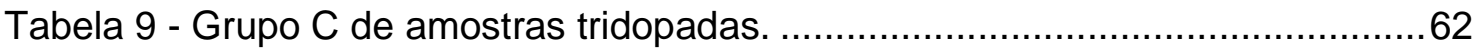

Tabela 10 - Transições do $\mathrm{Er}^{3+}$ e do $\mathrm{Yb}^{3+}$ e os respectivos comprimentos de onda para as amostras $\mathrm{T} 1$ dopadas e codopadas com $\mathrm{Er}_{2} \mathrm{O}_{3}$ e $\mathrm{Yb}_{2} \mathrm{O}_{3}$ 


\section{LISTA DE ABREVIATURAS E SIGLAS}

CCTM Centro de Ciências e Tecnologia dos Materiais

CIE Comissão Internacional de l'Eclairage

CLA Centro de Lasers e Aplicações

CNPq Conselho Nacional de Desenvolvimento Científico e Tecnológico

CRT Cathode Ray Tube

CVD Chemical Vapor Deposition

EDFA Erbium Doped Fiber Amplifier

EDS Energy Dispersive Spectroscopy

FATEC-SP Faculdade de Tecnologia de São Paulo

FPD Flat Planel Display

IFUSP Instituto de Física da USP

IPEN Instituto de Pesquisas Energéticas Nucleares

IV Infravermelho

LED Light Emitting Diode

LCD Liquid Crystal Display

LTMFO Laboratório de Tecnologia em Materiais Fotônicos e Optoeletrônicos

MET Microscopia Eletrônica de Transmissão

NP Nanopartícula

PPD Plasma Planel Display

PS Plasmons de Superfície

QD Quantum Dot

OLED Organic Light Emitting Diode

RPS Ressonância dos Plasmons Superficiais

TR Terra Rara

SHG Second Harmonic Generation

UFPE Universidade Federal de Pernambuco

USP Universidade de São Paulo

UV Ultravioleta 



\section{LISTA DE SÍMBOLOS}

$2 \lambda \mathrm{L} \quad$ Constante característica do feixe de elétrons do microscópio.

dhkl Distância interplanar característica de cada elemento

E1 Nível fundamental

E2 Nível excitado

$\mathrm{m}^{*} \mathrm{e} \quad$ Massa efetiva do elétron

$\mathrm{m}^{*} \mathrm{~h} \quad$ Massa efetiva do buraco

$\mathrm{Ne} \quad$ Número de elétrons

q Fração do volume das partículas metálicas

R Raio da partícula

Tc Temperatura de cristalização

$T_{f} \quad$ Temperatura de fusão

Tg Temperatura de transição vítrea

$\hbar$ Constante reduzida de Planck

em Função dielétrica do material constituinte da partícula

бesp Seção de choque de espalhamento

бext Seção de choque de extinção

cabs Seção de choque de absorção

T Tempo de relaxação

TC Tempo de colisão

$\omega \quad$ Frequência angular

$\omega$ w $\quad$ Frequência de oscilação do plasma

wr Frequência de ressonância de oscilação do plasma 


\section{SUMÁRIO}

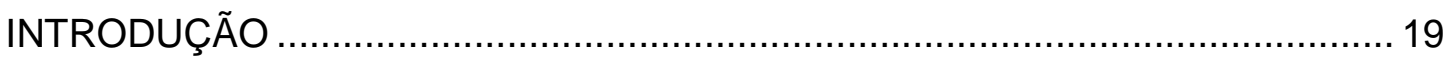

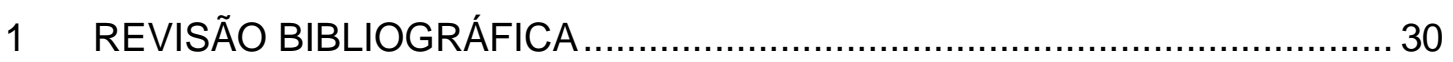

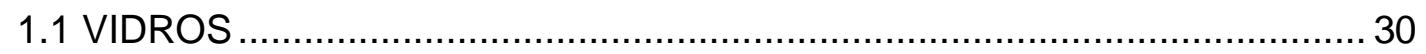

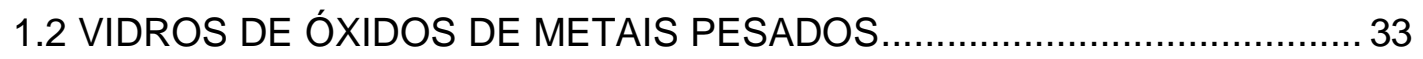

1.2.1 Vidro de Dióxido de Telúrio ........................................................... 33

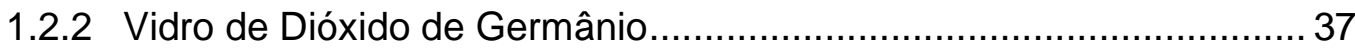

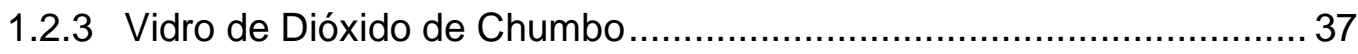

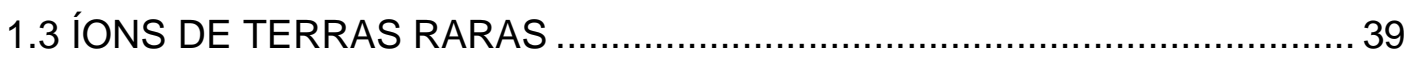

1.3.1 Processo de Conversão Ascendente e Transferência de Energia .....39

1.3.2 Processo de Conversão Ascendente dos Íons de $\mathrm{Er}^{3+} \mathrm{e} \mathrm{Tm}^{3+}$.......... 43

1.3.3 Processo de Transferência de Energia do $\mathrm{Yb}^{3+}$ para os Ílons de $\mathrm{Er}^{3+} \mathrm{e}$

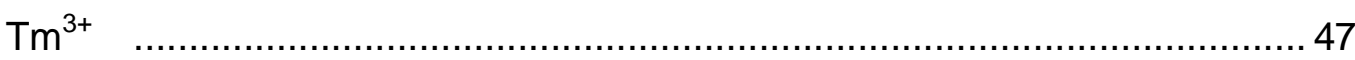

1.4 NANOPARTÍCULAS METÁLICAS E PLASMÔNICA .....................................51

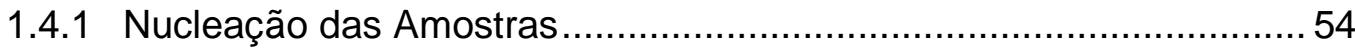

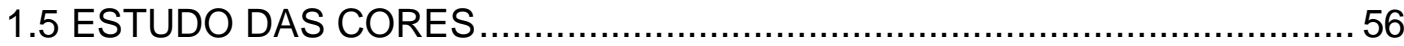

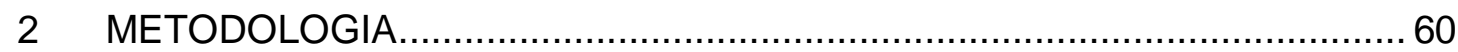

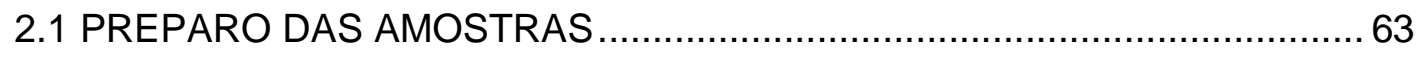

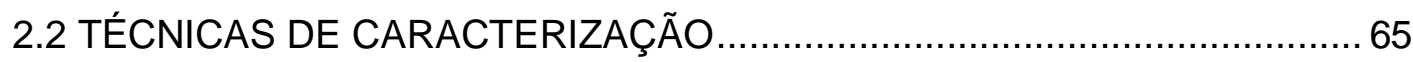

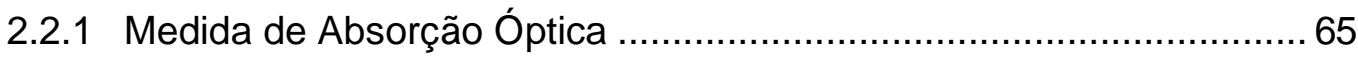

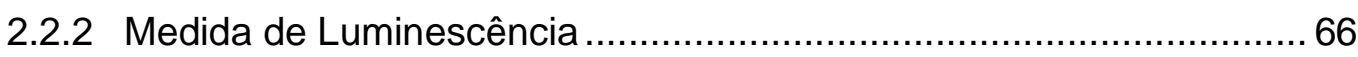

2.2.3 Microscopia Eletrônica de Transmissão ………………………….... 67

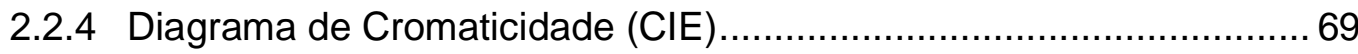

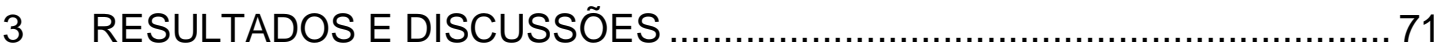

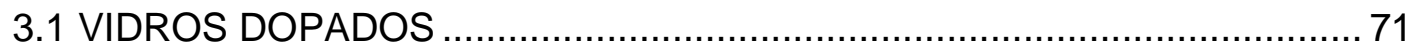

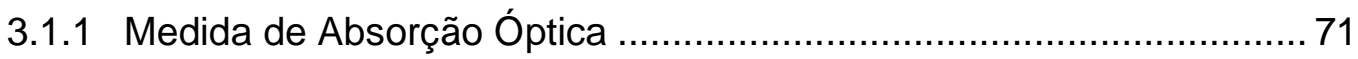

3.1.2 Medida de Luminescência ............................................................ 72

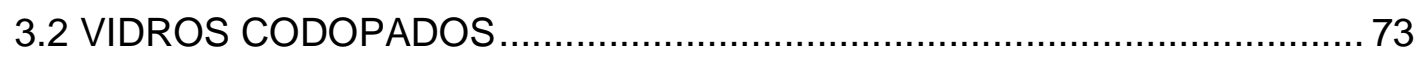

3.2.1 Medida de Absorção Óptica ........................................................ 73

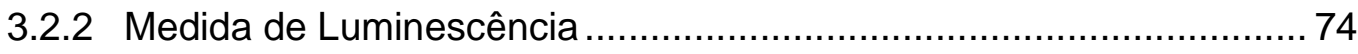

3.3 VIDROS CODOPADOS E CONTENDO NANOPARTÍCULAS ................... 77

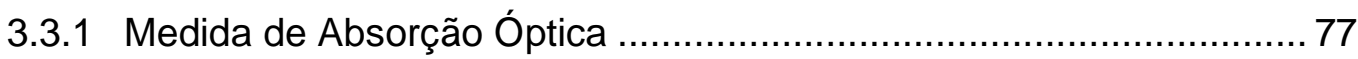

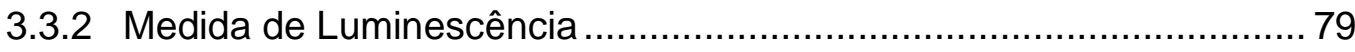




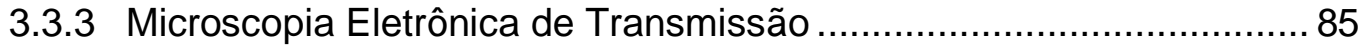

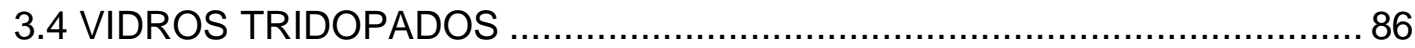

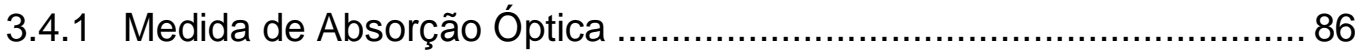

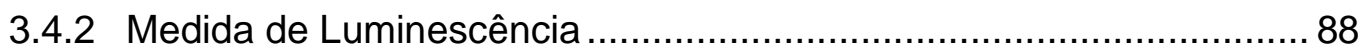

3.5 VIDROS TRIDOPADOS COM NANOPARTÍCULAS ………...................... 99

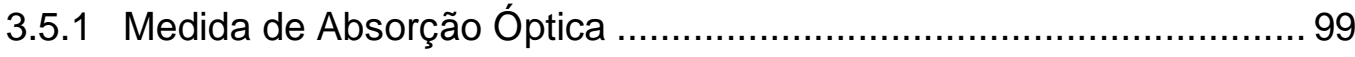

3.5.2 Medida de Luminescência .......................................................... 100

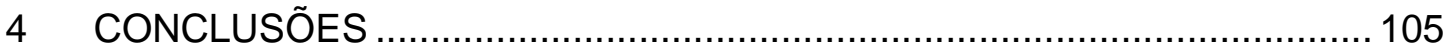

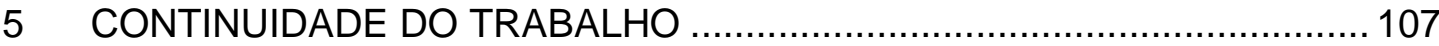

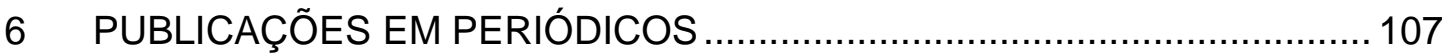

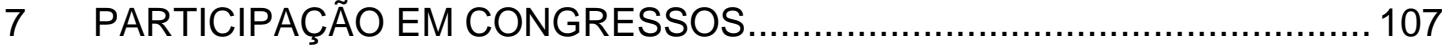

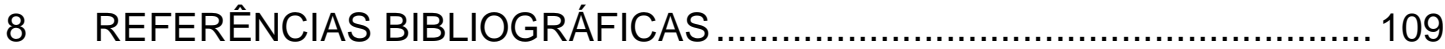




\section{INTRODUÇÃO}

Displays são dispositivos chave na era da informação, sendo indispensáveis em nossas vidas, pois atuam na interface final entre a informação gerada por sistemas como um computador ou telefone celular e os olhos humanos [1]. Iniciada há 100 anos com os tubos de raios catódicos (Cathode Ray Tube - CRT), esta foi à tecnologia predominante usada ao longo do século 20 , sendo recentemente substituída, por displays planos (Flat Planel Display - FPD) como os diplays de cristais líquido (Liquids Crystal Displays - LCDs) e pelos displays de plasma (PDPs). Novas tecnologias promissoras estão surgindo como os LED orgânicos (OLED), por permitir trabalhar com materiais e dispositivos flexíveis e leves.

Novas tecnologias para o desenvolvimento e produção de displays coloridos ou dispositivos de iluminação (lâmpadas) vêm levando diversos grupos de pesquisa a investir no desenvolvimento de novos materiais que permitam a produção de dispositivos com melhor performance, tais como: maior variação de cor, brilho, nitidez, contraste, resolução, baixo consumo de energia e de custo de produção, além de pequeno peso e espessura [2]. Nestas tecnologias, há a necessidade de fonte luminosa ou/e de materiais que gerem luminescência $[1,2]$.

A luminescência ou emissão é gerada por compostos que contêm impurezas ativadas, geralmente, presentes na concentração de 0,01-100 mol\%. Tipicamente, estes ativadores são os íons de terras raras ou íons de metais de transição, íons que apresentam transições s-p $\left(\mathrm{Bi}^{3+}\right)$ e ânions moleculares com os tungstatos e os do grupo do vanádio [2]. São usados também sensibilizadores, quando o ativador não pode ser excitado diretamente pela fonte de energia. Ativadores e sensibilizadores podem ser excitados de várias maneiras como, por exemplo: fótons de alta energia (raios-x, radiação UV - fotoluminescência), bombardeio de elétrons (catodoluminescência), campo elétrico (eletroluminescência) e através de radiação no infravermelho IV(conversão ascendente - fotoluminescência) [2].

Estes materiais para serem aplicados na produção de displays devem ser facilmente excitados por uma fonte adequada (eficiência energética), devem 
apresentar alta eficiência quântica (relação entre o número de fótons no visível emitido pelo o número de fótons absorvidos), além de converter a energia absorvida em radiação no espectro visível e apresentar um grande tempo de vida operacional (degradação) [2,3]. Sua fabricação deve ser compatível com outros materiais empregados e com os processos de fabricação.

Os vidros de telureto dopados com íons de terras raras (TRs) têm sido intensamente estudados, nos últimos anos pela possibilidade de aplicações em dispositivos que possam ser usados em diversas áreas, como na medicina, comunicação, fotônica, optoeletrônica etc [4]. Para a fabricação de displays coloridos, os vidros de telureto apresentam propriedades adequadas, como boa solubilidade para os íons de terras raras, evitando a formação de aglomerados, pequena absorção óptica no visível, além de apresentarem baixa energia fônon, favorecendo uma alta eficiência energética e quântica.

Nestes vidros as emissões ocorrem através de fotoluminescência, com fonte de excitação no infravermelho, mecanismo conhecido com conversão ascendente. Os vidros de telureto dopados com íons de terras raras são, geralmente, empregados na fabricação de amplificadores ópticos, guias de onda e lasers do estado sólido [5, 6, 7]. Para a produção de display, existem, desde década de 90, algumas patentes onde foram desenvolvidos sistemas que utilizam o principio da fotoluminescência em cristais e em vidros dopados com íons de terras raras, entre eles érbio, túlio e itérbio [8, 9, 10].

Materiais contendo nanopartículas (NPs) metálicas têm atraído muita atenção de pesquisadores no mundo, devido às possibilidades de modificação das propriedades físicas e químicas dos materiais. Estas modificações estão relacionadas com a forma, tamanho, distribuição e composição das NPs, permitindo aplicações em diversas áreas. Matrizes vítreas de telureto dopadas com íons de terras-raras com presença de NPs metálicas podem apresentar um aumento significativo de luminescência, como observado através de vários trabalhos do grupo [11,12].

Este trabalho têm como motivação o estudo de amostras preparadas com íons de $\mathrm{Er}^{3+}, \mathrm{Tm}^{3+}$ e $\mathrm{Yb}^{3+}$ e a interferência de NPs metálicas nas referidas amostras, visando aplicações em displays coloridos.

Este trabalho foi dividido em três partes diferentes. Na primeira parte, foi estudado o efeito da dopagem dos íons de érbio e itérbio na luminescência; na 
segunda, foi estudado a interferência da nucleação das NPs metálicas na luminescência nos vidros codopados; e finalmente, na terceira, foi feito o estudo da tridopagem com presença de nucleação de NPs de prata e estudo das cores emitidas.

No Capítulo 1 é apresentada uma revisão bibliográfica, bem como os fundamentos teóricos para o entendimento dos fenômenos expostos neste trabalho.

No Capítulo 2 é apresentada a metodologia utilizada para preparação das amostras e as técnicas de caracterização utilizadas. Já no Capítulo 3, são apresentados os resultados experimentais, onde são feitas também as discussões relevantes aos resultados obtidos. E por fim, as conclusões são apresentadas no Capítulo 4.

As propostas de continuidade do trabalho são apresentadas no Capítulo 5. 


\section{Histórico do Grupo}

Materiais dopados com TRs com presença de NPs metálicas e semicondutoras, assim como vidros usados para produção de dispositivos luminescente, têm sido pouco estudados. Neste sentido o grupo vem reportando resultados nestas linhas de pesquisa, desde 2001, com colaboração de outros grupos, com estudos em matrizes vítreas de germanato e de telureto. Nos últimos anos, o grupo de vêm estudando vidros dopados com terras raras com NPs metálicas e semicondutoras para aplicações em fotônica, além de filmes finos e guias de ondas.

Os vidros de telureto começaram a ser estudados pelo grupo em 2004 [11]. Foram desenvolvidas sete matrizes vítreas, sendo três binárias, uma ternária e três quaternárias e que apresentam alto índice de refração linear, quando comparados com vidros de germanatos e os tradicionais vidros de sílica. As composições dos vidros estudados e seus respectivos índices de refração (n) são mostrados na Tabela 1.

Tabela 1 - Composições e índices de refração dos vidros de telureto [11].

\begin{tabular}{ccc}
\hline Composição (\% em peso) & Código & $\mathbf{n}$ \\
\hline $85,5 \mathrm{TeO}_{2}-15,5 \mathrm{ZnO}$ & $\mathrm{B} 1$ & 2,10 \\
$83,93 \mathrm{TeO}_{2}-16,61 \mathrm{BaO}$ & $\mathrm{B} 3$ & 2,06 \\
$82,77 \mathrm{TeO}_{2}-17,23 \mathrm{Nb}_{2} \mathrm{O}_{5}$ & $\mathrm{~B} 4$ & 2,14 \\
$33,3 \mathrm{TeO}_{2}-33,3 \mathrm{GeO}_{2}-33,3 \mathrm{PbO}$ & $\mathrm{T} 1$ & 1,96 \\
$85,4 \mathrm{TeO}_{2}-6,97 \mathrm{ZnO}-4,43 \mathrm{Na}_{2} \mathrm{O}-3,2 \mathrm{PbO}$ & $\mathrm{Q} 1$ & 2,06 \\
$88,35 \mathrm{TeO}_{2}-7,5 \mathrm{ZnO}-2,65 \mathrm{Na}_{2} \mathrm{O}-1,5 \mathrm{GeO}_{2}$ & $\mathrm{Q} 2$ & 1,98 \\
$41,9 \mathrm{TeO}_{2}-20,6 \mathrm{GeO}_{2}-14,7 \mathrm{Nb}_{2} \mathrm{O}_{5}-20,1 \mathrm{BaO}$ & $\mathrm{Q} 3$ & 1,89 \\
\hline
\end{tabular}

O primeiro trabalho do grupo a respeito da interferência das NPs metálicas nas propriedades ópticas dos vidros de telureto foi publicado em 2006 [12]. Naquela ocasião, foram observadas a formação de centros diméricos e poliméricos de $\mathrm{Pb}^{2+}$ na matriz $\mathrm{T} 1$, responsáveis, respectivamente, por bandas de emissão entre $500 \mathrm{~nm}$ e $800 \mathrm{~nm}$. A presença de NPs de prata de tamanho médio de $3 \mathrm{~nm}$ foi responsável por um aumento de $100 \%$ da referida luminescência em 
amostras tratadas termicamente por 57 horas. A Figura 1 apresenta uma micrografia desta amostra com NPs de prata com tamanho médio de 3nm.
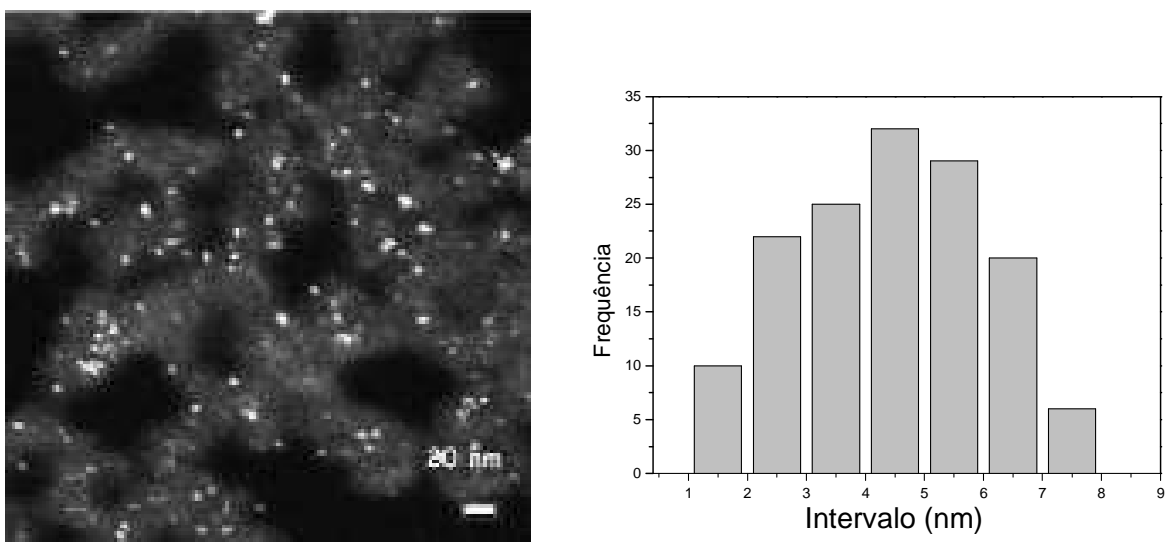

Figura 1 - Imagem de MET e histograma da amostra T1 com NPs de prata tratada por 57 horas [12].

Em 2007 foram publicados diversos estudos referentes à interferência da presença de NPs metálicas nas propriedades luminescentes de íons de terras raras em vidros de telureto. O primeiro estudo baseou-se na interferência de NPs de ouro na luminescência de íons de $\mathrm{Eu}^{3+}$ no sistema T1 [13]. Materiais luminescentes dopados com esta terra rara apresentam emissões na região do vermelho, sendo a emissão principal em torno de $614 \mathrm{~nm}$, uma transição de dipolo-elétrico, hipersensível às alterações do campo local promovidas pela presença das NPs de ouro. É possível com esses vidros, produzir sensores luminescentes, filmes finos para guias de onda, lâmpadas tricromáticas e displays de alta definição $[14,15]$. Foi observado um aumento em torno de $100 \%$ desta emissão em amostras tratadas termicamente por 41 horas. A Figura 2 mostra a imagem de TEM da amostra T1 dopada com 0,5\% em peso de $\mathrm{Eu}_{2} \mathrm{O}_{3}$ e $0,5 \%$ em peso de $\mathrm{Au}_{2} \mathrm{O}_{3}$, tratada termicamente por 41 horas. $\mathrm{O}$ tamanho médio das NPs de ouro presentes nessa amostra é de $4 \mathrm{~nm}$. 

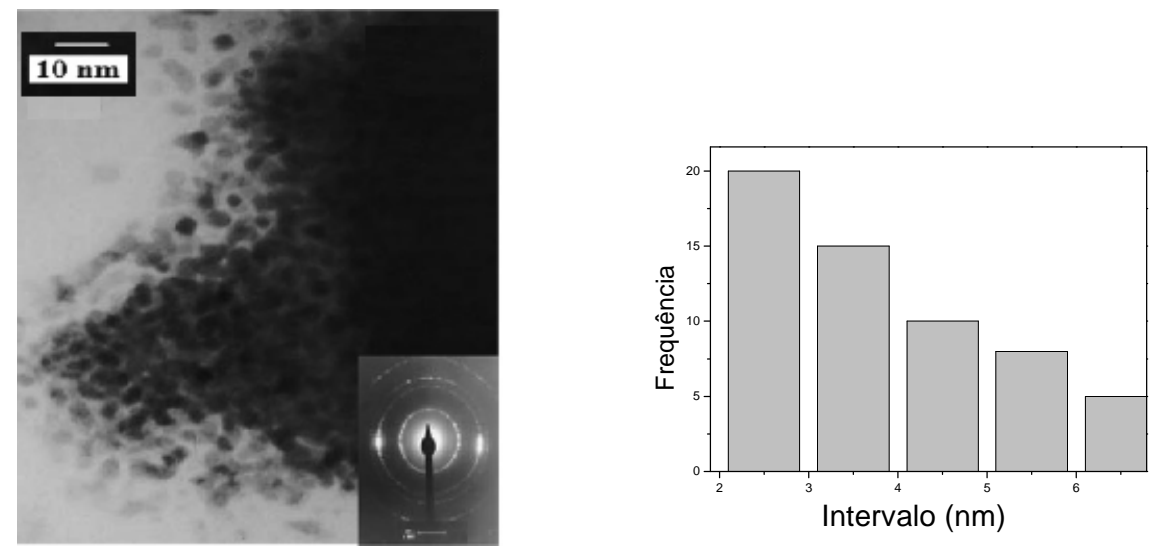

Figura 2 - Imagem de TEM e histograma da amostra T1 com NPs de ouro com tamanho médio de 2,5 $\mathrm{nm}[13]$.

A influência das NPs de prata na luminescência dos íons de $\mathrm{Pr}^{3+}$ também foi observada na matriz $\mathrm{T} 1$ [16]. Os íons de $\operatorname{Pr}^{3+}$ são bons candidatos para aplicações em lasers do estado sólido [17], contadores quânticos no infravermelho [18] e dispositivos de conversão ascendente [19]. Esses vidros apresentam emissões em nove comprimentos de onda de luz visível, quando excitadas em 454 nm: 486, 530, 544, 596, 615, 647, 685, 709 e 731 nm. A emissão em $486 \mathrm{~nm}$ (azul) é a mais intensa. A presença das NPs de prata, nas amostras tratadas termicamente por 17 horas, promoveu um aumento de $100 \%$ da emissão em $486 \mathrm{~nm}$. Também foi estudada nesse trabalho a influência das NPs no processo de conversão ascendente de energia (luminescência antiStokes) dos íons de $\operatorname{Pr}^{3+}$. Ao excitar as amostras com $520 \mathrm{~nm}$, são observadas transições em 454 e $485 \mathrm{~nm}$, além de emissões na região do vermelho (em 605, 625, 645 e $670 \mathrm{~nm}$ ). Um aumento três vezes maior na emissão em $605 \mathrm{~nm}$ foi observado nas amostras tratadas por 7 horas. Na Figura 3 é possível observar a presença das NPs de prata na amostra tratada termicamente por 7 horas, com tamanho médio em torno de $3 \mathrm{~nm}$. 

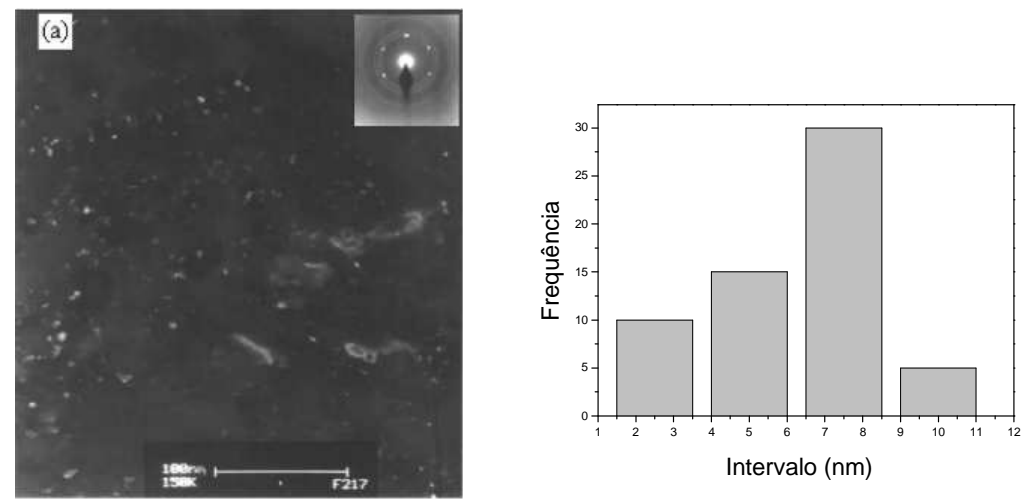

Figura 3 - Imagem de TEM e histograma da amostra T1 dopada com íons de $\operatorname{Pr}^{3+} \mathrm{e}$ NPs de prata e tratada termicamente por 7 horas.

Estudos da não-linearidade em vidros de telureto também foram feitos pelo grupo. Foram ainda determinadas, para todas as composições, as propriedades térmicas através da técnica de lente térmica, para quantificar os coeficientes termo-ópticos $d s / d T$ (mudança do trajeto óptico com a temperatura), difusividade térmica e condutividade dos vidros de telureto dopados com $\mathrm{Yb}^{3+}$ [20], apresentados na Tabela 2 seguir. Os íons de $\mathrm{Yb}^{3+}$ foram usados para determinar a fração da energia convertida em calor e consequentemente, 0 parâmetro $d s / d T$. Os parâmetros $d s / d T$, difusividade (D) e condutividade (K) térmica desempenham um importante papel no projeto de lasers e dispositivos fotônicos que devem exibir alta difusividade e condutividade térmica quando considerada a alta potência de operação. Além disso, ds/dT deve ser o menor possível para que não haja distorções ópticas, especialmente a altas temperaturas. Os resultados obtidos (tabela 2) indicam que a composição Q3 é a mais adequada para ser usada em dispositivos fotônicos de alta temperatura devido aos altos valores de $\mathrm{D}, \mathrm{K}$ e pequeno valor de $d s / d T$, quando comparados com os valores de outros teluretos produzidos pelo grupo.

Tabela 2 - Parâmetros termo ópticos dos vidros de teluretos produzidos pelo grupo [20].

\begin{tabular}{|c|c|c|c|c|c|c|c|}
\hline Sistema & $\begin{array}{c}t_{c} \\
(\mathbf{m s})\end{array}$ & $\begin{array}{c}\rho c \\
\left(\mathrm{~J} / \mathrm{K} . \mathrm{cm}^{3}\right)\end{array}$ & $\begin{array}{c}\mathrm{D} \\
\left(\times 10^{-3} \mathrm{~cm}^{2} / \mathrm{s}\right)\end{array}$ & $\begin{array}{c}\mathrm{K} \\
\left(\times 10^{-3} \mathrm{~W} / \mathrm{cm} . \mathrm{K}\right)\end{array}$ & $\eta(\%)$ & $\varphi(\%)$ & $\begin{array}{c}d s / d T \\
\left(\times 10^{-5} K^{-1}\right)\end{array}$ \\
\hline B1 & 2,30 & 2,30 & 2,04 & 4,69 & 79 & 62 & 0,21 \\
\hline B3 & 1,90 & 2,10 & 2,47 & 5,19 & 81 & 60 & 0,35 \\
\hline B4 & - & 2,30 & - & - & 70 & 65 & - \\
\hline $\mathrm{T} 1$ & 2,20 & 2,40 & 2,13 & 5,11 & 72 & 64 & 0,74 \\
\hline Q1 & 2,15 & 2,00 & 2,18 & 4,36 & 79 & 61 & 1,26 \\
\hline Q2 & 2,90 & 1,97 & 1,62 & 3,19 & 74 & 61 & 1,08 \\
\hline Q3 & 1,60 & 2,30 & 2,93 & 6,75 & 78 & 63 & 0,59 \\
\hline
\end{tabular}


$\mathrm{Na}$ Tabela 3, $t_{c}$ representa o tempo de decaimento, $\rho$ representa a densidade, $c$ o calor específico, $\eta$ a eficiência quântica dada pela relação entre os tempos de vida radiativo e experimental $\left(\tau_{\text {rad }} / \tau_{\text {exp }}\right)$, e $\varphi$ a fração de energia absorvida e convertida em calor.

A seguir, são apresentados na Tabela 3, os parâmetros ópticos de alguns vidros de teluretos encontrados na literatura. Comparando os resultados da Tabela 2 com os da Tabela 3, observa-se que o vidro Q3 acima destacado possui valores de condutividade e difusividade térmica, similares ao vidro com composição $\mathrm{TeO}_{2}-\mathrm{Li}_{2} \mathrm{O}-\mathrm{TiO}_{2}$ [21]. Isto é atribuído ao fato de que o sistema Q3 contém os reagentes $\mathrm{GeO}_{2}, \mathrm{Nb}_{2} \mathrm{O}_{5}$ e $\mathrm{BaO}$, os quais não estão presentes nas demais composições quaternárias. Além disso, a amostra Q3 apresenta para ds/dT valor inferior, indicando que o mesmo sofreria baixa distorção óptica quando submetido a altas temperaturas. Cabe acrescentar que a amostra B3 de composição binária, também apresenta parâmetros ópticos satisfatórios.

Tabela 3 - Parâmetros termo ópticos de vidros de telureto reportados na literatura [21-23].

\begin{tabular}{|c|c|c|c|}
\hline Composição (mol\%) & $\begin{array}{c}\text { D } \\
\left(\times 10^{-3} \mathrm{~cm}^{2} / \mathrm{s}\right)\end{array}$ & $\begin{array}{c}\mathrm{K} \\
\left(\times 10^{-3} \mathrm{~W} / \mathrm{cm} . \mathrm{K}\right) \\
\end{array}$ & $\begin{array}{c}d s / d T \\
\left(\times 10^{-5} K^{-1}\right)\end{array}$ \\
\hline $80 \mathrm{TeO}_{2}-20 \mathrm{Li}_{2} \mathrm{O}[21]$ & 2,7 & 6,4 & 1,1 \\
\hline $80 \mathrm{TeO}_{2}-15 \mathrm{Li}_{2} \mathrm{O}-5 \mathrm{TiO}_{2}[21]$ & 3,0 & 6,8 & 1,2 \\
\hline $80 \mathrm{TeO}_{2}-10 \mathrm{Li}_{2} \mathrm{O}-10 \mathrm{TiO}_{2}[21]$ & 2,9 & 6,5 & 1,4 \\
\hline $\mathrm{TeO}_{2}-\mathrm{Na}_{2} \mathrm{O}-\left(\mathrm{Al}_{2} \mathrm{O}_{3}, \mathrm{GeO}_{2}, \mathrm{TiO}_{2}\right)[22]$ & 5,8 a 7,2 & - & - \\
\hline $70 \mathrm{TeO}_{2}-19 \mathrm{WO}_{3}-7 \mathrm{Na}_{2} \mathrm{O}_{-} 4 \mathrm{Nb}_{2} \mathrm{O}_{5}[23]$ & 2,9 & - & - \\
\hline
\end{tabular}

As Amostras do sistema T1 dopadas com 0,5\% em peso de $\mathrm{Eu}_{2} \mathrm{O}_{3}$ e 0,5 e 1,0\% em peso de $\mathrm{Au}_{2} \mathrm{O}_{3}$ foram alvo de estudo de suas propriedades piezoópticas em função da variação de temperatura [24]. O efeito piezoóptico consiste na variação das propriedades refringentes dos materiais, principalmente nos cristais, sob ação das tensões mecânicas exteriores estáticas ou variáveis (incluindo os defeitos ou estruturas de defeitos criados por essas tensões) [25]. Através de análises de calorimetria exploratória diferencial (DSC), verificou-se que as amostras desse sistema apresentam duas temperaturas que delimitam as propriedades piezoópticas do vidro: uma temperatura mínima, que varia entre 655 e $695 \mathrm{~K}$ e uma temperatura máxima, em torno de $850 \mathrm{~K}$. Acima dessa temperatura, o coeficiente piezoóptico se torna mínimo, ou seja, há uma dependência das propriedades térmicas do vidro em função das propriedades 
piezoópticas. A presença de NPs de ouro aumenta significativamente as propriedades piezoópticas do vidro, que podem influenciar também as propriedades não-lineares de terceira ordem desses vidros [26].

Estudos recentes, desenvolvidos em parceria com a Universidade Federal de Pernambuco (UFPE), estão sendo realizados para a gravação de trilhas através de um laser de fentosegundos na amostra Q1 (matriz) e Q1 dopada com $0,5 \%$ em peso de $\mathrm{Er}_{2} \mathrm{O}_{3}$. Foi possível verificar que esses vidros apresentam uma boa superfície de gravação e excelentes propriedades ópticas, que evitam o espalhamento da luz, como é possível observar na Figura 4, que apresenta o guiamento da luz em $980 \mathrm{~nm}$.

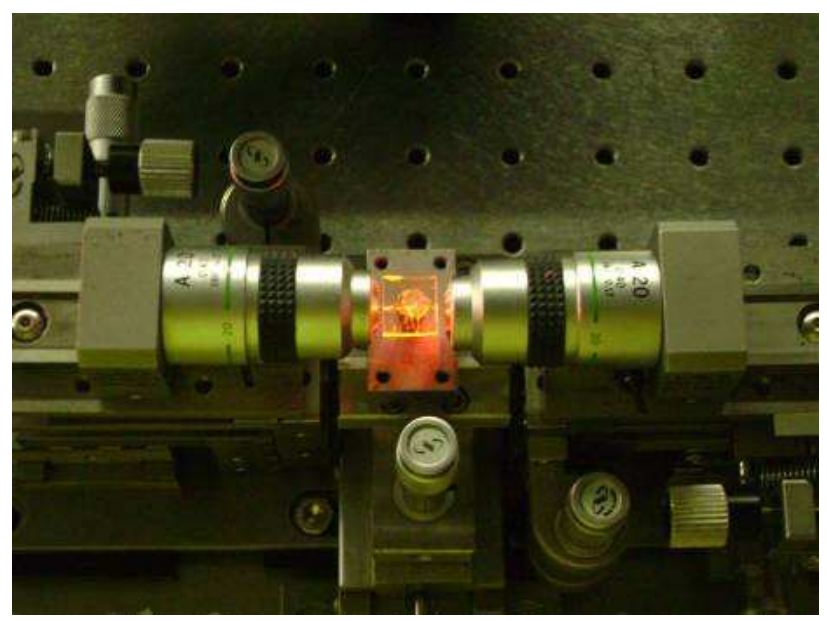

Figura 4 - Gravação na amostra Q1.

A gravação da trilha é realizada por um laser de femtosegundos, que produz uma região de alto índice de refração no vidro, o que permite que o material se torne um potencial guia de onda [27]. A possibilidade de se produzir guias de onda a partir de vidros de óxidos de metais pesados tem atraído a atenção de pesquisadores, pois podem ser aplicadas em amplificadores ópticos e dispositivos fotônicos, como por exemplo, divisores de potência, acopladores ópticos monomodo, acopladores direcionais, acopladores direcionais 3D, fibras de Bragg, comutador óptico baseados em interferômetros Mach-Zehnder, lentes de Fresnel birrefringentes e cristais fotônicos e nanoestruturas [28].

Recentemente foi realizado pelo grupo um estudo sobre investigação da metodologia adequada de tratamento térmico para nucleação de NPs metálicas de prata em vidros de germanato do sistema binário GP dopados com $\mathrm{Tm}^{3+} \mathrm{e}$ 
codopados com $\mathrm{Yb}^{3+}$ e $\mathrm{Tm}^{3+}$ [29]. Este estudo foi realizado visando o controle da variação da forma e do tamanho das NPs a partir da variação dos parâmetros de processo como temperatura e tempo de tratamento, de modo a se obter maior domínio sobre a luminescência dos íons de TRs. Foi constatado que nos tratamentos contínuos há maior tendência para a formação de aglomerados que coalescem formando agregados. Para tratamentos não contínuos foi observado fragmentação das NPs. As imagens de microscopia eletrônica de transmissão (figura 5) mostram a diferença do tamanho das NPs de prata em amostras GP preparadas com $\mathrm{Tm}^{3+}$ para tratamentos contínuos e não contínuos de 72 horas. $\mathrm{A}$ figura 6 também mostra o aumento da luminescência para tratamentos contínuos e não contínuos de 72 horas.

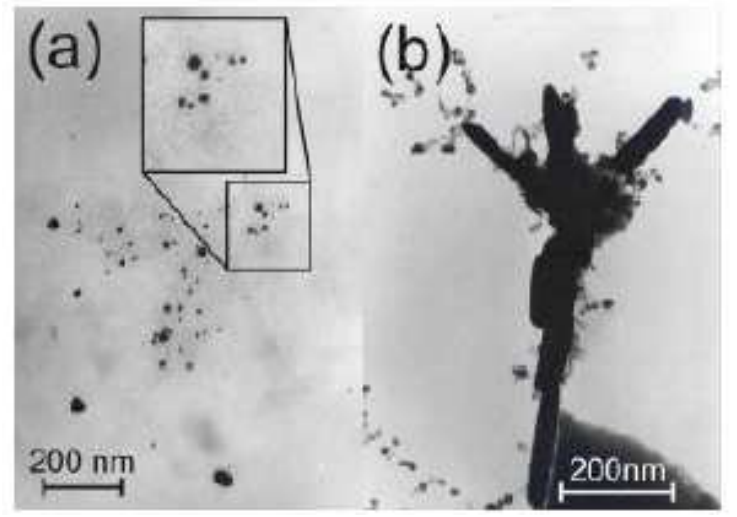

Figura 5 - Micrografias das amostras GP dopadas com $\mathrm{Tm}^{3+}$ contendo NPs de prata, tratadas por (a)72 horas não-contínuas e (b) 72 horas contínuas [29].

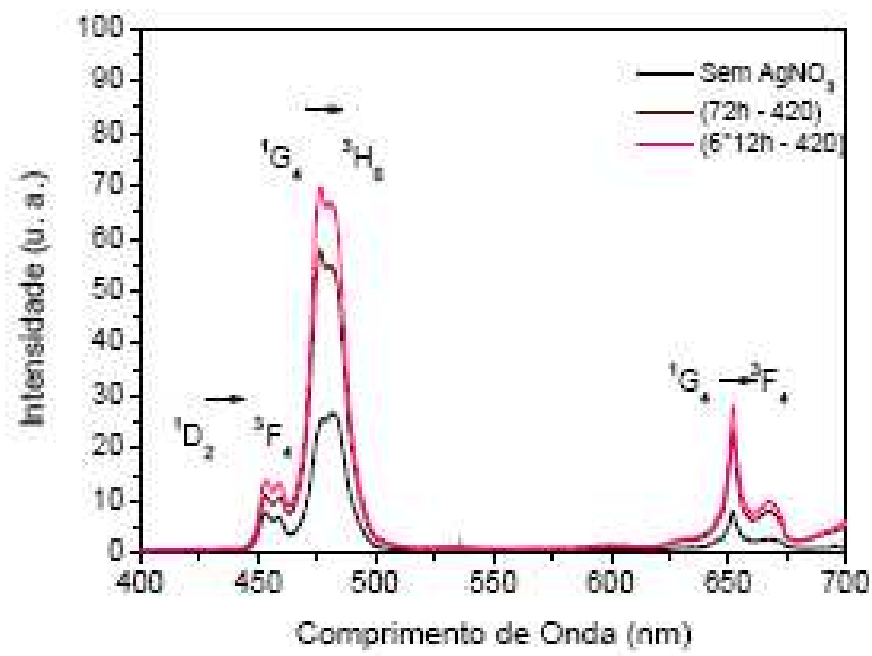

Figura 6 - Espectro de emissão de amostras de germanato de mesma composição, tratadas em diferentes temperaturas [29]. 
Por este motivo optou-se neste trabalho pelo uso do tratamento térmico não contínuo para nucleação das NPs, em temperaturas próximas a de transição vítrea, que foi usada com sucesso nos trabalhos citados anteriormente e realizados pelo grupo. Cabe acrescentar também que normalmente para partículas menores os efeitos do aumento do campo local são maiores, o que pode favorecer o aumento da luminescência [30].

Por meio da combinação adequada de íons TRs e potência de excitação, em materiais como vidros, é possível se obter a luz branca ou dispositivos que possam ser utilizados como displays coloridos. Para display baseado no princípio do processo de conversão ascendente, a partir da excitação no infravermelho, em materiais dopados com TRs, o controle das emissões e da intensidade das cores primárias vermelho, verde e azul, são necessários para formação da luz branca. Assim amostras de vidro de telureto tridopados com concentrações adequadas dos íons de $\mathrm{Er}^{3+}, \mathrm{Tm}^{3+}$ e $\mathrm{Yb}^{3+}$ foram estudadas na literatura e as emissões das cores vermelha $(680 \mathrm{~nm})$, verde (525 e $550 \mathrm{~nm})$ e azul (475 nm), analisadas visando a obtenção de luz branca [31]. Este é o tema da proposta do trabalho em questão que tem também como objetivo o estudo da interferência das NPs metálicas nas emissões dos íons de $\mathrm{Er}^{3+}, \mathrm{Tm}^{3+}$ e $\mathrm{Yb}^{3+}$. 


\section{REVISÃO BIBLIOGRÁFICA}

\subsection{VIDROS}

As aplicações dos vidros são muitas sendo utilizados na sua forma natural por nossos ancestrais desde Idade da Pedra, na fabricação de objetos como lanças, facas e pontas de flechas. E ao longo dos tempos como objetos de decoração, artigo de luxo, utensílios domésticos e de estrutura [32]. Além de ser empregados atualmente em aparelhos médicos, eletrônicos, em telecomunicação.

A formação dos vidros ocorre por meio do resfriamento rápido de líquidos, se diferenciando dos cristais cujo resfriamento é lento. Isto pode ser explicado pela disposição das moléculas que formam o material. Os cristais possuem estruturas organizadas que se repetem, ao contrário dos vidros que possuem estruturas desordenadas (sólido amorfo) [33].

Na figura a seguir, a partir do resfriamento de um líquido, é observado a desordenação das moléculas dispersas no estado líquido e sua ordenação no material cristalino.

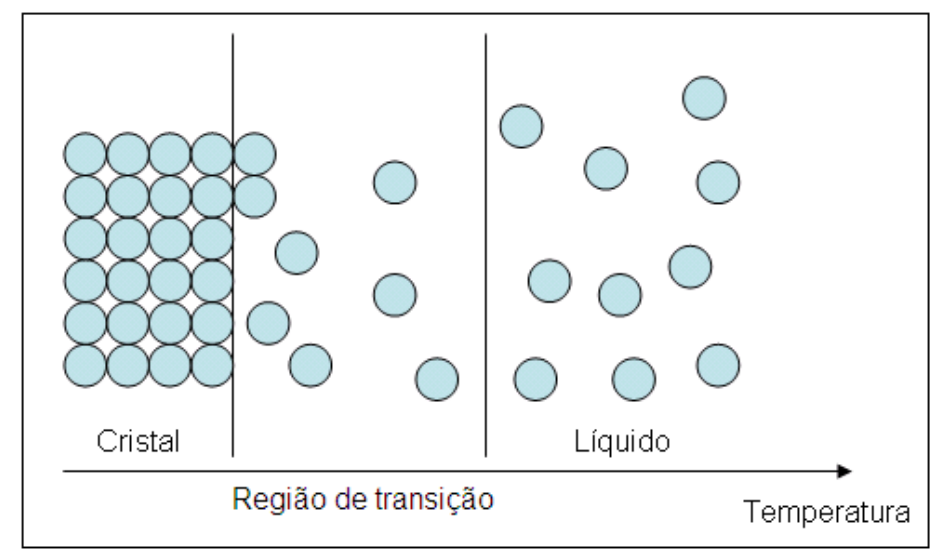

Figura 7 - Resfriamento de um líquido e a ordenação das moléculas no estado sólido [34].

Todo material possui um intervalo de temperatura transição vítrea ( $\mathrm{Tg}$ ) característica, e é a partir dela que se determina até que temperatura deve ser feito o resfriamento até a solidificação para um posterior tratamento térmico [34]. A partir de um material super-resfriado, passando do seu ponto de fusão, temos intervalo de transição vítrea $(\mathrm{Tg})$ onde ocorre o rearranjo das moléculas do 
material. Este rearranjo não é, entretanto, ordenado como o de um cristal. Neste rearranjo ocorre aumento da viscosidade e uma pequena diminuição do volume do material resfriado, o que é decorrente da diminuição da temperatura, provocando alteração na distância e tamanho das estruturas formadas.

Assim como a transição vítrea, os materiais possuem também uma temperatura de transição cristalina (TC) que determina a temperatura na qual o material deve ser submetido e mantido para que a cristalização ocorra; quanto maior for o tempo de permanência neste ponto, maior poderá ser a distribuição cristalina no material [34]. É importante, também determinar a temperatura de cristalização para a produção de fibras, pois a diferença $T c-T g>100^{\circ} \mathrm{C}$ é condição fundamental neste caso. Tal fato está relacionado à variação de viscosidade do material nas diferentes temperaturas.

A Figura 8 mostra a relação entre o volume e a temperatura para um material resfriado em diferentes condições. Quando o material é resfriado abaixo do ponto $(\mathrm{Tg})$, seguindo condições de amortização, que é alta taxa de resfriamento e não-descontinuidade na variação do volume da fase líquida para a sólida, tem-se a formação de um vidro.

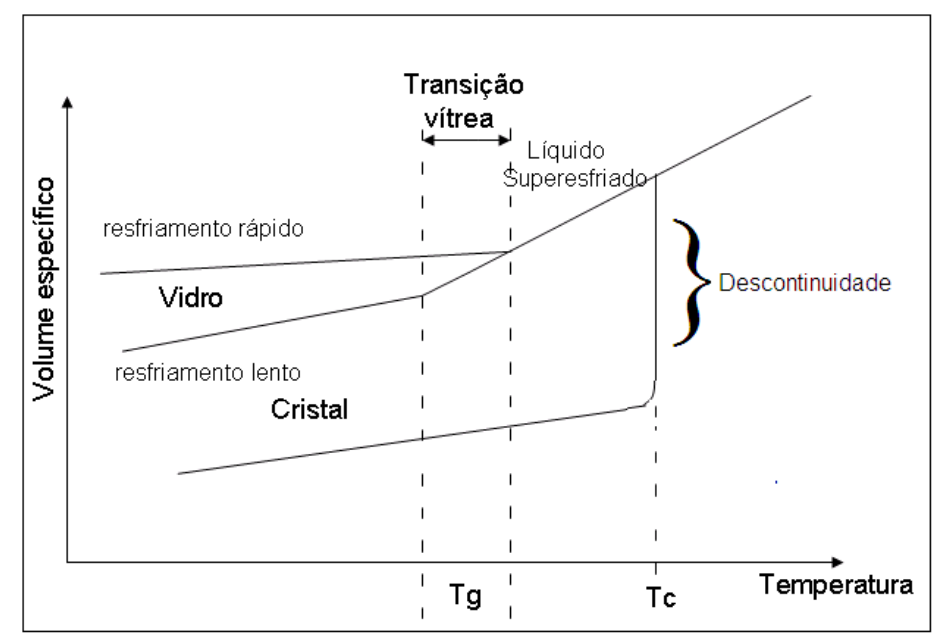

Figura 8 - Formação dos cristais e vidros.

$\mathrm{Na}$ figura acima, pode-se observar a faixa de temperatura de transição vítrea $(\mathrm{Tg})$ a partir do líquido super-resfriado sendo caracterizado pela ausência de cristalização. Dentro da faixa nota-se que pode ocorrer à formação de vidros com diferentes volumes, provocado pela taxa de resfriamento. Também pode se notar a temperatura de cristalização (Tc). 
Na definição de vidro está relacionado o fenômeno da transição vítrea e a desordenação das suas estruturas, podendo ser obtido de material inorgânico resultante que resfriou até um estado rígido sem ausência de cristalização, podendo também ser obtidos por deposição [32]. Algumas propriedades importantes dos vidros são [32]:

- Ausência de estruturas cristalinas;

- Não possuem ponto de fusão definidos. O vidro quando aquecido, amolece gradualmente até ter sua viscosidade reduzida;

- Não são estáveis a altas temperaturas. Quando mantidos por longo período temperatura acima do seu ponto de amolecimento, pode ocorrer rearranjo dos átomos, ocorrendo a cristalização;

- Mau condutor de calor e eletricidade;

- Não provocam desvio da luz polarizada.

Os vidros, de maneira em geral, são compostos de óxidos, que são classificados como: os óxidos formadores (são compostos que sozinhos formam a estrutura básica da rede vítrea e tem caráter covalente, ligação do tipo oxigênio ligante (brinding oxygen) e são formados por óxidos como: $\mathrm{SiO}_{2}, \mathrm{TeO}_{2}$ e $\mathrm{GeO}_{2}$; os óxidos modificadores (são formados, em geral, por óxidos alcalinos que tendem fazer a ligações iônicas com os ânions da rede, ligações do tipo oxigênio não ligante (nonbrinding oxygen), alterando as propriedades do vidro); e os intermediários (são compostos que podem substituir os óxidos formadores e modificadores, como $\mathrm{Pb}^{2+}, \mathrm{Al}^{3+}$ e $\mathrm{Be}^{2+}$, melhorando as qualidades dos vidros) [35].

Nas figuras a seguir, são mostradas duas estruturas vítreas, uma formada apenas com óxido formador Si-O (a) e a outra com óxido modificador incorporada na rede $\mathrm{Si}^{-} \mathrm{O}^{-} \mathrm{Na}^{+}(\mathrm{b})$. 


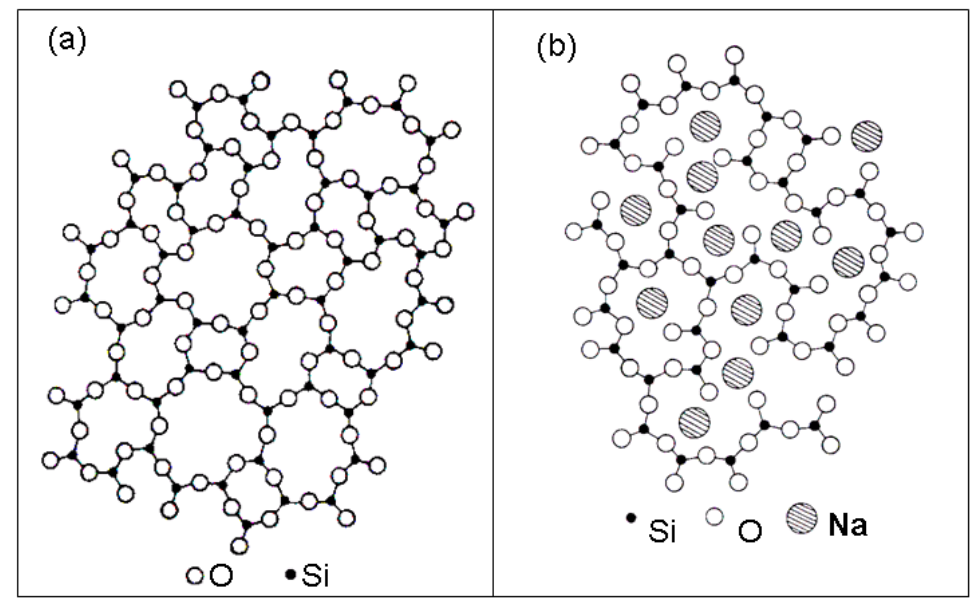

Figura 9 - Estrutura de um vidro bidimensional (a) arranjo formado por Si-O e (b) estrutura de um vidro binário Si-O-Na [34].

Na Figura 9(b) pode-se observar que ocorreu quebra de ligação de Si-O-Si para incorporação do sódio, formando-se as estruturas do tipo $\mathrm{Si}^{-} \mathrm{O}^{-} \mathrm{Na}^{+}$. Estas estruturas alteram as propriedades do vidro como sua viscosidade, índice de refração e o peso molecular. Todas essas alterações também são observadas nos vidros de teluretos [35].

\subsection{VIDROS DE ÓXIDOS DE METAIS PESADOS}

São apresentadas, a seguir algumas características dos reagentes e propriedades dos vidros utilizados para a produção da matriz vítrea estudada no presente trabalho.

\subsubsection{Vidro de Dióxido de Telúrio}

$\mathrm{Na}$ década de 70 ocorreu uma corrida por novos materiais promissores para aplicação em dispositivos acústico-ópticos, tais como moduladores [36]. Dentre estes materiais destacaram-se os vidros de telureto, por apresentarem uma boa qualidade óptica ( $80 \%$ da transmitância de luz), baixa energia de fônon quando comparados com outros vidros obtidos a partir de certos óxidos [37], e alta 
solubilidade para os óxidos de $\mathrm{Er}_{2} \mathrm{O}_{3}$ [38]. $\mathrm{Na}$ década de 80 , os vidros de telureto apresentaram-se como ótimos hospedeiros para altas concentrações de íons de érbio, com isso, foi possível a fabricação de dispositivos ópticos como fibras ópticas, amplificadores ópticos e dispositivos para sistemas de comunicações como lasers [35].

O primeiro pesquisador a descobrir a estrutura básica de vidros de óxido de telúrio foi S. Neov, 1979, por intermédio da difração de nêutrons em um vidro de $\mathrm{TeO}_{2}-\mathrm{Li}_{2} \mathrm{O}$ [39]. As unidades básicas descobertas eram compostas por três estruturas básicas de poliedros que incluem átomos de Te com número de coordenação 4, 3+1 e 3, conforme a figura abaixo:
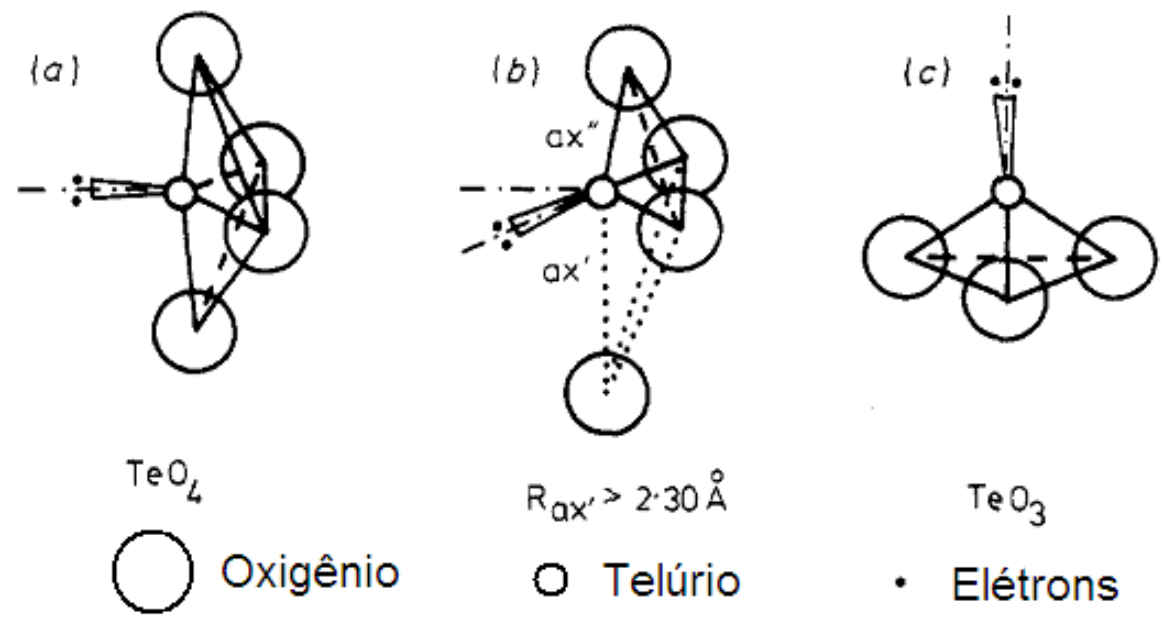

Figura 10 - Estruturas básicas presentes em vidros de teluretos com número de coordenação 4 , $3+1$ e 3 , respectivamente em (a), (b) e (c) [39].

Estudos mais detalhados realizados por T. Sekiya em vidros binários do tipo $\mathrm{MO}_{1 / 2^{-}}-\mathrm{TeO}_{2}(\mathrm{M}=\mathrm{Li}, \mathrm{Na}, \mathrm{K}, \mathrm{Rb}, \mathrm{Cs}$ and $\mathrm{TI})$, usando espectroscopia Raman, sobre a coexistência das unidades estruturais $\mathrm{TeO}_{4}, \mathrm{TeO}_{3+1}$ e $\mathrm{TeO}_{3}$. Mostraram que as três estruturas básicas de $\mathrm{S}$. Neov podem ser obtidas através da introdução de óxidos alcalinos (óxidos modificadores) na rede, sendo elas:

- Bipirâmides trigonais $\mathrm{TeO}_{4}$ (tbp) que são compostas por 2 átomos de oxigênio axiais, dois átomos de oxigênio equatoriais e dois pares de elétrons isolados; a distância da ligação $\mathrm{Te}-\mathrm{O}_{\text {axial }}=2,08 \AA$, sendo maior 
que a ligação Te- $\mathrm{O}_{\text {equatorial }}=1,90 \AA$ (Figura $10(\mathrm{a})$ ), neste caso não há introdução de óxido alcalino.

- Vidros com uma baixa concentração de óxidos alcalinos apresentam estruturas poliédricas assimétricas do tipo $\mathrm{TeO}_{3-1}$ (tp), onde a distância de uma das ligações Te-O $\mathrm{O}_{\text {axial }}$ apresenta maior distância (Figura 10 (b) ).

- Em vidros com concentrações de óxidos alcalinos entre 20 e 30 mol\%, são formadas as estruturas $\mathrm{TeO}_{3}$, formada por três ligações curtas $\mathrm{Te}-\mathrm{O}=1,88$ $\AA$ (Figura 10(c)) [40].

Para obter a estrutura de $\mathrm{TeO}_{3+1}$ (tp) é necessário que ocorra a quebra de ligação da estrutura bipiramide trigonal $\mathrm{TeO}_{4}$ (tbp) pela adição de um óxido $\mathrm{M}_{2} \mathrm{O}$, formando um único oxigênio não ligante do tipo Te---O- estável, conforme a figura abaixo:

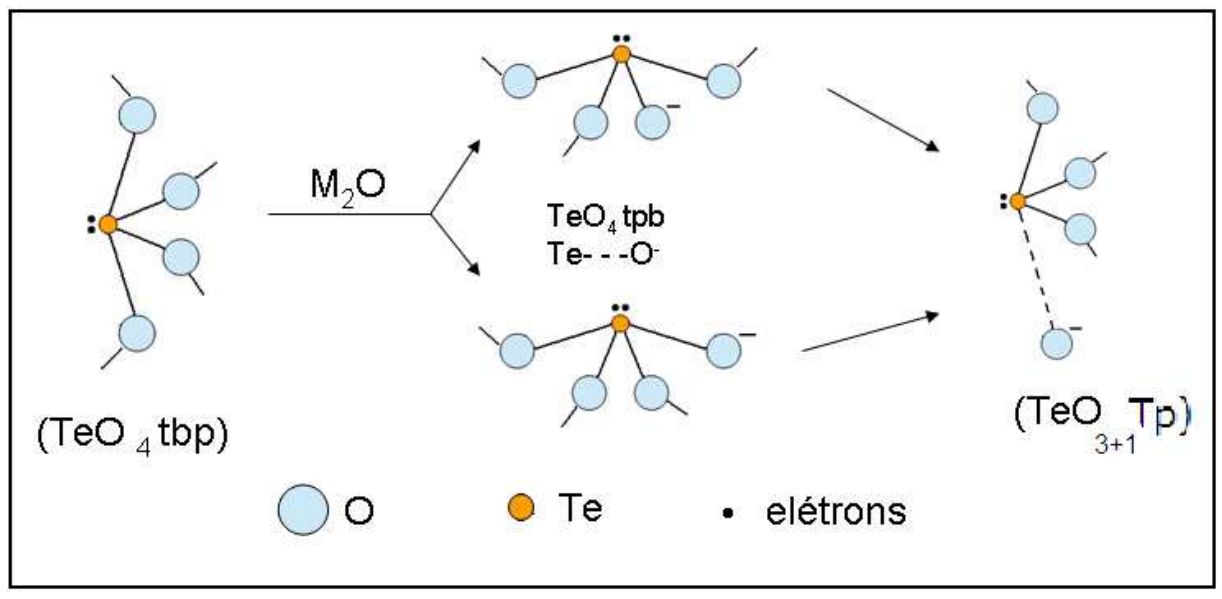

Figura 11 - Formação da estrutura $\mathrm{TeO}_{3+1}$ a partir de uma estrutura $\mathrm{TeO}_{4}$ [41].

$\mathrm{Na}$ quebra da estrutura $\mathrm{TeO}_{4}$ pela adição de $\mathrm{M}_{2} \mathrm{O}$, há a possibilidade que ocorra a formação de uma estrutura $\mathrm{Te}-\mathrm{O}_{\text {axial }}$ ou Te-O $\mathrm{O}_{\text {equatorial, }}$ devido ao fato da unidade Te - - O-axila ser instável, esta se distorce e transforma-se na unidade estrutural $\mathrm{TeO}_{3+1}$, formando uma ligação oxigênio não ligante $>2,2 \AA$. A outra unidade que pode ser formada é a Te - - O- equatorial que pode sofrer pequena distorção, dependendo da concentração de $\mathrm{M}_{2} \mathrm{O}$ [41].

A estrutura $\mathrm{TeO}_{3}$ é formada a partir do alongamento das ligações $\mathrm{Te}$ - - O da estrutura $\mathrm{TeO}_{3+1}$ e da clivagem devido à transferência de elétrons e dos íons modificadores, conforme a figura abaixo: 


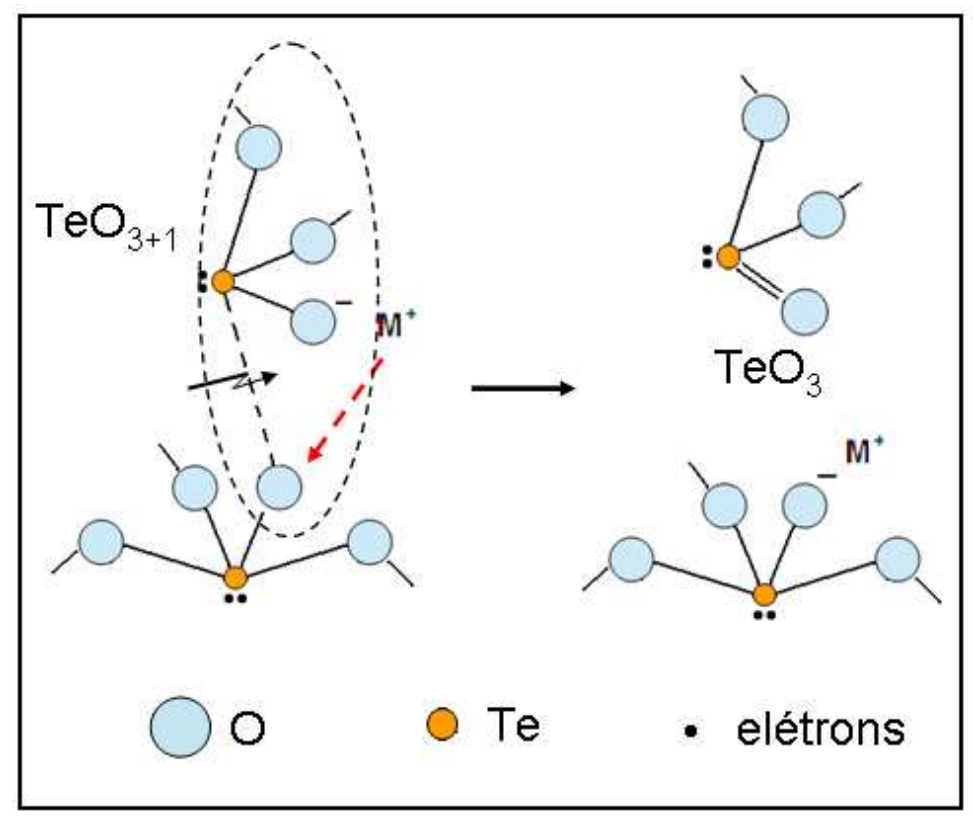

Figura 12 - Formação da estrutura $\mathrm{TeO}_{3}$ a partir da estrutura $\mathrm{TeO}_{3+1}[41]$.

A estrutura $\mathrm{TeO}_{3}$ apresenta uma ligação dupla, a qual foi formada devido à transferência de elétrons do íon modificador.

O dióxido de telúrio pertence à família dos calcogênios, sendo responsável pela formação dos vidros de telureto que são conhecidos por suas excelentes propriedades ópticas lineares e não-lineares [42]. Ao longo dos últimos anos, suas propriedades estruturais, ópticas e elétricas vêm sendo minuciosamente investigadas com o intuito de viabilizar aplicações tecnológicas para a óptica integrada [43]. A fabricação de fibras ópticas produzidas a partir de vidros de telureto tem uma enorme importância nas telecomunicações, sendo classificado como um dos principais hospedeiros para os íons de terras raras [44]. Confere transmissão de 300 a 7000 nm; esta ampla faixa de transmissão proporciona aos vidros de telureto a capacidade de serem utilizados não somente para telecomunicação, mas também na medicina, sensores e outras aplicações, operando na faixa do infravermelho médio de 2000 - 5000 nm [45]. Também apresentam boa estabilidade vítrea frente à cristalização, alto índice de refração $(\sim 2,0)$, estabilidade química, baixa temperatura de fusão, sendo facilmente obtidos em atmosfera ambiente [46]. 


\subsubsection{Vidro de Dióxido de Germânio}

O dióxido de germânio é um composto largamente utilizado na composição de matrizes vítreas empregadas em meios ópticos, apresentando como característica uma boa faixa de transmissão no infravermelho (até $4500 \mathrm{~nm}$ ).

Uma série de estudos foi conduzida [47-49] para obter novos materiais ópticos, especialmente estudos de vidros com características particulares de dispersão. Poluklin [47-49] descobriu que o formador de vidro por dióxido de germânio tem uma pequena constante de dispersão menor na região do azul do espectro, similar ao vidro de boro.

Comparando os sistemas de silicato e borato, com sistemas de germanato, altos índices de refração podem ser obtidos para concentrações consideravelmente baixas de óxidos de metais pesados $\left(\mathrm{PbO}, \mathrm{TiO}_{2}, \mathrm{Nb}_{2} \mathrm{O}_{5}\right.$, $\mathrm{Ta}_{2} \mathrm{O}_{5}$ ). Para índices de refração no intervalo de 1,60-1,65 estes óxidos não são necessários. O dióxido de germânio permite a obtenção de vidros com alto índice de refração, o que não é possível em sistemas borosilicatos [50].

\subsubsection{Vidro de Dióxido de Chumbo}

O óxido de chumbo é um dos componentes que mais enobrece a qualidade do vidro, proporcionando um alto grau de índice de refração e brilho, uma elevada densidade e uma boa sonoridade. Os vidros que contêm chumbo devem ser fundidos, preferencialmente em atmosfera fortemente oxidante para evitar redução de óxido a metal elementar [51].

Esse tipo de vidro tem baixa temperatura de fusão e é facilmente moldado em um grande intervalo de temperatura. O óxido de chumbo é muito empregado em vidros ópticos, em vidros para aplicações elétricas e eletrônicas, em vidros especiais absorventes de radiação $X$ e radiação $\gamma$ (gama), em vidros artísticos $e$ decorativos [51].

O óxido de chumbo volatiliza acima de $1200^{\circ}$ C e é tóxico. Além disso, se os vidros não são formulados de maneira adequada, tornam-se sujeitos a ataque 
químico, inicialmente por meio ácidos; neste caso, pode haver liberação do chumbo dentro da solução [51]. 


\section{3 ÍONS DE TERRAS RARAS}

O maior interesse de estudo de novos compostos com íons de terras raras está relacionado às propriedades ópticas luminescentes que estes materiais apresentam. De fato, o campo de aplicações é muito vasto, variando desde os fósforos até fibras amplificadoras em sistemas de telecomunicações.

Os elementos de terras raras têm as camadas $4 \mathrm{f}$ incompletas [52]. As transições eletrônicas para estas camadas conferem propriedades luminescentes que têm muitas aplicações em dispositivos ópticos, desde que sua incorporação esteja no estado trivalente dos íons. Os elétrons mais externos dos íons de terras raras formam uma camada chamada "xenon" (pois apresentam a configuração eletrônica do gás xenônio), opticamente inativa, com dois elétrons na camada $5 \mathrm{~s}$ e seis na $5 p$. A camada $4 f$ é vizinha e interna à "camada xenon". Enquanto a camada $4 \mathrm{f}$ é preenchida com 14 elétrons, um dado número de níveis $4 \mathrm{f}$ fica desocupado, e os elétrons presentes na camada $4 \mathrm{f}$ podem ser levados por absorção da radiação eletromagnética para este nível vazio. Estas transições originam os espectros de absorção e de emissão das terras raras. Tais espectros são mais estreitos do que os relativos às transições de metais de transição. Isto se deve ao fato de que durante a transição o elétron fica na região interna à "camada xenon" e interage fracamente com íons externos.

\subsubsection{Processo de Conversão Ascendente e Transferência de Energia}

A emissão na região do visível pode ocorrer pelo processo chamado de conversão ascendente (upconversion), que se caracteriza pela emissão de fótons com maior energia que a utilizada pela fonte de bombeio (fonte de excitação). Assim, se torna possível a utilização de lasers de diodo operando nas regiões do infravermelho e vermelho como fonte de excitação [53].

Este processo pode ser obtido a partir de vários mecanismos, sendo que quatro deles ocorrem com emissão no visível, podendo ser classificados como: 
- Absorção de estado excitado (AEE): ocorre quando há absorção de um fóton com energia ressonante por um elétron que sai do nível fundamental e passa para um nível intermediário e, em seguida, absorve outro fóton que o leva para um nível de maior energia que o intermediário. Ao decair deste nível para o fundamental emite um fóton com maior energia.

- Conversão Ascendente por Transferência de Energia (CATE): ocorre quando dois íons vizinhos se encontram excitados por bombeio (nível intermediário), e quando um deles decai para o nível fundamental, emitindo um fóton que poderá ser absorvido pelo outro, levando-o para um nível de maior energia.

- Sensibilização Cooperativa (SC): ocorre quando dois íons se encontram em nível intermediário, e ao decaírem, transferem sua energia a outro íon, que se eleva do nível fundamental para um nível de maior energia.

- Emissão Cooperativa (EC): ocorre quando dois íons em estado intermediário de energia, ao decaírem, emitem um único fóton com o dobro da energia emitida por um único íon.

A figura 13 ilustra os mecanismos acima explicados.

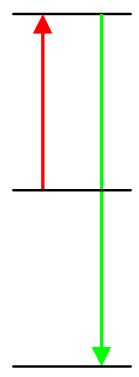

(a)

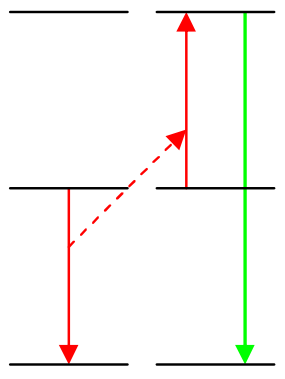

(b)

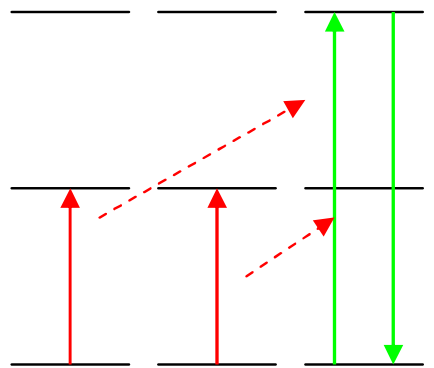

(c)

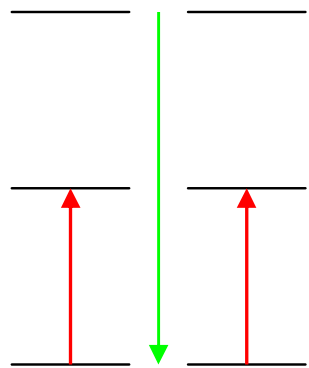

(d)

Figura 13 - Mecanismo de conversão ascendente (a) Absorção de Estado Excitado, (b) Conversão Ascendente por Transferência de Energia, (c) Sensibilização Cooperativa e (d) Emissão Cooperativa.

A partir destes mecanismos pode-se explicar os processos de transferência de energia que ocorrem em matrizes vítreas que sofreram dopagem e codopagem. No caso da codopagem tem-se usado muito o itérbio como íon doador, pois apresenta alta secção de choque de absorção na região do infravermelho e um eficiente mecanismo de transferência de energia para outro 
íon [53]. Passa-se a explicar os processos de conversão ascendente do $\mathrm{Er}^{3+}$ e a situação onde há codopagem de $\mathrm{Er}^{3+} \mathrm{e} \mathrm{Yb}^{3+}$.

No processo de conversão ascendente a intensidade de emissão ou de fluorescência $\mathrm{I}_{\mathrm{F}}$, é diretamente proporcional à potência da intensidade de excitação no infravermelho $I_{R}$, tal que:

$$
I_{F}=I_{R}^{n}
$$

Na equação acima n pode assumir valores de $2,3,4 \ldots$ que é o número de fótons absorvidos no processo de conversão ascendente.

Os valores com algarismos decimais são decorrentes de processos de decaimento não-radiativo. Estas medidas são necessárias para identificar o número de fótons que participam do processo de conversão ascendente, conforme será mostrado na parte experimental.

As propriedades de emissões dos íons de terras raras encontram aplicação em diversas áreas, como industriais, telecomunicações e medicina. Estas aplicações devem-se, essencialmente, às intensas e quase monocromáticas emissões por parte destes elementos quando se encontram diluídos em redes hospedeiras apropriadas (Figura 14). As causas destas emissões podem ser explicadas pelo processo de conversão ascendente.

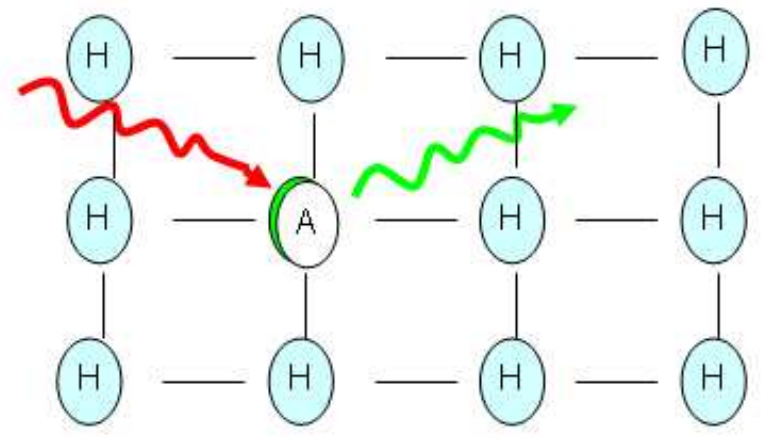

Figura 14 - Representação do íon ativador na matriz hospedeira.

Os processos de transferência de energia ocorrem de várias maneiras, mas os mais comumente estudados são devidos a processos de luminescência (fótons) e dissipação de calor (fônons). O processo de luminescência ocorre quando a radiação de excitação é absorvida por um íon ativador, passando do estado fundamental (Ef) para um estado excitado de energia (E1), Ef $\rightarrow$ E1, 
seguido de um decaimento energético do estado excitado para o estado fundamental, E1 $\rightarrow$ Ef, quando ocorre a emissão de um fóton de energia hv = E1 $\rightarrow$ Ef. Antes do decaimento radiativo pode haver um decaimento não-radiativo (perda de energia na forma de calor ou fônons), diminuindo a eficiência do processo radiativo.

A emissão do processo de luminescência que se pode obter dos íons de terras raras se dá por diferentes mecanismos de transferência de energia, que ocorrem por meio da transferência de energia de um doador para um íon aceitador, e podem ser divididos basicamente em quatro processos [54]:

- Transferência radiativa ressonante: ocorre entre diferentes íons que necessitam da mesma energia para serem excitados. A diferença de energia entre os estados fundamental e excitado é igual (estado intermediário) a do íon doador e aceitador, quando um fóton é emitido por um íon doador e absorvido por outro íon aceitador; este processo é dado como ressonante;

- Transferência não-radiativa ressonante: é a transferência de energia nãoradiativa entre os íons doadores e aceitadores por meio de interação eletromagnética, podendo haver a possibilidade de retorno da energia para o íon doador chamado processo de retrotransferência (Backtransfer);

- Transferência não-radiativa assistida por fônons: processo de equilíbrio energético entre os íons doador e o aceitador por meio de interação eletromagnética, onde há necessidade da interação de fônons que irão absorver ou fornecer o excesso de energia para manter o equilíbrio entre os íons;

- Transferência por relaxação cruzada: processo no qual a energia de excitação do doador é transferida parcialmente para o íon aceitador, por meio de interação eletromagnética, ficando ambos em estados excitados intermediários.

Os mecanismos descritos anteriormente podem ocorrer entre íons iguais, com exceção do mecanismo de transferência não-radiativa assistida por fónons, pois a energia para excitar o íon doador não é a mesma necessária para o íon aceitador. Quando a transferência de energia ocorre entre íons iguais, a 
luminescência pode ser comprometida, ocorrendo quando há grande concentração de dopante, esse efeito é chamando de "concentration quenching", podendo ocorrer em amostras dopadas e codopadas.

\subsubsection{Processo de Conversão Ascendente dos Íons de $\mathrm{Er}^{3+} \mathrm{e} \mathrm{Tm}^{3+}$}

Os íons de érbio atuam como centros de cor, conferindo ao vidro tonalidade rósea que se acentua com 0 aumento de sua concentração. Geralmente os íons de érbio são incorporados pelo vidro na forma trivalente $\left(\mathrm{Er}^{3+}\right)$, embora, sob determinadas condições, também seja possível a incorporação dos íons de TR na forma bivalente.

$\mathrm{O}$ diagrama do $\mathrm{Er}^{3+}$ está mostrado na Figura 14. As emissões em $1,5 \mu \mathrm{m}$ e em 2,7 $\mu$ m são devidas respectivamente às transições: ${ }^{4} I_{13 / 2} \rightarrow{ }^{4} I_{15 / 2}$ e ${ }^{4} I_{11 / 2} \rightarrow$ ${ }^{4} I_{13 / 2}$. O nível ${ }^{4} I_{15 / 2}$ corresponde ao estado fundamental.

Devido à necessidade de uma maior capacidade de transmissão de dados existe um aumento no interesse pela produção de novos materiais que atuem como amplificadores ópticos nas janelas de telecomunicação [55]. A transição correspondente ao $1,5 \mu \mathrm{m}$ (terceira janela de comunicação) oferece a possibilidade para aplicações tecnológicas bastante interessantes em telecomunicações. Neste caso, com alta dopagem de érbio, consegue-se amplificar pequenos sinais em 1,5 $\mu \mathrm{m}$ em fibras de sílica ou de fosfato. Outra aplicação do érbio como amplificador consiste na elaboração de filmes finos através de processos fotolitográficos adequados.

No caso da transição em 2,7 $\mu \mathrm{m}$, o érbio oferece a possibilidade para aplicações em aparelhos médicos hospitalares, devido à proximidade de sua banda de absorção com a banda principal de absorção da molécula $\mathrm{H}_{2} \mathrm{O}$. 


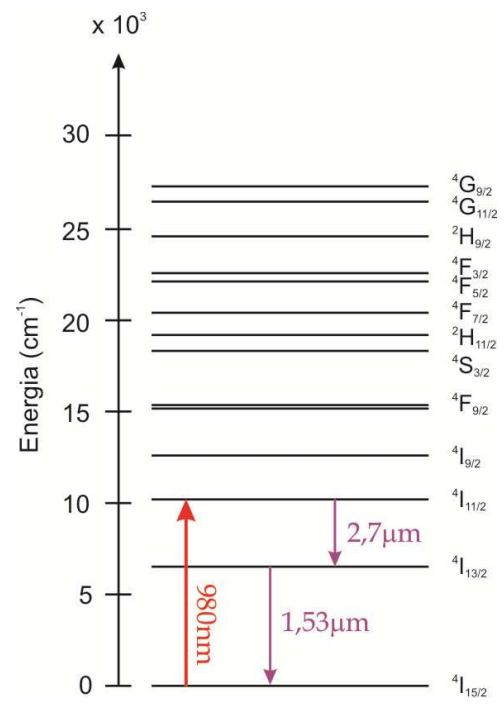

Figura 15 - Diagrama de energia $\mathrm{Er}^{3+}[56]$.

A Figura 16 apresenta o diagrama simplificado de energia do $\mathrm{Er}^{3+}$, mostrando o mecanismo de conversão ascendente por absorção do estado excitado (AEE) e por transferência de energia (TE), quando bombeado por radiação de 980nm. O mecanismo de absorção do estado excitado é predominante em amostras com baixa concentração de dopante.
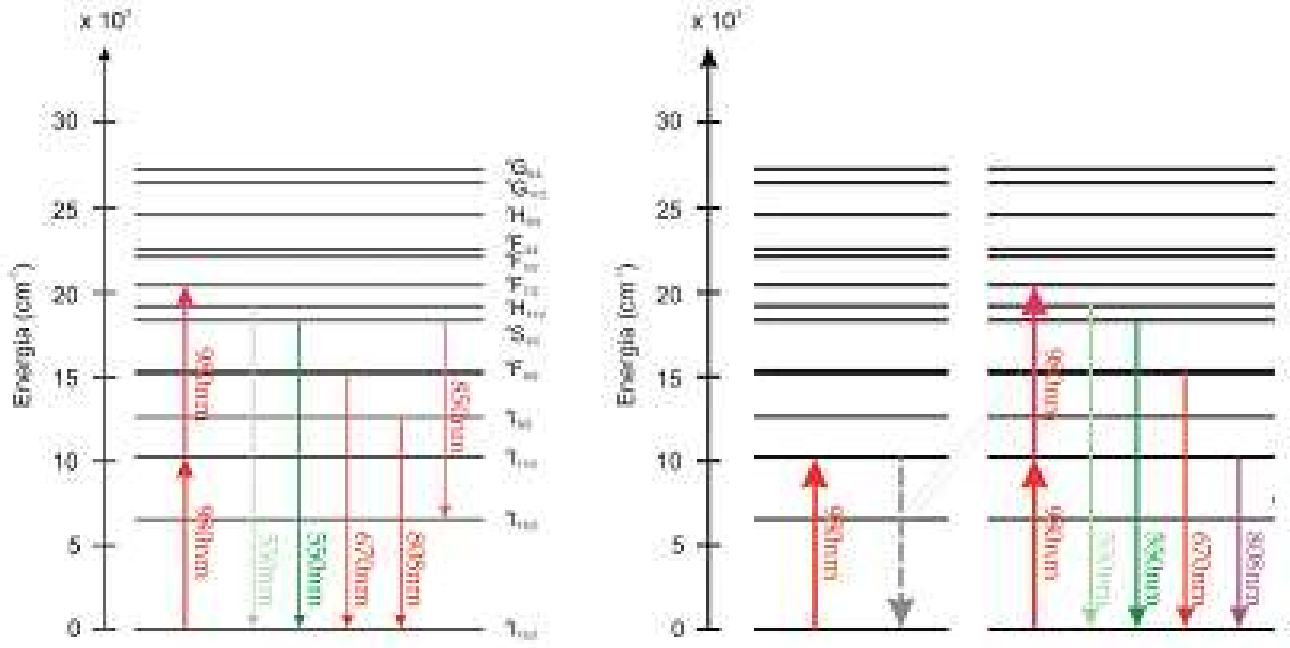

Figura 16 - Diagrama de energia simplificado do $\mathrm{Er}^{3+}$, mostrando os processos de conversão ascendente por (a) absorção do estado excitado e (b) transferência de energia [56].

O surgimento de novas emissões pode ocorrer, dependendo da quantidade de fótons envolvida no processo de conversão ascendente. Em um 
trabalho com vidros de fluoroindato dopadas com íons de $\mathrm{Er}^{3+}$ [55], foi utilizado um laser de 1,48 $\mu \mathrm{m}$ para o bombeio e foram observadas emissões em 407, 530, 550, 670, 808 e 854 nm. A Figura 17 mostra o mecanismo de conversão ascendente neste caso. Os autores concluíram que o processo de conversão ascendente deve ter ocorrido, majoritariamente, por transferência de energia, devido à alta concentração do dopante nas amostras.

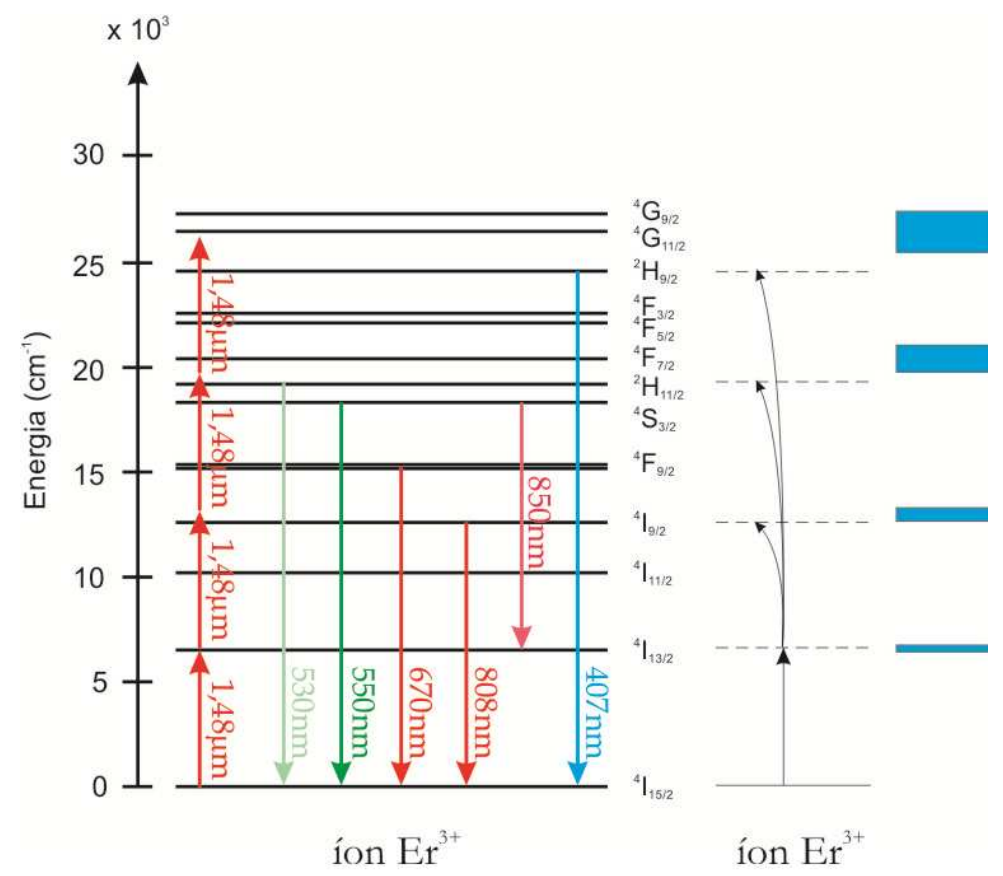

Figura 17 - Diagrama simplificado do $\mathrm{Er}^{3+}$, mostrando possíveis emissões, quando excitado em $1,48 \mu \mathrm{m}[56]$.

Nem sempre é possível observar este processo de conversão ascendente. Ele depende da matriz usada (janela de transmissão no visível) e da potência e do comprimento de onda do laser de bombeamento.

Entre as aplicações para as emissões no visível, decorrentes dos processos de conversão ascendente, estão a produção de leds, lasers planos para dispositivos de telecomunicações, displays tridimensionais, bistabilidade intrínseca para chaveamento óptico.

O túlio foi separado pela primeira vez na forma de óxido em 1879, por Per Teodor Cleve, como sendo uma das impurezas encontradas na TR já conhecida como érbio, de onde foi encontrada também a TR hólmio. A sua forma metálica foi obtida nos primórdios a partir do aquecimento de seu óxido misturado com o 
lantânio, entretanto, nos dias atuais ele é obtido a partir do aquecimento do fluoreto de túlio com cálcio, devido o alto custo do processo. Por ser uma das TRs menos abundante e mais difícil de obter, no passado era considerada de baixo interesse e poucas eram as aplicações. As primeiras aplicações foram 0 dosímetro de radiação e os equipamentos de raios $\mathrm{X}$ portáteis para uso na medicina [58].

Com o avanço da ciência, novas aplicações para os íons de TRs foram surgindo à medida que os métodos de produção dos materiais, de obtenção dos reagentes e as técnicas de caracterização foram evoluindo. Da mesma forma, o túlio passou a ser mais empregado e investigado. $O$ interesse surgiu quando foram observadas novas possibilidades de aplicação, tais como, telecomunicações, sensoriamento químico, gravação óptica de dados, displays [58], laser de estado sólido no visível $[58,59]$ e fibras dopadas com $\mathrm{Tm}^{3+}$ que emitem em 2,3 $\mu \mathrm{m}$ e são aplicadas em procedimentos cirúrgicos [60].

Dentre as emissões apresentadas pelos íons $\mathrm{Tm}^{3+}$ estamos interessados nas que se encontram na região visível do espectro eletromagnético. Na Figura 18 são apresentadas algumas probabilidades de emissões e respectivas transições na região do visível. É apresentada também uma emissão no IV, em torno de $800 \mathrm{~nm}$.

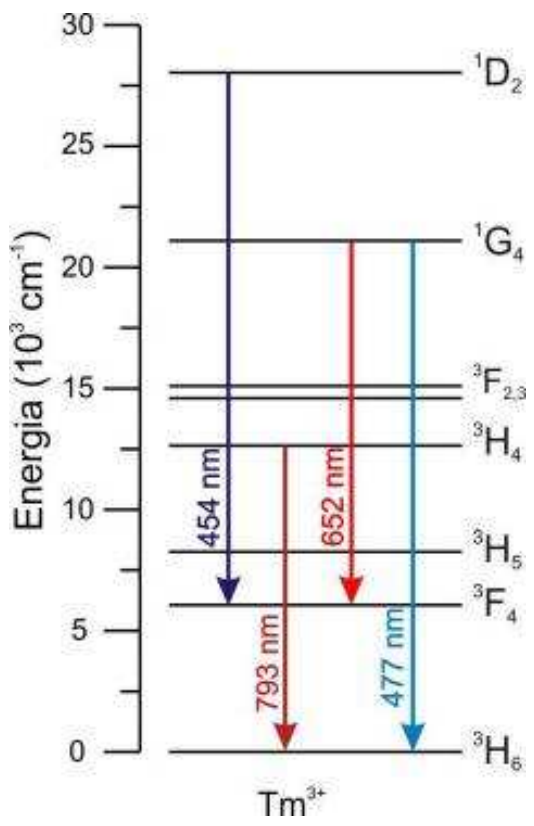

Figura 18 - Diagrama simplificado dos níveis de energia dos íons $\mathrm{Tm}^{3+}$ com a representação das emissões possíveis no visível. 
Nem sempre é possível observar este processo de conversão ascendente. Ele depende da matriz usada (janela de transmissão no visível) e da potência e do comprimento de onda do laser de bombeamento.

Entre as aplicações para as emissões no visível, decorrentes dos processos de conversão ascendente, estão à produção de leds, lasers planos para dispositivos de telecomunicações, displays tridimensionais e chaveamento óptico, etc.

\subsubsection{Processo de Transferência de Energia do $\mathrm{Yb}^{3+}$ para os Íons de $\mathrm{Er}^{3+}$ e $\mathrm{Tm}^{3+}$}

Em matriz hospedeira que sofreu o processo de codopagem (introdução de mais de um íon diferente de terra rara), é possível haver produção de maior luminescência com menor potência de bombeio. Neste trabalho são estudados também os mecanismos de transferência de energia que ocorrem entre íons diferentes, isto é, transferência de energia do itérbio para o érbio e túlio.

Em materiais que foram codopados, com $\mathrm{Yb}^{3+}$ e $\mathrm{Er}^{3+}$, o processo de conversão ascendente pode resultar de diferentes processos de transferência de energia, incluindo a absorção no estado excitado, energia transferida entre íons vizinhos de $\mathrm{Er}^{3+} \mathrm{e}$ incorporação de fótons por transferência de energia entre os íons de $\mathrm{Yb}^{3+}$ para os íons de $\mathrm{Er}^{3+}[61]$.

Em amostras codopadas a eficiência da população do nível ${ }^{4} \mathrm{I}_{11 / 2}\left(\mathrm{Er}^{3+}\right)$ aumenta devido à grande secção de choque do $\mathrm{Yb}^{3+}$ e a um eficiente mecanismo de transferência de energia $\mathrm{Yb}^{3+} \rightarrow \mathrm{Er}^{3+}$ que pode popular os níveis emissores de radiação do visível do infravermelho [30]. O processo de conversão ascendente entre $\mathrm{Yb}^{3+} \mathrm{e} \mathrm{Er}^{3+}$ colabora para minimizar a potência necessária para iniciar a emissão laser a partir de níveis emissores [1,38]. Outra vantagem da codopagem consiste no fato de que uma pequena quantidade de íons aceitadores $\left(\mathrm{Er}^{3+}\right)$ consegue melhorar as características do laser com aumento da quantidade de íons doadores $\left(\mathrm{Yb}^{3+}\right)$ [61].

A figura a seguir mostra as possíveis formas de popular os níveis emissores da radiação verde $\left({ }^{2} H_{11 / 2}\right.$ e $\left.{ }^{4} S_{3 / 2}\right)$ e vermelha $\left({ }^{4} F_{9 / 2}\right)$ em uma amostra 
codopada com íons de $\mathrm{Er}^{3+}$ e $\mathrm{Yb}^{3+}$, quando excitada por um laser de infravermelho (980 $\mathrm{nm})$.

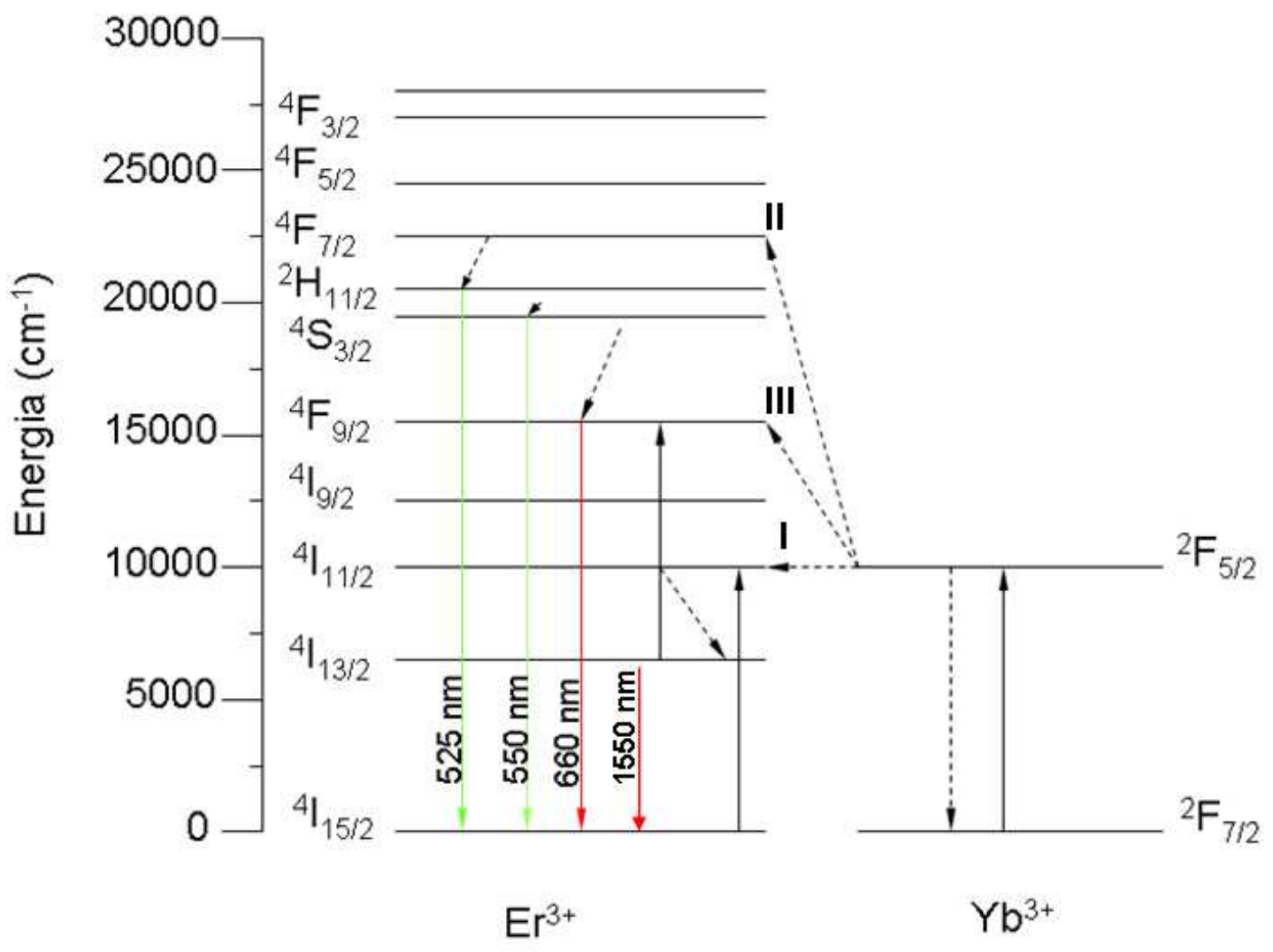

Figura 19 - Transferência de energia entre os íons de $\mathrm{Yb}^{3+}$ e $\mathrm{Er}^{3+}$ para popular os níveis emissores de radiação do visível e do vermelho [62].

O processo de conversão ascendente pode ser explicado por meio da Figura 19. Excita-se o $\mathrm{Yb}^{3+}$ para o nível ${ }^{2} \mathrm{~F}_{5 / 2}$ a partir do qual há um decaimento para o nível ${ }^{2} \mathrm{~F}_{7 / 2}$. Neste processo de transição há transferência de energia para 0 $\mathrm{Er}^{3+}$ que passa do nível ${ }^{4} \mathrm{I}_{15 / 2}$ (nível fundamental) para o nível excitado ${ }^{4} \mathrm{I}_{11 / 2}$ (em I). Em seguida, o $\mathrm{Er}^{3+}$ é elevado ao nível ${ }^{4} \mathrm{~F}_{7 / 2}$ pela absorção de um segundo fóton de mesma energia (em II). A partir deste nível, o $\mathrm{Er}^{3+}$ pode decair para os níveis ${ }^{2} \mathrm{H}_{11 / 2}$ e ${ }^{4} \mathrm{~S}_{3 / 2}$ por relaxação não-radiativa. A partir destes níveis, há decaimento para o nível fundamental com emissão de luz com comprimentos de onda de 530 $\mathrm{nm}$ e $550 \mathrm{~nm}$ [62].

Para a emissão do vermelho $(660 \mathrm{~nm})$ há as duas possibilidades de decaimento do $\mathrm{Er}^{3+}$ [58]. O primeiro decaimento ocorre do nível ${ }^{4} \mathrm{~S}_{3 / 2}$, por relaxação não radiativa, para o nível ${ }^{4} \mathrm{~F}_{9 / 2}$, que ao decair para nível ${ }^{4} \mathrm{I}_{15 / 2}$, emite radiação vermelha; outro caminho ocorre quando o $\mathrm{Er}^{3+}$ se encontra no nível ${ }^{4} \mathrm{I}_{11 / 2}$ 
e decai para o nível ${ }^{4} I_{13 / 2}$, por relaxação, e em seguida, o $\mathrm{Er}^{3+}$ absorve um fóton, transferido do $\mathrm{Yb}^{3+}$ (em III), que o eleva para o nível ${ }^{4} \mathrm{~F}_{9 / 2}$ que ao decair para $\mathrm{o}$ nível fundamental emite a radiação de $660 \mathrm{~nm}$.

A emissão em $1550 \mathrm{~nm}$ ocorre a partir da transição ${ }^{4} \mathrm{I}_{13 / 2}$ para o nível ${ }^{4} \mathrm{I}_{15 / 2}$. Esta emissão é intensificada pela transferência de energia do $\mathrm{Yb}^{3+}$ para o $\mathrm{Er}^{3+}$, pela transferência de um fóton do $\mathrm{Yb}^{3+}$ para o nível ${ }^{4} \mathrm{I}_{11 / 2}$ do $\mathrm{Er}^{3+}$ (I). Em seguida, ocorre o decaimento, por relaxação não-radiativa, para o nível ${ }^{4} \mathrm{I}_{13 / 2}$ a partir do qual há um decaimento para o nível ${ }^{4} I_{15 / 2}$ e emissão de luz em 1550 nm [63].

$\mathrm{Na}$ Figura 20 é representado o diagrama dos níveis de energia dos íons $\mathrm{Er}^{3+}, \mathrm{Tm}^{3+}$ e $\mathrm{Yb}^{3+}$ e o processo de transferência de energia entre os íons $\mathrm{Yb}^{3+}$ com os íons de $\mathrm{Tm}^{3+}$ e $\mathrm{Er}^{3+}$ e suas respectivas emissões.

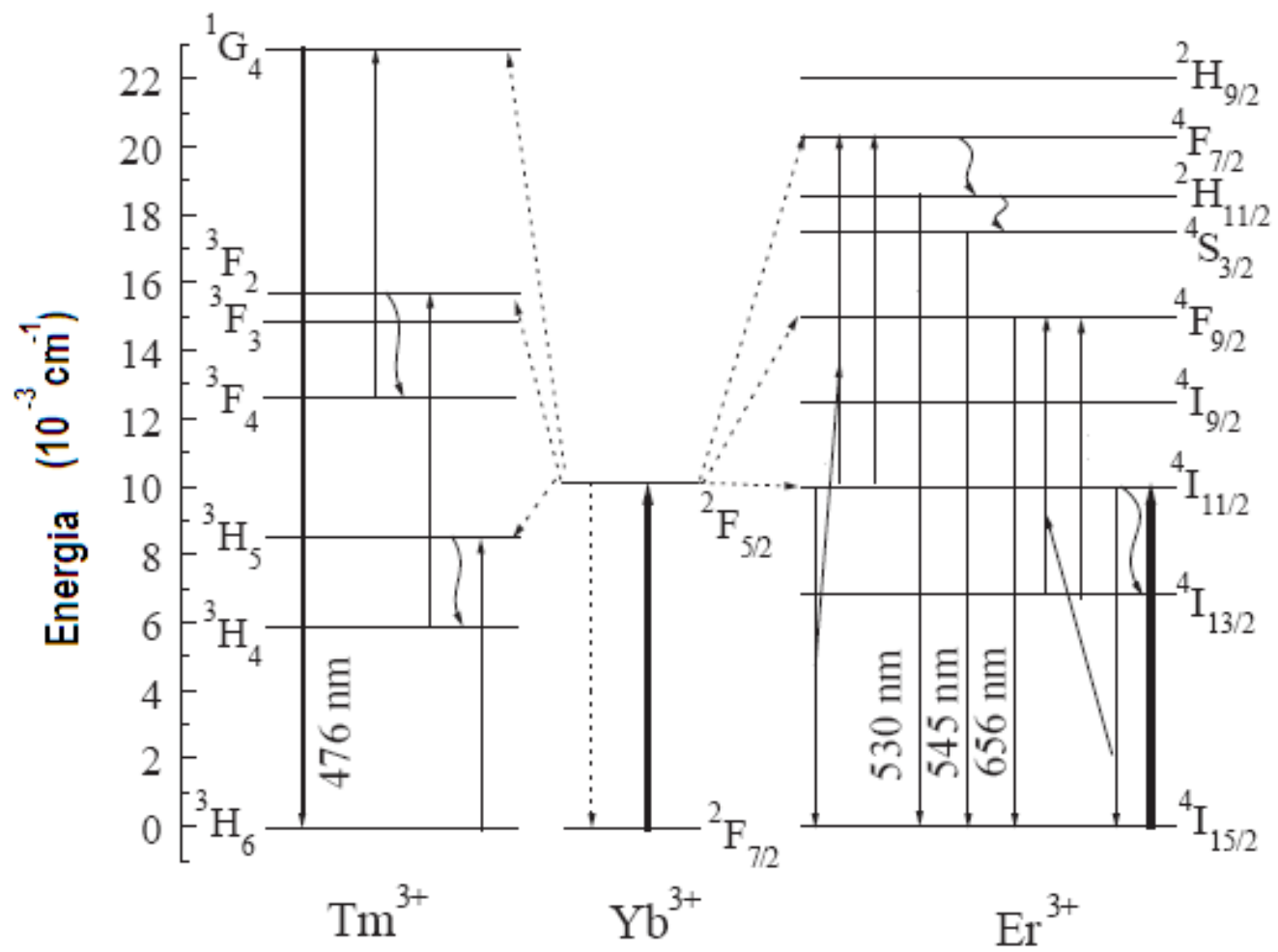

Figura 20 - Diagrama dos processos de transferência de energia entre as TRs. As linhas sólidas representam os processos de absorção e emissão; as pontilhadas as transferências de energia; as linhas distorcidas os processos não radiativos [64].

$\mathrm{O} \mathrm{Yb}^{3+}$ ao ser bombeado em $980 \mathrm{~nm}$ promove íons do nível ${ }^{2} \mathrm{~F}_{7 / 2}$ para 0 nível ${ }^{2} \mathrm{~F}_{5 / 2}$, que ao decaírem emitem fótons com energia suficiente para excitar 0 $\mathrm{Tm}^{3+}$ do estado fundamental ${ }^{3} \mathrm{H}_{6}$ ao nível ${ }^{3} \mathrm{H}_{5}\left({ }^{2} \mathrm{~F}_{5 / 2}+{ }^{3} \mathrm{H}_{6} \rightarrow{ }^{2} \mathrm{~F}_{7 / 2}+{ }^{3} \mathrm{H}_{5}\right)$, libera fônons e decai para o estado metaestável ${ }^{3} \mathrm{H}_{4} . \mathrm{O} \mathrm{Tm}^{3+}$ continua a ser excitado 
pelo $\mathrm{Yb}^{3+}$, absorve mais um fóton chegando ao nível ${ }^{3} \mathrm{~F}_{2}\left({ }^{2} \mathrm{~F}_{5 / 2}+{ }^{3} \mathrm{H}_{4} \rightarrow{ }^{2} \mathrm{~F}_{7 / 2}+{ }^{3} \mathrm{~F}_{2}\right)$ para em seguida decair para o nível ${ }^{3} \mathrm{~F}_{4}$ por liberação de fônon.

A partir desse estado $\circ \mathrm{Tm}^{3+}$ é excitado para o nível ${ }^{1} \mathrm{G}_{4}$ por absorção de um fóton e transferência de energia com o $\mathrm{Yb}^{3+}\left({ }^{2} \mathrm{~F}_{5 / 2}+{ }^{3} \mathrm{~F}_{4} \rightarrow{ }^{2} \mathrm{~F}_{7 / 2}+{ }^{1} \mathrm{G}_{4}\right)$. Então 0 $\mathrm{Tm}^{3+}$ decai radiativamente para o estado fundamental emitindo um fóton de $\sim 476$ $\mathrm{nm}\left({ }^{1} \mathrm{G}_{4} \rightarrow{ }^{3} \mathrm{H}_{6}\right)$.

$\mathrm{Na}$ conversão ascendente do $\mathrm{Er}^{3+}$, no estado fundamental ele pode ser tanto excitado pela fonte de bombeio de $980 \mathrm{~nm}$ ou pela energia transferida pelo $\mathrm{Yb}^{3+}$ chegando ao estado excitado ${ }^{4} \mathrm{I}_{11 / 2}\left({ }^{2} \mathrm{~F}_{5 / 2}+{ }^{4} \mathrm{I}_{15 / 2} \rightarrow{ }^{4} \mathrm{I}_{11 / 2}+{ }^{2} \mathrm{~F}_{7 / 2}\right)$. Neste estado, que possui longo tempo de vida, ocorrem as seguintes transições: $\left({ }^{4} \mathrm{l}_{11 / 2}+\right.$ $\left.{ }^{4} \mathrm{I}_{11 / 2} \rightarrow{ }^{4} \mathrm{~F}_{7 / 2}+{ }^{4} \mathrm{I}_{15 / 2}\right)$ por relaxação cruzada e por AEE o $\mathrm{Er}^{3+}$ absorve um fóton e recebe energia do $\mathrm{Yb}^{3+}$, atingindo o nível ${ }^{4} \mathrm{~F}_{7 / 2}\left({ }^{2} \mathrm{~F}_{5 / 2}+{ }^{4} \mathrm{I}_{11 / 2} \rightarrow{ }^{2} \mathrm{~F}_{7 / 2}+{ }^{4} \mathrm{~F}_{7 / 2}\right)$. A população desse nível sofre decaimento não radiativo, resultando nos estados ${ }^{2} \mathrm{H}_{11 / 2}$ e ${ }^{4} \mathrm{~S}_{3 / 2}$. A partir desses estados ocorrem as emissões em torno de $530 \mathrm{e}$ $545 \mathrm{~nm}\left({ }^{2} \mathrm{H}_{11 / 2} \rightarrow{ }^{4} \mathrm{I}_{15 / 2} \mathrm{e}{ }^{4} \mathrm{~S}_{3 / 2} \rightarrow{ }^{4} \mathrm{I}_{15 / 2}\right.$ respectivamente). A emissão em $\sim 656 \mathrm{~nm}$ é causada pela transição ${ }^{4} \mathrm{~F}_{9 / 2} \rightarrow{ }^{4} \mathrm{I}_{15 / 2}$. A população do estado excitado ${ }^{4} \mathrm{~F}_{9 / 2}$ é determinada através do seguinte mecanismo: $\mathrm{O} \mathrm{Er}^{3+}$, no estado ${ }^{4} \mathrm{I}_{13 / 2}$, absorve um fóton por AEE causando a transição ${ }^{4} \mathrm{I}_{13 / 2} \rightarrow{ }^{4} \mathrm{~F}_{9 / 2}$, por relaxação cruzada entre os íons de $\mathrm{Er}^{3+}\left({ }^{4} \mathrm{I}_{1 / 2}+{ }^{4} \mathrm{I}_{11 / 2} \rightarrow{ }^{4} \mathrm{I}_{15 / 2}+{ }^{4} \mathrm{~F}_{9 / 2}\right)$ e pela transferência de energia com os íons de $\mathrm{Yb}^{3+}\left({ }^{2} \mathrm{~F}_{5 / 2}+{ }^{4} \mathrm{I}_{13 / 2} \rightarrow{ }^{2} \mathrm{~F}_{7 / 2}+{ }^{4} \mathrm{~F}_{9 / 2}\right)$.

Neste processo de tridopagem, o íon $\mathrm{Yb}^{3+}$ foi utilizado como doador de energia para os íons aceitadores $\mathrm{Er}^{3+} \mathrm{e} \mathrm{Tm}^{3+}$. No processo de AEE por parte do $\mathrm{Tm}^{3+}$, ela ocorre mais facilmente entre $\mathrm{Tm}^{3+} \mathrm{e} \mathrm{Yb}^{3+}$; o mesmo não ocorre somente com $\circ \mathrm{Tm}^{3+}$, devido ao curto tempo de vida do estado ${ }^{3} \mathrm{H}_{5}$, tornando assim baixa a probabilidade de ocorrer este efeito. No caso do $\mathrm{Er}^{3+}$, a eficiência da população do nível ${ }^{4} \mathrm{I}_{11 / 2}$ aumenta devido à maior secção de choque com $\mathrm{O}$ íon $\mathrm{Yb}^{3+}$ e a eficiente transferência de energia que ocorre entre esses íons $\left({ }^{2} \mathrm{~F}_{5 / 2} \rightarrow{ }^{4} \mathrm{I}_{1 / 2}\right)$ [65]. 


\subsection{NANOPARTÍCULAS METÁLICAS E PLASMÔNICA}

Nanopartículas (NPs) e nanoestruturas metálicas apresentam propriedades interessantes devido aos efeitos plasmons, que são caracterizados pela oscilação coletiva dos elétrons de condução. Materiais que contêm NPs podem apresentar melhoras nas características ópticas, magnéticas e elétricas [66], sendo empregados em diversas aplicações, desde tempos históricos, como pigmentos em peças decorativas e em vitrais, e atualmente, em diversas áreas como aplicações em biomedicina, fotônica e eletrônica [67, 68]. Neste trabalho, o interesse se dá em aplicações em fotônica provenientes das interações das NPs metálicas com os íons de TRs.

A plasmônica inicia-se em 1950, com estudo das propriedades ópticas NPs atribuídas a geração de bandas de plasmons superfícies (PS). Este fenômeno ocorre pelo fato de que livre caminho médio dos elétrons nas NPs metálicas apresenta-se menor que o tamanho das NPs metálicas, que quando interagem com a luz, ocorre uma oscilação coletiva destes elétrons em ressonância com o campo eletromagnético da luz, formando os plasmons de superfícies, e induzindo a formação de momento de dipolo nas NPs metalicas (Figura 21).

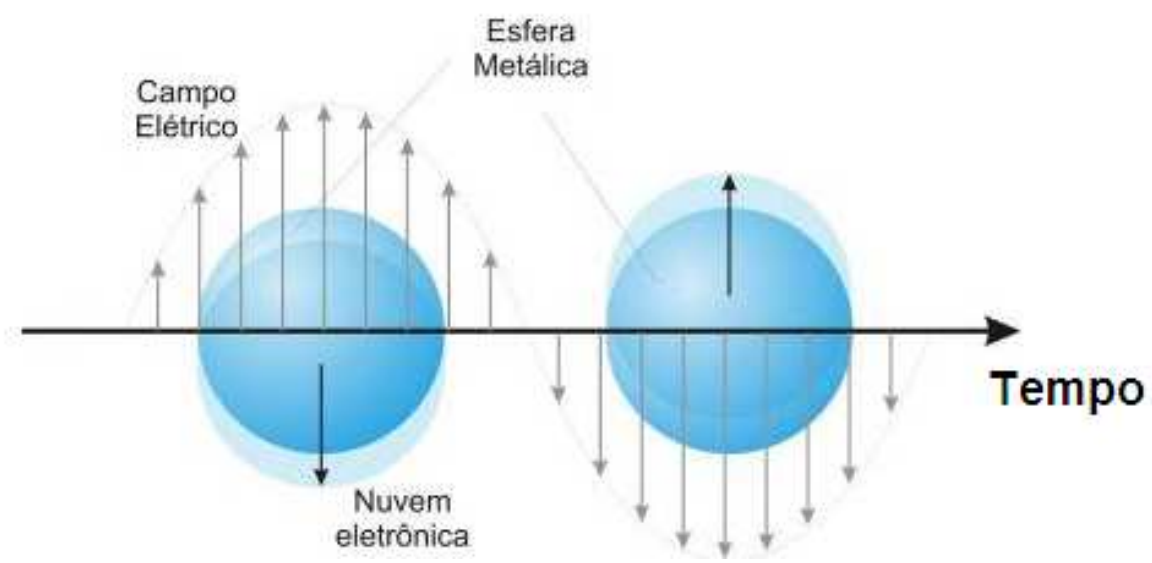

Figura 21 - Esquema para a oscilação plasmônica de uma esfera, mostrando o deslocamento da nuvem dos elétrons livres em relação ao núcleo [69].

O campo elétrico de uma luz incidente induz a polarização dos elétrons presente na superfície de uma NP, o que cria uma oscilação dipolar em todos os elétrons com a mesma fase. Quando a freqüência de campo eletromagnético torna-se ressonante coerente com a oscilação dos elétrons, uma grande banda 
de absorção no espectro é observada [69]. A intensidade e a freqüência (comprimento de onda) da banda de absorção ou ressonância dos plasmons de superfícies (RPS) são devidas as diversas características [66, 68, 70]:

- Tipo de material metálico compostos das NPs (prata, ouro, platina, cobre);

- Tamanho e formas das NPs;

- Distribuição de tamanhos das NPs;

- Meio hospedeiro onde as NPs se encontram.

A figura abaixo mostra a interferência dos tamanhos das NPs de ouro na banda de absorção de plasmon.

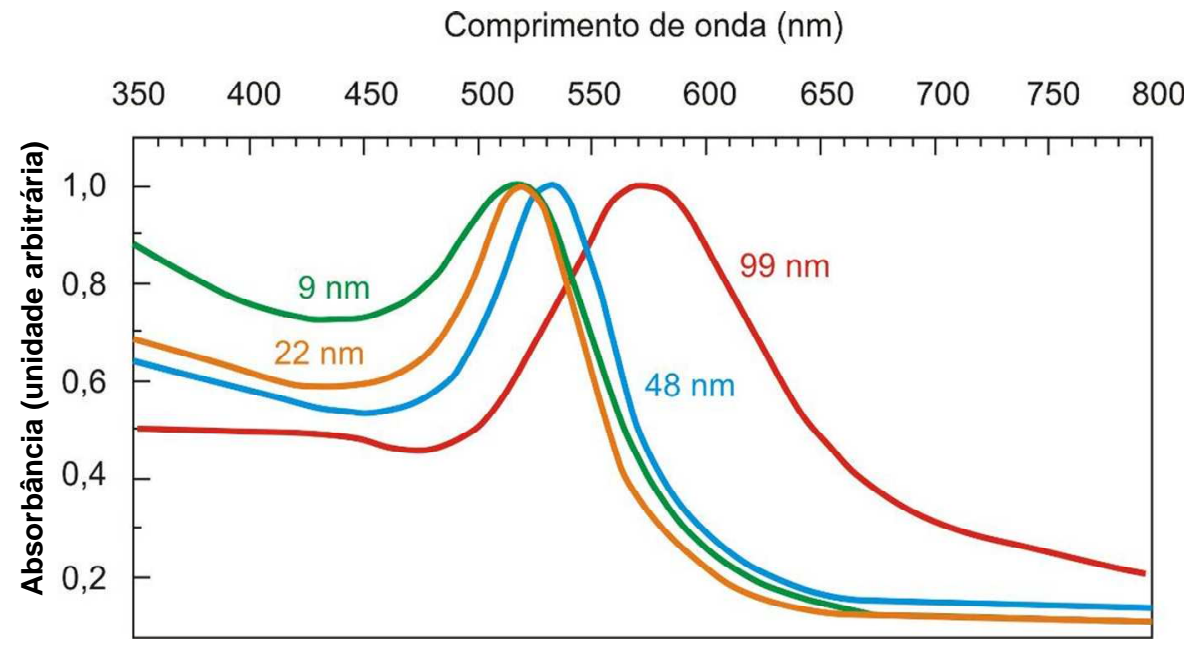

Figura 22 - Espectro de absorção de NPs de ouro com diferentes tamanhos.

O espectro de absorção das NPs pode ser medido em espectrômetro na região UV-Visível. Para metais nobres $(\mathrm{Ag}, \mathrm{Au}, \mathrm{Cu})$ a banda de absorção é observada na região visível do espectro, isto sendo atribuído pela forte acoplamento entre a transição plasmon e a banda interna de excitação, e o fato que a banda de condução dos metais nobres se aproxima do modelo Drude para elétrons livres [69]. Para propriedades relacionadas com a óptica linear, como quenching e dispersão decorrida de RPS, assume-se a teoria de Mie, onde se resolve as equações de Maxwell para um a interação de onde eletromagnética da luz com uma pequena esfera e com a dependência de constante dielétrica do material [69]. Esta teoria explica que a localização da banda de ressonância plasmônica é dependente da função dielétrica e do tamanho e forma da NPs, 
portanto, NPs de mesma composição e diferente tamanhos apresentam bandas de ressonâncias plasmônicas diferentes [65].

A RPS relativa à NPs metálicas pode alterar a luminescência produzida pelos íons de TRs. Os três diferentes tipos de efeitos plasmônicos que podem interferir nas propriedades radiativas e não radiativas dos íons de TRs são [71].

- Aumento do campo local: o aumento do campo local em torno dos íons de TRs devido à presença das NPs metálicas concentra a densidade de excitação local ao redor dos íons, aumentando a emissão luminescente;

- Transferência de energia entre os íons de TRs e as NPs: esta interação é caracterizada pelo decaimento não-radiativo, que depende da distância entre o íon aceitador e a NP;

- Aumento da taxa radiativa: interação entre o íon de TR e uma NP metálica que aumenta a taxa intrínseca do íon de TR.

Portanto, se os íons de TRs se encontram a uma distância inferior que 5 $\mathrm{nm}$ da superfície da NP, geralmente a luminescência tende a diminuir (região I). Para distâncias compreendidas entre 5 a $20 \mathrm{~nm}$, o aumento da luminescência pode ser favorecido, tanto pelo aumento do campo local, como pelo aumento das taxas de radiativas (região II); para distâncias superiores, acima de $20 \mathrm{~nm}$, o tempo de vida das radiações diminui (região III), como mostra a Figura 23.

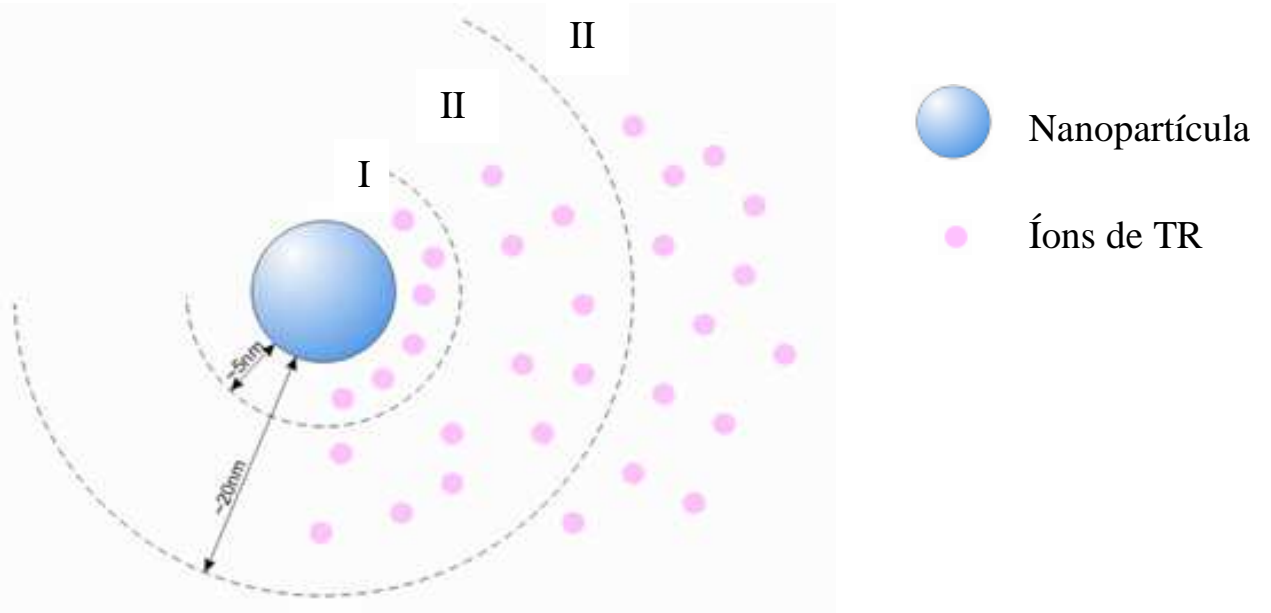

Figura 23 - Representação das distâncias entre NPs e íons de TRs. 
Cabe ressaltar que a distribuição não homogênea das NPs na matriz hospedeira, a nucleação inadequada das NPs e a formação de aglomerados, pode ocasionar o deslocamento das bandas de absorção dos PS e influenciar a transferência de energia para os íons de TRs. Passaremos a expor a revisão bibliográfica referente aos trabalhos de amostras vítreas de telureto com NPs metálicas reportadas na literatura.

\subsubsection{Nucleação das Amostras}

Dentre os vários métodos de nucleação, o empregado neste trabalho foi o tratamento térmico, que já vem sendo utilizado há algum tempo pelo grupo. Normalmente, utilizamos como temperatura de tratamento para nucleação a mesma utilizada no tratamento para alívio de tensões. As primeiras nucleações foram realizadas empiricamente. A Figura 24 mostra o método adotado pelo grupo. Todas as amostras são tratadas juntamente e atingido o tempo escolhido, elas são guardadas uma a uma. Por exemplo, se os tratamentos desejados são de 2, 24, 48 e 72 horas. Uma delas é mantida como referência e as outras três são submetidas a tratamentos em intervalos de 24 horas, sempre tirando uma, após atingido o intervalo de tempo desejado.

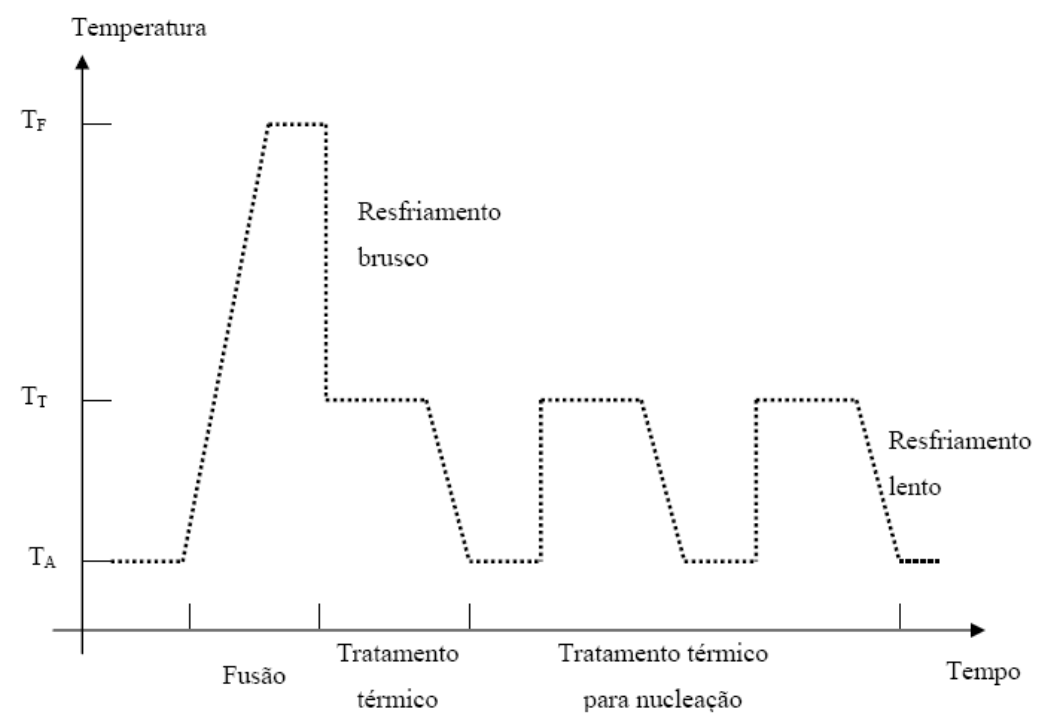

Figura 24 - Diagrama das etapas de produção do vidro e nucleação das NPs metálicas. 
Na Figura 24, apresentada acima, as temperaturas representadas por $T_{F}$, $\mathrm{T}_{\mathrm{T}}$ e $\mathrm{T}_{\mathrm{A}}$ são as temperaturas de fusão, tratamento térmico e do ambiente, respectivamente. Em tratamentos térmicos contínuos há maior tendência para a formação de aglomerados que coalescem formando agregados, já em tratamentos não continuidade ou alternados ocorre a formação das NPs metálicas [29]

Devido às várias composições de matriz estudadas pelo grupo, a temperatura de tratamento térmico varia de acordo com a transição vítrea; logo, o mesmo ocorre para a temperatura de nucleação das NPs. Por meio de resultados anteriores obtidos pelo grupo decidimos usar a temperatura de transição vítrea para o processo de nucleação. 


\subsection{ESTUDO DAS CORES}

As cores são formadas por estímulos eletromagnéticos no sistema visual humano, que é composto por células sensíveis à intensidade e a determinadas freqüências do espectro eletromagnético, cujos comprimentos de ondas variam de 380 a $760 \mathrm{~nm}$, indo do azul ao vermelho. A combinação de todas as cores do espectro visível resulta-se na formação da luz branca.

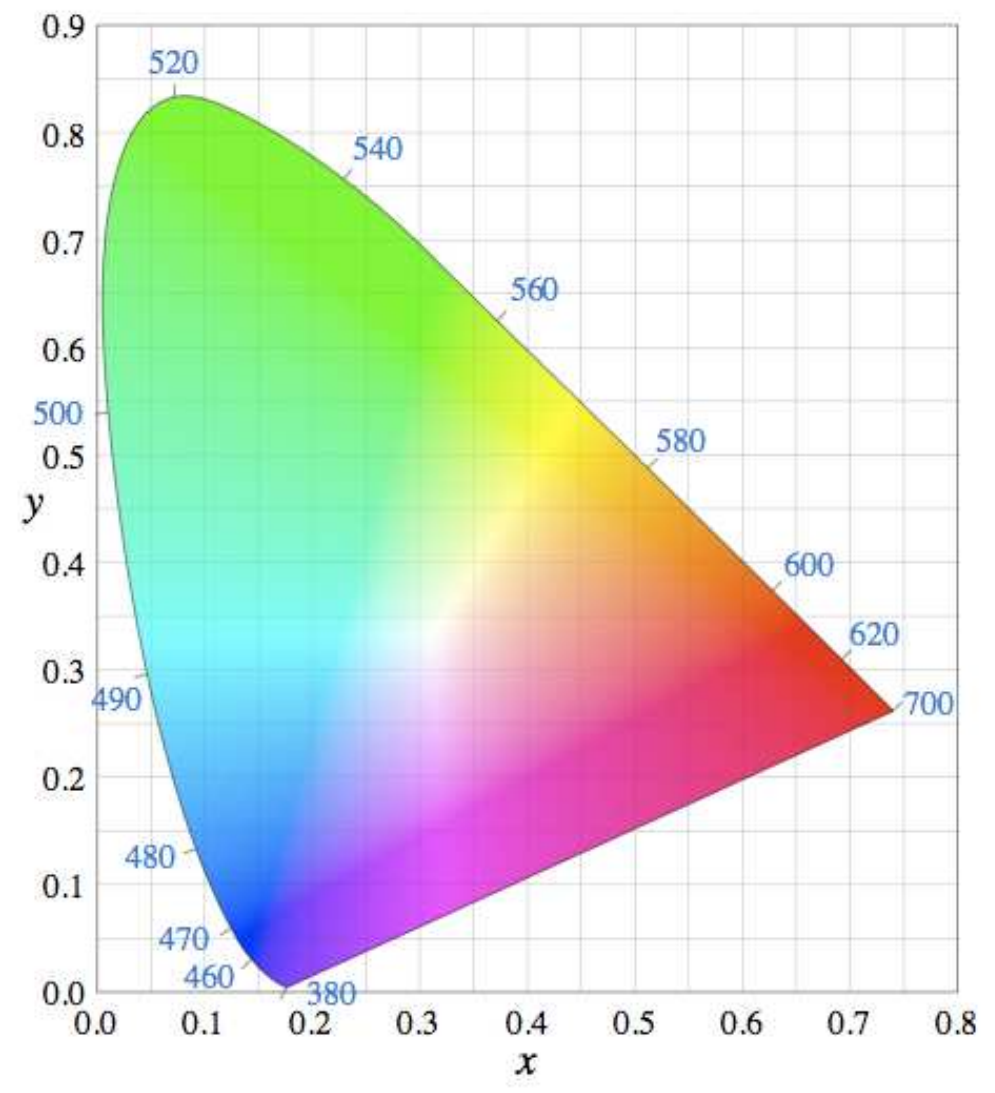

Figura 25 - Diagrama de cores CIE 1931 [72].

Através de experimentos realizados em 1931 pela Comissão Internacional sobre lluminação (CIE), criou-se o diagrama de cores que representa as cores perceptíveis pela visão humana. Este diagrama apresenta-se na forma de "ferradura", cujo contorno representa os comprimentos de onda do espectro eletromagnético situados na região do visível e no seu interior são encontradas as cores obtidas pela combinação destas freqüências. 
A formação das cores inicia-se na retina, dos olhos humanos, onde há células especializadas denominadas bastonetes responsáveis pela percepção da intensidade (amplitude). Para a distinção das cores primárias (azul, verde e vermelho) existem as células cones, que se diferenciam em três tipos sendo uma para cada estimulo de cor primária. Os estímulos que essas células recebem são transmitidos para o cérebro que interpola essas informações gerando uma cor correspondente no diagrama CIE. Para cores que não são observáveis no diagrama CIE há necessidade que o espaço de cores seja representado em um eixo de intensidade, conforme a Figura 26. Na ausência de luz (intensidade) temos a formação da cor preta.

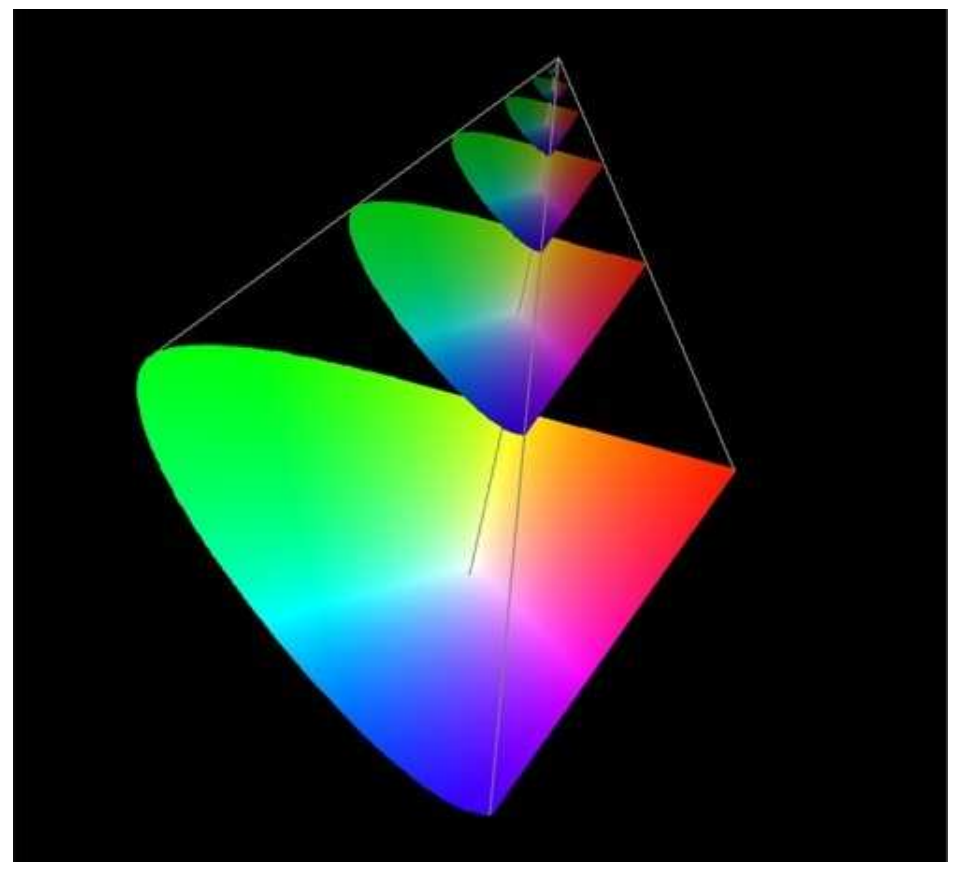

Figura 26 - Diagrama de cores CIE 1931 com eixo de intensidade [72].

Este conceito de cor onde a intensidade relativa da emissão das cores primárias é utilizado para formação da gama cores em dispositivos como displays. Este conceito de cromaticidade pode ser chamado de cor-luz, ou o modelo RGB - Red, Green e Blue. Diversos modelos de cromaticidade vem sendo propostos, como forma de solucionar problemas de reprodução específicos em aplicação em multimídia, como por exemplo o modelo RGB, criado pela HP e Microsoft, para uso em monitores e impressoras, etc [73]. Na Figura 27 é possível 
observar as gamas de cores que podem ser obtidas de alguns modelos de cromaticidade adotados em displays.

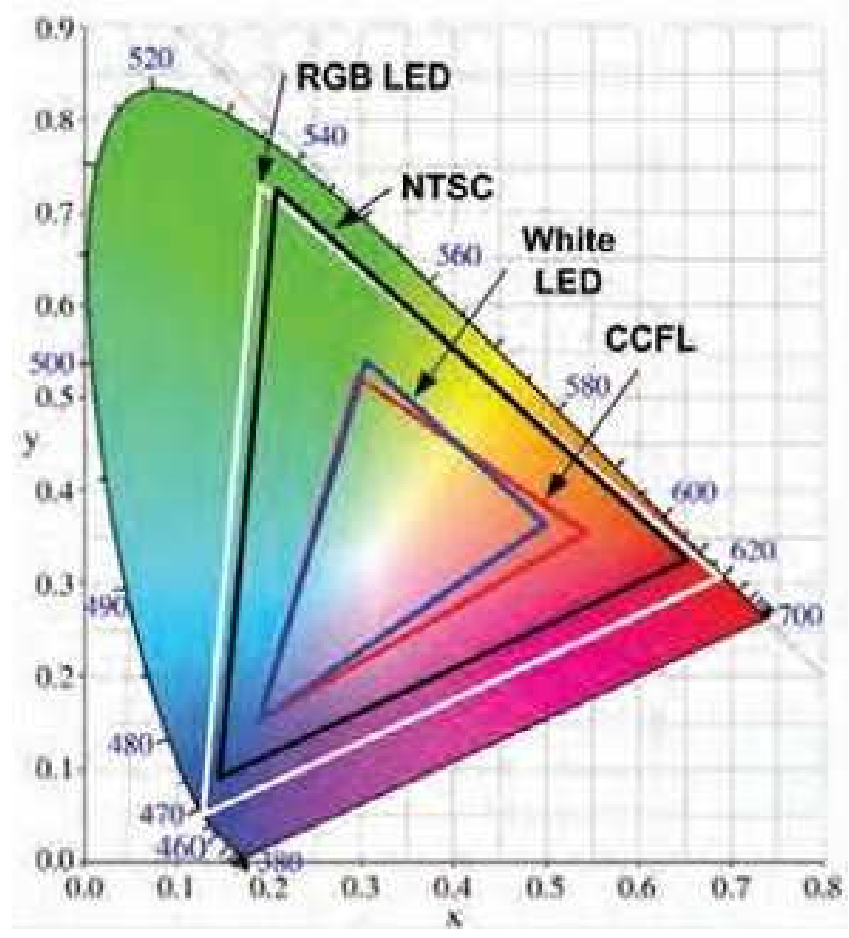

Figura 27 - Diagrama de cores com os modelos de cromaticidade [73].

$\mathrm{Na}$ produção destes dispositivos são utilizados filtros ópticos que permitem a variação das cores nos mesmos. Na figura abaixo é mostrado um exemplo do espectro destes filtros junto com espectro de emissão de um dispositivo RGB.

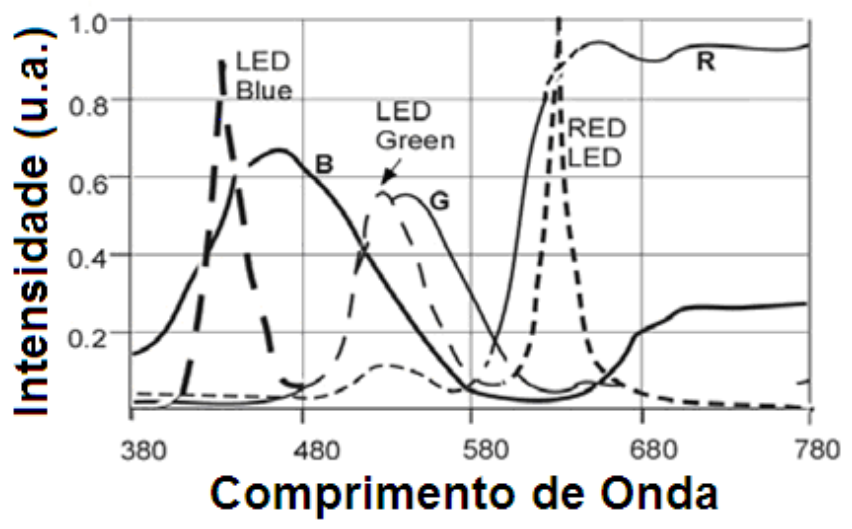

Figura 28 - Espectro de atenuação de filtro ópticos utilizado em um sistema RGB de emissão [73]. 
Na Figura 28 é mostrado o espectro de atenuação de um filtro óptico é representado por meio de linha continua e o de emissão por meio de linha pontilhada. 


\section{METODOLOGIA}

Neste capítulo será discutido e descrito o método utilizado para obtenção das amostras de vidro de telureto dopadas com íons de terras raras e NPs metálicas.

Foram preparadas amostras pertencentes ao sistema ternário $\mathrm{T} 1$ composto por $33,3 \% \mathrm{TeO}_{2}-33,3 \% \mathrm{PbO}-33,3 \% \mathrm{GeO}_{2}$ em porcentagem de peso. A escolha desta matriz é decorrente da continuidade do estudo feito em matrizes vítreas de telureto codopadas com íons de érbio e itérbio, realizado na iniciação cientifica, onde foram abordados dois sistemas que seguem: (T1) 33,3\% $\mathrm{TeO}_{2}-33,3 \% \mathrm{PbO}-33,3 \% \mathrm{GeO}_{2}$ e (T3) $76 \% \mathrm{TeO}_{2}-4 \% \mathrm{ZnO}-20 \% \mathrm{Nb}_{2} \mathrm{O}_{5}$ [1]. A escolha do sistema $\mathrm{T} 1$ foi motivada pelo fato de apresentar maior janela de transmissão na região do visível. Outra motivação foi referente ao fato de que o sistema T1 apresenta em relação a T3 uma maior emissão do vermelho (em 660 nm) em relação a outras emissões (530 e 550 nm) com o aumento da concentração de íon de itérbio, conforme mostrado abaixo.
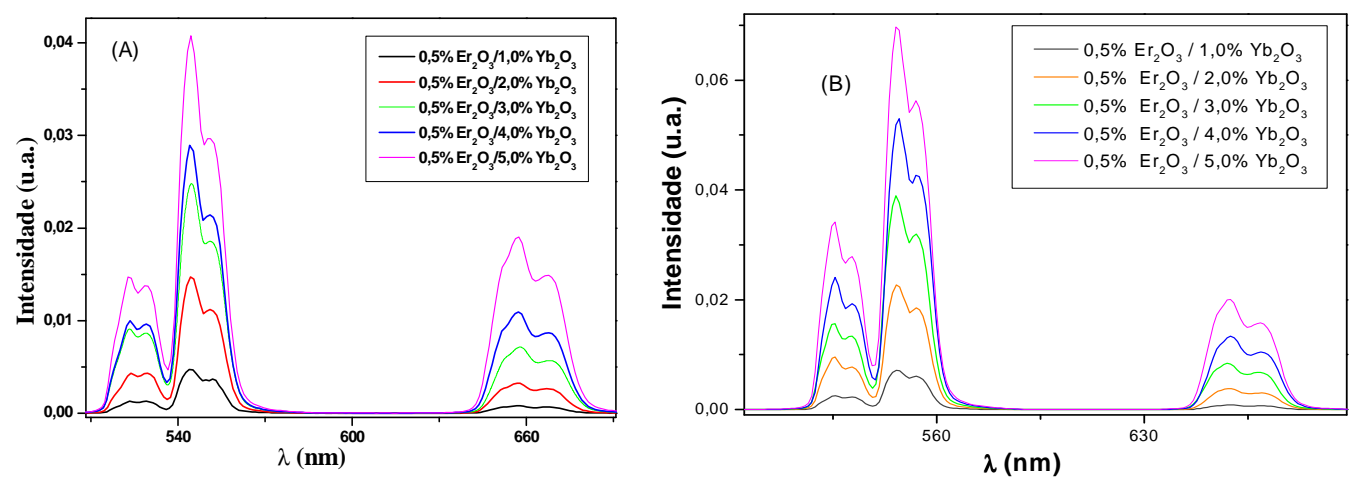

Figura 29 - Espectro de emissão dos sistemas T1 (A) e T3 (B) [76].

$\mathrm{Na}$ primeira parte foram produzidas e caracterizadas amostras dopadas com diferentes concentrações de $\mathrm{Er}_{2} \mathrm{O}_{3}$ e amostras codopadas com $0,5 \%$ de $\mathrm{Er}_{2} \mathrm{O}_{3}$ variando a concentração de $\mathrm{Yb}_{2} \mathrm{O}_{3}(1,0 \%$ a $5,0 \%$ em peso). A tabela a seguir apresenta as amostras $\mathrm{T} 1$ preparadas com $\mathrm{Er}_{2} \mathrm{O}_{3}$ e $\mathrm{Yb}_{2} \mathrm{O}_{3}$. 
Tabela 4 - Amostras $\mathrm{T} 1$ dopadas com $\mathrm{Er}^{3+}$ e codopadas $\mathrm{Er}^{3+} / \mathrm{Yb}^{3+}$.

\begin{tabular}{ccccccc}
\hline Matriz Vítrea & \multicolumn{5}{c}{ Concentração de $\mathrm{Er}_{2} \mathrm{O}_{3}$ (\% em peso) } \\
\hline $\mathrm{T1}$ & 1,0 & 2,0 & 3,0 & 5,0 & 8,0 & 10,0 \\
\hline & Concentração de $\mathrm{Yb}_{\mathbf{2}} \mathrm{O}_{3}$ (\% em peso) \\
\hline $\mathbf{0 , 5} \%$ de $\mathrm{Er}_{2} \mathrm{O}_{3}$ & 1,0 & 2,0 & 3,0 & 4,0 & 5,0 \\
\hline
\end{tabular}

$\mathrm{Na}$ segunda parte foram produzidas amostras codopadas com $0,5 \% \mathrm{Er}_{2} \mathrm{O}_{3}$ e $\mathrm{Yb}_{2} \mathrm{O}_{3}$ com concentrações de 2,0\% e 3,0\% $\mathrm{Yb}_{2} \mathrm{O}_{3}$ e com NPs metálicas de diferentes compostos $\left(\mathrm{Au}_{2} \mathrm{O}_{3}, \mathrm{Ag}_{2} \mathrm{O}\right.$ e $\left.\mathrm{AgNO}_{3}\right)$ usando para nucleação o processo de tratamento térmico estudado pelo grupo mostrado anteriormente na histórico do grupo. A tabela a seguir apresenta as amostras produzidas nestas condições.

Tabela 5 - Amostras $\mathrm{T} 1$ codopadas com $\mathrm{Er}^{3+} / \mathrm{Yb}^{3+}$ e com NPs metálicas.

\begin{tabular}{|c|c|c|c|}
\hline \multirow{2}{*}{$\begin{array}{c}\text { Matriz Vítrea T1 } \\
\text { com } 0,5 \% \mathrm{Er}_{2} \mathrm{O}_{3} \\
\text { (\% em peso) }\end{array}$} & \multicolumn{3}{|c|}{$\begin{array}{l}\text { Concentração usadas dos composto para } \\
\text { nucleação das NPs metálicas ( } \% \text { em peso) }\end{array}$} \\
\hline & $\mathrm{Ag}_{2} \mathrm{O}$ & $\mathrm{AgNO}_{3}$ & $\mathrm{Au}_{2} \mathrm{O}_{3}$ \\
\hline $2,0 \% \mathrm{Yb}_{2} \mathrm{O}_{3}$ & 1,0 & 1,0 & 1,0 \\
\hline $3,0 \% \mathrm{Yb}_{2} \mathrm{O}_{3}$ & 1,0 & 1,0 & 1,0 \\
\hline
\end{tabular}

Cabe acrescentar que as concentrações acima determinadas e os períodos de tratamento usados para nucleação foram escolhidos através de outros trabalhos do grupo [26, 29, 71].

$\mathrm{Na}$ terceira parte, foram produzidas amostras do sistema $\mathrm{T} 1$ dopadas com diferentes concentrações dos compostos: $\mathrm{Er}_{2} \mathrm{O}_{3}, \mathrm{Tm}_{2} \mathrm{O}_{3}$ e $\mathrm{Yb}_{2} \mathrm{O}_{3}$. A tabela abaixo mostra as referidas amostras.

Tabela 6 - Amostras $\mathrm{T} 1$ com diferente concentração de $\mathrm{Er}_{2} \mathrm{O}_{3}, \mathrm{Tm}_{2} \mathrm{O}_{3}$ e $\mathrm{Yb}_{2} \mathrm{O}_{3}$

\begin{tabular}{ccc}
\hline $\mathrm{Er}_{2} \mathrm{O}_{3}$ (\% em peso) & $\mathrm{Tm}_{2} \mathrm{O}_{3}$ (\% em peso) & $\mathrm{Yb}_{2} \mathrm{O}_{3}(\%$ em peso) \\
\hline 0,50 & 0,50 & 2,00 \\
0,50 & 0,50 & 3,00 \\
0,50 & 0,25 & 2,00 \\
0,50 & 0,25 & 3,00 \\
0,50 & 0,25 & 4,00 \\
0,50 & 0,25 & 5,00 \\
2,00 & 0,50 & 3,00 \\
2,00 & 1,00 & 3,00 \\
0,50 & 0,15 & 3,00 \\
\hline
\end{tabular}


As escolhas das concentrações dos dopantes a seguir foram feitas empiricamente a partir da composição da amostra contendo 0,8\% $\mathrm{Er}_{2} \mathrm{O}_{3}-0,16 \%$ $\mathrm{Tm}_{2} \mathrm{O}_{3}-3,0 \% \quad \mathrm{Yb}_{2} \mathrm{O}_{3}$, obtida na literatura [31]. A partir da reprodução desta amostra, foram analisadas as emissão e feito os ajuste na concentração, a fim de obter a melhor a emissão mais próxima da luz branca.

Com intuito de organizar os dados e ajudar no entendimento da variação de concentração dos dopantes presentes nestas amostras tridopadas, podemos dividir em 3 grupos diferentes essas amostras. Conforme as tabelas abaixo.

Tabela 7 - Grupo A de amostras tridopadas.

\begin{tabular}{ccc}
$\mathrm{Er}_{2} \mathrm{O}_{3}$ (\% em peso) & $\mathrm{Tm}_{2} \mathrm{O}_{3}$ (\% em peso) & $\mathrm{Yb}_{2} \mathrm{O}_{3}$ (\% em peso) \\
\hline 0,50 & 0,50 & 2,0 \\
0,50 & 0,50 & 3,0 \\
0,50 & 0,25 & 2,0 \\
0,50 & 0,25 & 3,0
\end{tabular}

Tabela 8 - Grupo B de amostras tridopadas.

\begin{tabular}{ccc}
\hline $\mathrm{Er}_{2} \mathrm{O}_{3}$ (\% em peso) & $\mathrm{Tm}_{2} \mathrm{O}_{3}$ (\% em peso) & $\mathrm{Yb}_{2} \mathrm{O}_{3}$ (\% em peso) \\
\hline 0,5 & 0,25 & 2,0 \\
0,5 & 0,25 & 3,0 \\
0,5 & 0,25 & 4,0 \\
0,5 & 0,25 & 5,0 \\
\hline
\end{tabular}

Tabela 9 - Grupo $\mathrm{C}$ de amostras tridopadas.

\begin{tabular}{ccc}
$\mathrm{Er}_{2} \mathrm{O}_{3}$ (\% em peso) & $\mathrm{Tm}_{2} \mathrm{O}_{3}$ (\% em peso) & $\mathrm{Yb}_{2} \mathrm{O}_{3}$ (\% em peso) \\
\hline 0,5 & 0,5 & 3,0 \\
2,0 & 0,5 & 3,0 \\
2,0 & 1,0 & 3,0 \\
\hline
\end{tabular}

No Grupo A é possível observar o efeito da variação de concentração de $\mathrm{Tm}_{2} \mathrm{O}_{3}(0,25 \%$ a $0,5 \%)$ e do $\mathrm{Yb}_{2} \mathrm{O}_{3}(2,0 \%$ a 3,0\%). Já no Grupo B, a análise é feita com a variação do $\mathrm{Yb}_{2} \mathrm{O}_{3}(2,0 \%$ a 5,0\%). E finalmente, no Grupo C, a análise é feita com variação na concentração de $\mathrm{Er}_{2} \mathrm{O}_{3}(0,5 \%$ e $2,0 \%)$ e $\operatorname{Tm}_{2} \mathrm{O}_{3}(0,5 \%$ e $1,0 \%)$.

Passa-se a apresentar o procedimento usado para a caracterização e para o preparo das amostras produzidas. 


\subsection{PREPARO DAS AMOSTRAS}

Para obtenção das amostras, inicialmente os reagentes são pesados em balança com precisão de $\pm 0,01 \mathrm{mg}$, introduzidos em cadinho de platina pura, misturados e homogeneizados, para então, serem levados ao forno de fusão de atmosfera não controlada. Após o período de fusão, o material fundido é resfriado rapidamente sendo vertido em molde de latão, pré-aquecido à temperatura de tratamento para, em seguida, ser introduzido em um segundo forno para tratamento térmico. Cabe lembrar que a temperatura de tratamento térmico deve ser sempre inferior à temperatura de transição vítrea $(\mathrm{Tg})$. A temperatura de fusão dos reagentes para formação do sistema T1 é de $1050^{\circ} \mathrm{C}$, por uma hora e tratamento térmico feito a $350^{\circ} \mathrm{C}$, por uma hora. Após este procedimento, o forno é desligado, e a amostra permanece em seu interior até que a temperatura ambiente seja alcançada. Este processo permite que as tensões internas sejam diminuídas e que o vidro obtenha maior resistência mecânica.

Em seguida as amostras são lixadas até espessura de $2 \mathrm{~mm}$ e polidas, em ambas faces. Estas são cortadas em quatro partes, com dimensões similares, para que sejam realizados os tratamentos térmicos para a nucleação das NPs. Assim, cada conjunto de amostras possui partes distintas com diferentes tempos de tratamento.

Para as amostras nas quais serão nucleadas as NPs metálicas, uma parte de cada conjunto é guardada e classificada com o tempo de tratamento intrínseco da amostra (tratamento para alívio das tensões). Assim sendo, se a amostra foi tratada, após fusão, por 2 horas, esta será assim classificada: 2 horas. Todas as demais amostras são colocadas sobre molde de latão e inseridas no forno de tratamento térmico, sendo este mantido à temperatura de tratamento de $350{ }^{\circ} \mathrm{C}$, ali permanecendo pelo tempo desejado. Passado este período, o forno é desligado e as amostras são resfriadas lentamente até a temperatura ambiente. Uma vez atingida a temperatura ambiente todas as amostras são retiradas do forno; uma delas é separada e classificada pelo tempo inicial somado ao tempo de tratamento adicional. A Figura 30 apresenta as etapas do processo de produção. Cabe acrescentar os cuidados tomados durante o preparo das amostras explicados a seguir. Os cadinhos de platina são limpos com solução de 
água e ácido fluorídrico após a produção de cada amostra. Os moldes de latão são sempre lixados e limpos antes de sua utilização; são usadas diferentes espátulas, descartáveis, na pesagem de cada reagente no intuito de evitar eventuais contaminações.

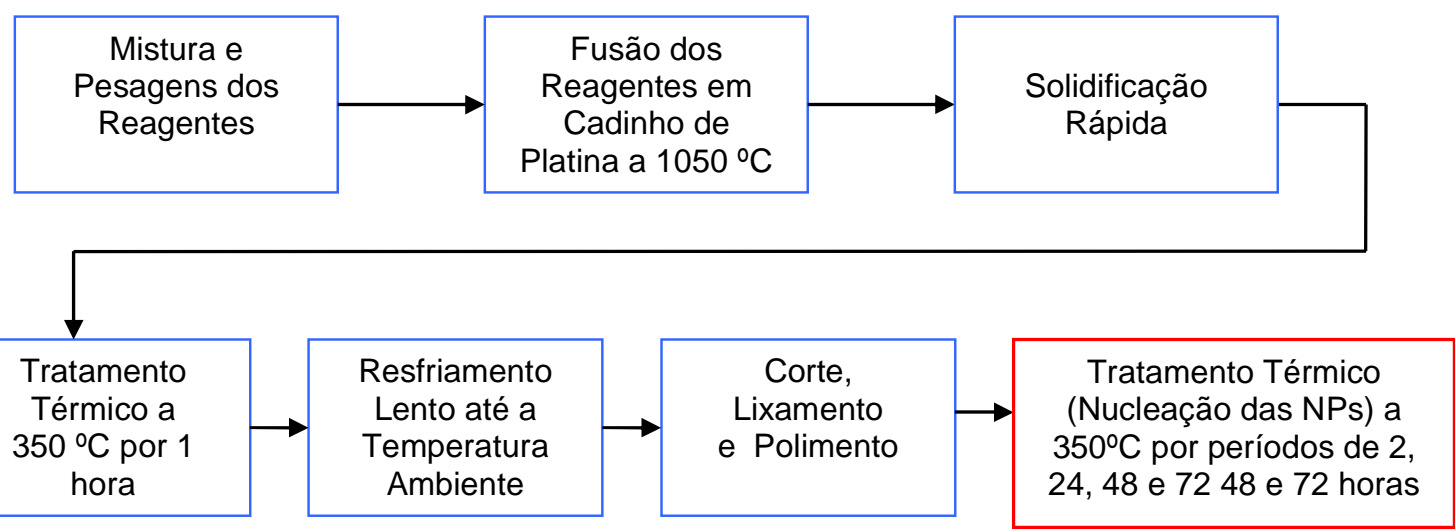

Figura 30- Fluxograma das etapas usadas para produção das amostras. 


\subsection{TÉCNICAS DE CARACTERIZAÇÃO}

As técnicas de caracterização utilizadas tiveram como objetivo verificação da incorporação dos íons de terra rara, suas luminescências e a observação de nucleação de NPs, assim como o tamanho médio, forma e distribuição das NPs nas amostras produzidas. Passamos a expor as aludidas técnicas.

\subsubsection{Medida de Absorção Óptica}

Para realizarem-se as medidas de absorção óptica é necessário que as amostras tenham espessura e as faces adequadas para medição (características citadas antes) para que sejam minimizadas perdas relativas ao espalhamento. As medidas foram feitas no IFUSP, pelo equipamento Cary Spectrom 500, à temperatura ambiente. O diagrama experimental usado para este tipo de medida está exibido na Figura 31 abaixo.

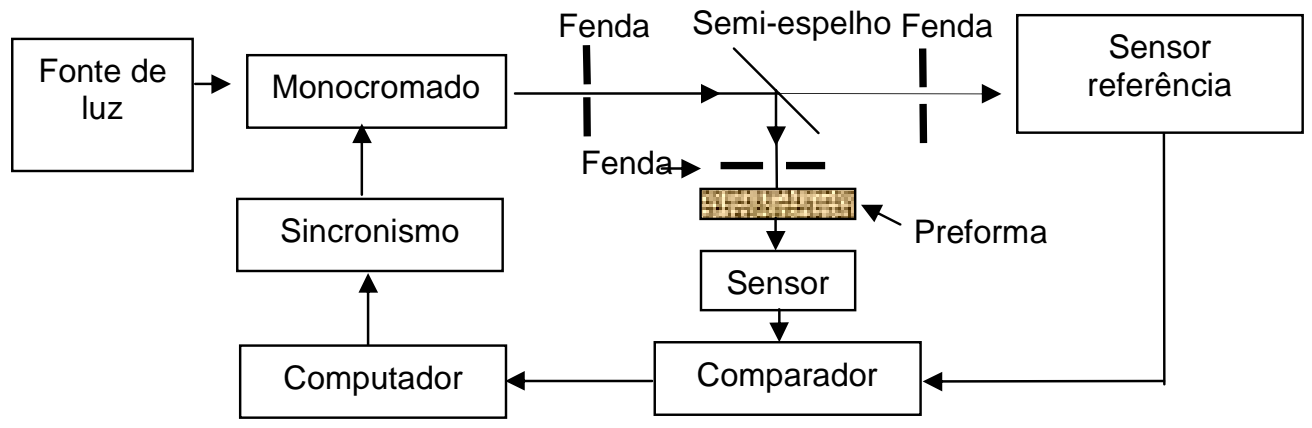

Figura 31 - Arranjo experimental para medidas de absorção óptica.

Pelo diagrama acima, observa-se que um feixe de luz passa por uma rede de difração no monocromador que o separa em vários comprimentos de onda; cada comprimento depende do ângulo formado entre a fonte de luz e a rede de difração. Este monocromador se move sincronizando com o computador. A luz com comprimento de onda é selecionada pelo monocromador, passando através do divisor de feixe (semi-espelho) sendo dividido em dois feixes. Um deles é detectado por um sensor de referência e o outro (que atravessa a amostra) é detectado por outro sensor; ambos os sinais, em seguida, são comparados, sendo feita uma relação entre transmissão óptica e o comprimento de onda. 
As bandas de absorção medidas estão relacionadas com as transições eletrônicas dos íons de terras raras revelando se foram incorporadas na matriz na forma trivalente ou em outra forma. Através destas bandas pode-se também determinar a relação entre a intensidade de absorção a e concentração de íons, isto é, se o aumento da banda é proporcional ao da concentração. Os picos das bandas também informam os comprimentos de onda adequados para excitação das amostras, a fim de se determinar o espectro de emissão.

\subsubsection{Medida de Luminescência}

Todas as medidas de luminescência foram feitas no espectro visível, algumas medidas foram realizadas no CLA do IPEN-SP (amostras dopadas e codopadas) e outras (codopadas com NPs metálicas e todas tridopadas) no LTMFO da FATEC-SP. A fonte de excitação é um laser de diodo, operando em $980 \mathrm{~nm}$, devido à banda de absorção dos íons de $\mathrm{Yb}^{3+}$ que está próxima a este comprimento. Na Figura 32 é mostrado o diagrama do arranjo do LTMFO.

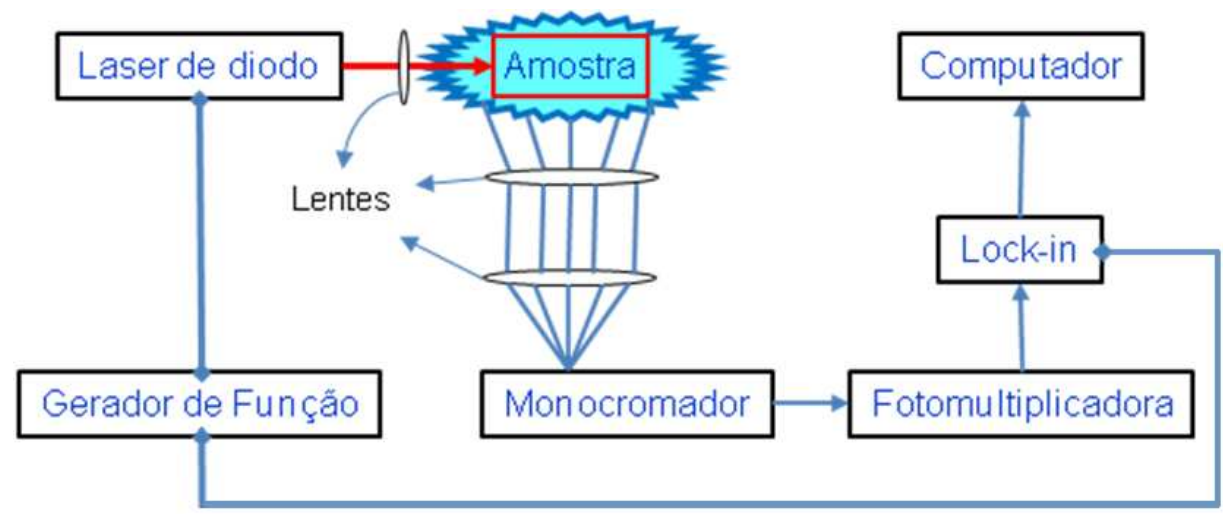

Figura 32 - Arranjo experimental das medidas de emissão realizadas nas amostras.

O feixe incidente do laser é colimado por uma lente, de modo que a amostra seja bombeada perpendicularmente à direção do detector (bombeio lateral). Caso contrário a medida poderia ser prejudicada ou ainda a fotomultiplicadora danificada. O laser de diodo é pulsado por um gerador de função que tem como propósito evitar efeitos térmicos na amostra e a interferência da luz ambiente $(60 \mathrm{~Hz})$ na medida. A luz emitida pela amostra é colimada por outras duas lentes e passa pela fenda do monocromador que separa os vários comprimentos de onda provenientes da emissão, através de 
uma grade de difração. Em seguida o feixe passa por uma segunda fenda, chegando à fotomultiplicadora que amplifica o sinal, e então os sinais elétricos alternados são convertidos pelo lock-in em contínuos e enviados para o computador.

No arranjo do CLA do IPEN-SP se distingue do LTMFO, pois nele usa-se um "chooper" que pulsa o feixe que incide na amostra.

Foram feitas medidas de variação de potência a fim de determinar 0 número de fótons que participam do processo de conversão ascendente dos íons de TRs. Para a medida da potência incidente nas amostras foi usado um medidor de potência da Newport modelo 1918-R na mesma região de incidência do laser na amostras.

\subsubsection{Microscopia Eletrônica de Transmissão}

Para a obtenção das imagens das NPs foi utilizado um de Microscópio Eletrônico de Transmissão em colaboração com o Laboratório de Microscopia Eletrônica do Instituto de Física da USP, modelo Philips CM 200 operado a 200 kV e o modelo JEM 2100 LaB6 do CCTM - IPEN.

O microscópio possui um cátodo de grampo de tungstênio, que ao ser aquecido emite elétrons que são acelerados pelo anodo e colimados pelo cilindro de Wehnelt. O feixe eletrônico divergente é focalizado sobre a amostra pelas

duas lentes condensadoras. Assim, com o condensador duplo, os elétrons deixando a ponta do catodo são focalizados na posição da amostra em uma mancha pequena que pode variar de 2 a $10 \mu \mathrm{m}$ de diâmetro. Com os feixes passando através da abertura da objetiva, é formada a primeira imagem ampliada da amostra. No plano desta imagem, a abertura designada seletora é focalizada. As lentes intermediárias e projetora ampliam sucessivamente a primeira imagem mais duas vezes. A ampliação total é obtida pela multiplicação dos aumentos individuais da série de lentes. A imagem ampliada em três estágios é visível sobre o anteparo fluorescente final; quando o anteparo é levantado esta é registrada na placa fotográfica. Importante ressaltar que a colimação do feixe de elétrons só é eficaz quando o sistema está em alto vácuo. O que garante a identificação da composição da amostra é a difração por feixes de elétrons que o 
microscópio gera durante o ensaio e através da eq.(4) são identificados os elementos da difração eletrônica [52].

$$
d_{h k l}=\frac{2 \lambda L}{2 R}
$$

onde $d_{h k l}$ são as distâncias interplanares características de cada elemento, $2 R$ são obtidos através das distâncias de pontos e/ou anéis da difração e $2 \lambda L$ é a constante de câmara característica do feixe de elétrons do microscópio.

A preparação das amostras para microscopia é feita através de moagem e diluição em água. Apenas as partículas que ficam na superfície da solução são colocadas em uma microtela com carbono previamente depositado. As partículas metálicas espalham muito mais o feixe de elétrons que o vidro, por isso as partículas podem ser identificadas por contraste claro-escuro nas micrografias.

Quando o feixe de elétrons incide sobre um determinado material, os elétrons mais internos do átomo podem ser arrancados - dependendo da potencia do feixe - deixando um espaço vazio no nível energético que se encontrava. Um elétron de uma camada externa, ao ocupar esta posição, libera a energia referente a esta transição, sendo ela de comprimento de onda do espectro de raios X. Um detector instalado na câmara de vácuo do MET mede a energia associada à esta fluorescência. Como a diferença entre os níveis de cada átomo possuem energias distintas, é possível, no ponto de incidência do feixe, determinar quais elementos químicos estão presentes naquele local e assim identificar que material está sendo observado. O diâmetro reduzido do feixe no MET permite a determinação da composição do material em amostras de tamanho muito reduzido, tornando possível uma análise quase pontual, logo, a determinação dos elementos presentes nas NPs. 


\subsubsection{Diagrama de Cromaticidade (CIE)}

Dispositivos luminescentes à base de íons de TRs têm sido empregados para produção de displays de cores mais puras. Toda a cor do espectro visível pode ser reproduzida pela combinação de três componentes monocromáticas [74]. Assim a análise das emissões destes dispositivos pode ser feita por meio do estudo da cromaticidade através do diagrama do CIE (Comissão Internacional de l'Eclairage) de 1931, que adota um padrão que representa os atributos de cor através de um diagrama tridimensional. O referido diagrama é composto por três vetores cartesianos que representam os estímulos espectrais gerados nos olhos humanos pela incidência da luz

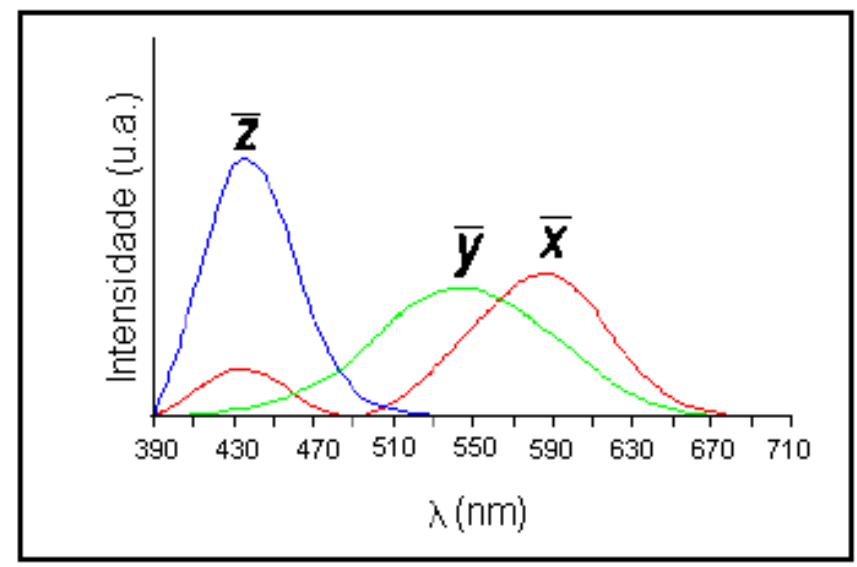

Figura 33 - Curva de cores do padrão CIE para os vetores $x(\lambda), y(\lambda)$ e $z(\lambda)$.

As coordenadas $\mathrm{x}, \mathrm{y}$ e $\mathrm{z}$ de cores definem a região da cor dominante no diagrama de $\mathrm{CIE}$, e são definidas pelas seguintes relações:

$$
x=\frac{X}{X+Y+Z} \quad y=\frac{Y}{X+Y+Z} \quad z=\frac{Z}{X+Y+Z}
$$

onde $\mathrm{X}, \mathrm{Y}$ e Z são calculados pela seguinte integração sob a curva de toda região do espectro visível:

$$
X=\int d \lambda \Phi(\lambda)^{\bar{x}}(\lambda) \quad Y=\int d \lambda \Phi(\lambda)_{\bar{y}}^{\bar{y}}(\lambda) \quad Z=\int d \lambda \Phi(\lambda)_{\bar{z}}^{\bar{z}}(\lambda)
$$

onde $\Phi(\lambda)$ corresponde as curvas de emissão luminescente. 
No diagrama de CIE são identificados apenas $x$ e y, como sendo uma projeção no plano xy. Na periferia do diagrama são representadas as cores puras, ou seja as de emissão monocromáticas. Para dispositivos como fullcolour displays é necessário que os pontos calculados a partir da emissão se encontrem nos vértices do triangulo $\mathrm{CIE}$, que correspondem as cores primárias vermelho, verde e azul [75]. A Figura 34 mostra o diagrama CIE de 1931.

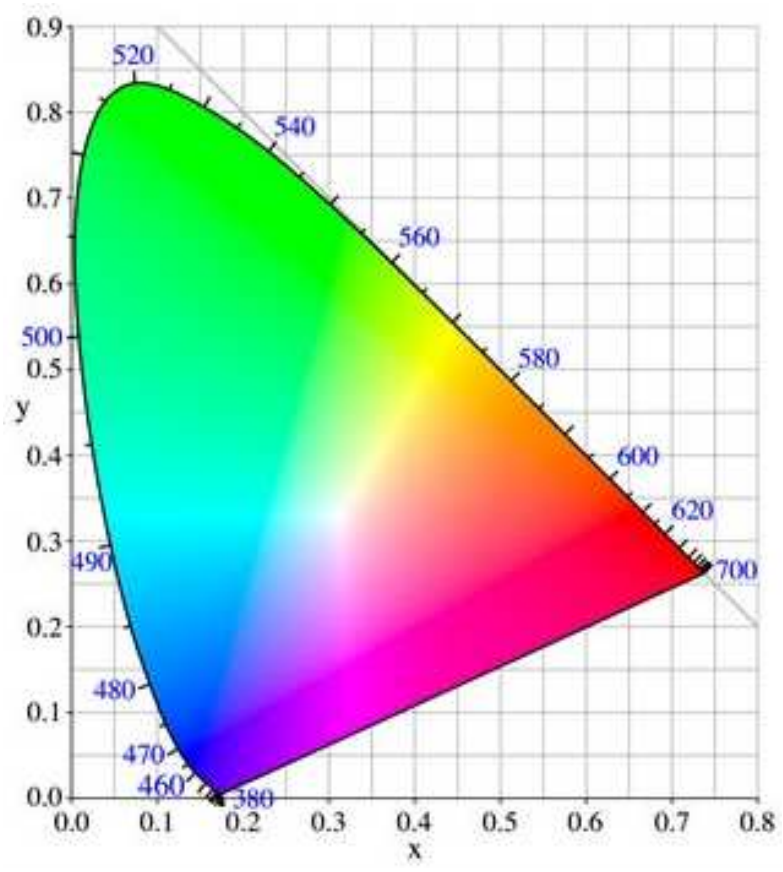

Figura 34 - Diagrama de cores CIE. 


\section{RESULTADOS E DISCUSSÕES}

Neste capitulo serão apresentados os resultados referentes a todas as amostras produzidas.

\subsection{VIDROS DOPADOS}

Apresentamos a seguir os resultados das amostras preparadas com $\mathrm{Er}_{2} \mathrm{O}_{3}$.

Nas amostras dopadas com maior da concentração de $\mathrm{Er}_{2} \mathrm{O}_{3}$ houve saturação de érbio e formação de agregados. Na Figura 30 são apresentados os aspectos das amostras produzidas.

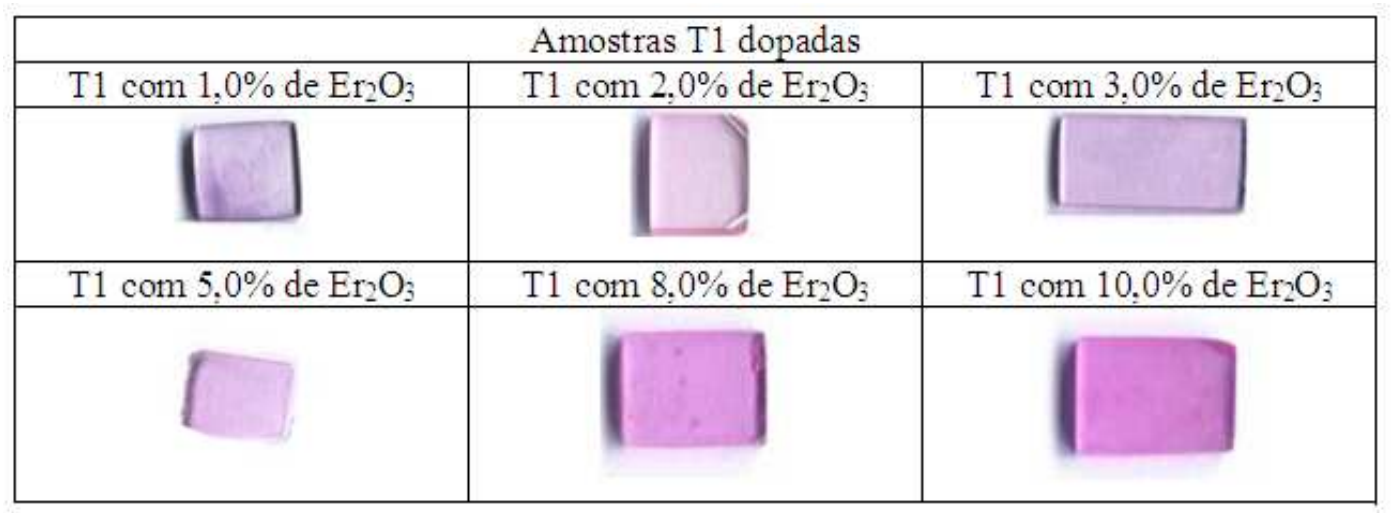

Figura 35 - Fotografia das amostras dopadas com $\mathrm{Er}_{2} \mathrm{O}_{3}$.

\subsubsection{Medida de Absorção Óptica}

As medidas de absorção óptica realizadas nas amostras T1 dopadas com $\mathrm{Er}_{2} \mathrm{O}_{3}$ mostram que os íons se encontram na forma trivalente, o que pode ser visto pelos picos característicos das transições eletrônicas associadas aos íons do érbio. O início da janela de transmissão no visível ocorre em torno de $380 \mathrm{~nm}$ para as amostras T1. A seguir são mostrados os espectros que apresentam as bandas de absorção e respectivas transições eletrônicas. 


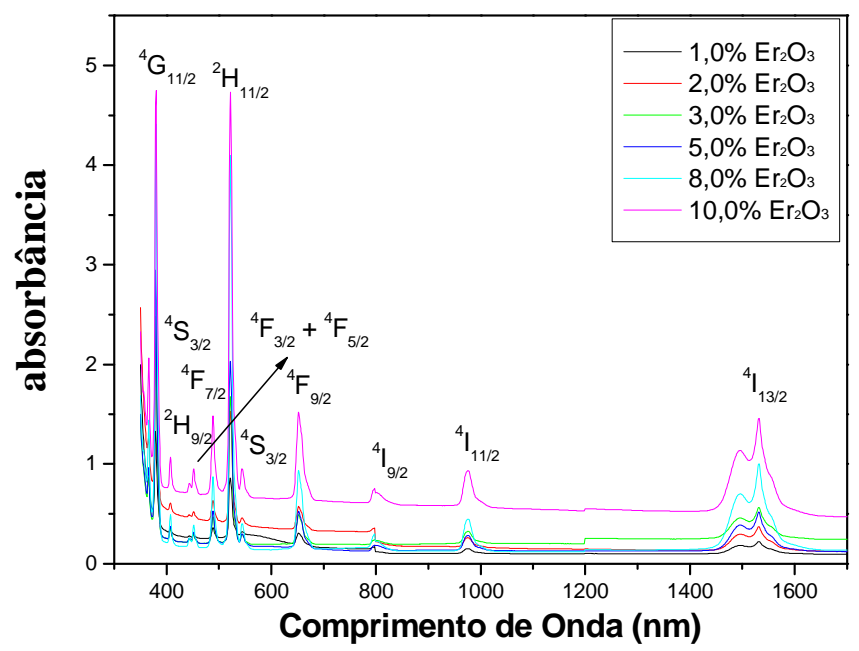

Figura 36 - Espectro de absorção óptica das amostras $\mathrm{T} 1$ dopadas apenas com $\mathrm{Er}_{2} \mathrm{O}_{3}$.

\subsubsection{Medida de Luminescência}

Os espectros de emissão no visível (erro de $\pm 5 \%$ ) das amostras T1 são mostrados na figura que segue. As emissões no visível têm bandas com picos em $525 \mathrm{~nm}, 550 \mathrm{~nm}$ e $660 \mathrm{~nm}$, e correspondem respectivamente, às seguintes transições do $\mathrm{Er}^{3+}$ referentes à conversão ascendente conforme explicado no item 1.3.2: ${ }^{2} \mathrm{H}_{11 / 2} \rightarrow{ }^{4} \mathrm{I}_{15 / 2} \mathrm{e}^{2} \mathrm{~S}_{3 / 2} \rightarrow{ }^{4} \mathrm{I}_{15 / 2},{ }^{4} \mathrm{~F}_{9 / 2} \rightarrow{ }^{4} \mathrm{I}_{15 / 2}$. Nas figuras a seguir são exibidos os espectros de emissão no visível das amostras T1 com concentração de $\mathrm{Er}_{2} \mathrm{O}_{3}$ em porcentagem de peso.

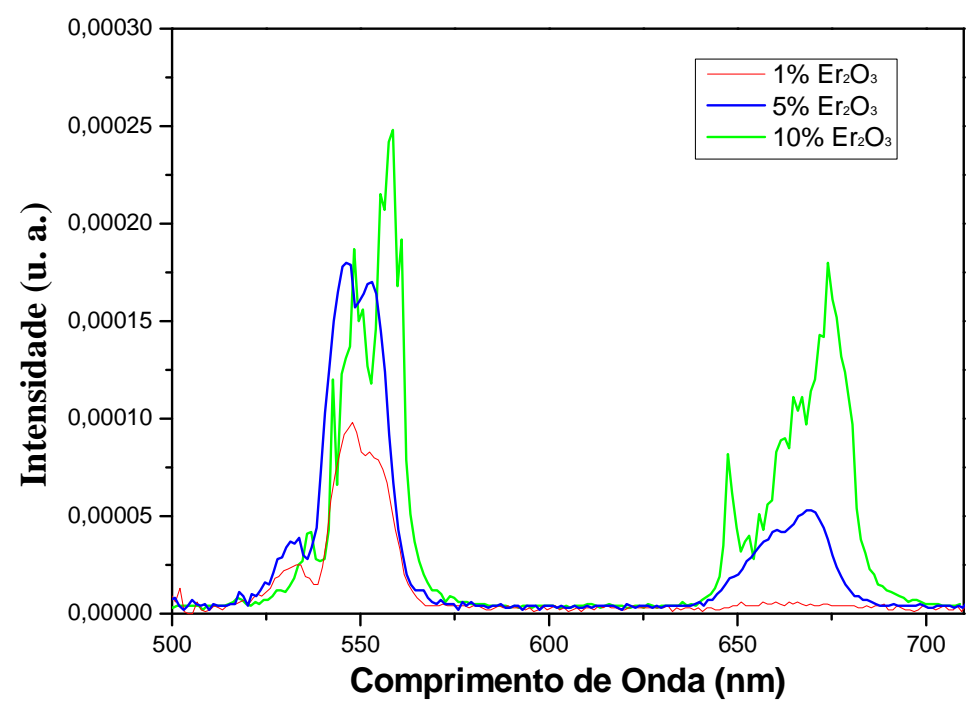

Figura 37 - Espectros de emissão no visível das amostras $\mathrm{T} 1$ dopadas com $\mathrm{Er}_{2} \mathrm{O}_{3}$. 
Nos espectros acima, observa-se que o aumento da emissão se dá com o aumento da concentração de $\mathrm{Er}_{2} \mathrm{O}_{3}$. Além disso, observa-se ruído para as amostras com 1,0\% e 10\% de $\mathrm{Er}_{2} \mathrm{O}_{3}$. Na amostra com 10,0\% de $\mathrm{Er}_{2} \mathrm{O}_{3}$, verificou-se a formação de aglomerados, devido a não solubilidade do $\mathrm{Er}_{2} \mathrm{O}_{3} \mathrm{O}$ que compromete certamente a emissão, alterando a forma do espectro.

\subsection{VIDROS CODOPADOS}

Todas das amostras codopadas com $\mathrm{Er}_{2} \mathrm{O}_{3}$ e $\mathrm{Yb}_{2} \mathrm{O}_{3}$ apresentaram as mesmas características, como cor e tamanho. As medidas de absorção óptica foram feitas na IFUSP com ajuda do equipamento Cary Spectrom 500 e as medidas de luminescência foram feitas no CLA-IPEN-SP.

\subsubsection{Medida de Absorção Óptica}

A Figura 38 mostra os espectros de absorção da amostra T1 dopada com $0,5 \%$ de $\mathrm{Er}_{2} \mathrm{O}_{3}$ e com diferentes concentrações $\mathrm{Yb}_{2} \mathrm{O}_{3}$, de 1,0\% até 5,0\% em peso de $\mathrm{Yb}_{2} \mathrm{O}_{3}$. A incorporação do érbio e do itérbio na forma iônica trivalente é observada devido à presença das bandas de absorção cujas transições associadas são indicadas.

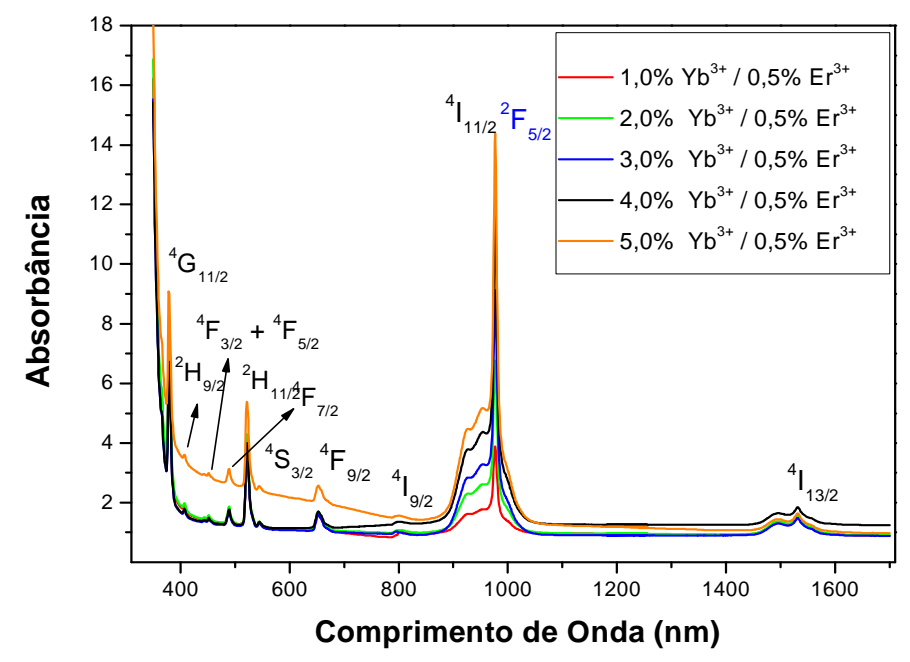

Figura 38 - Espectro de absorção óptica das amostras $\mathrm{T} 1$ codopadas com $\mathrm{Er}_{2} \mathrm{O}_{3}$ e $\mathrm{Yb}_{2} \mathrm{O}_{3}$.

Com o aumento da concentração do $\mathrm{Yb}_{2} \mathrm{O}_{3}$, observa-se o aumento da absorção em 980 nm, transição associada à absorção do íon de itérbio na 
forma trivalente $\left({ }^{2} \mathrm{~F}_{7 / 2} \rightarrow{ }^{2} \mathrm{~F}_{5 / 2}\right)$. A tabela a seguir apresenta as transições que foram observadas referentes à incorporação do $\mathrm{Er}^{3+} \mathrm{e}$ do $\mathrm{Yb}^{3+} \mathrm{e}$ os respectivos comprimentos de onda associados.

Tabela 10 - Transições do $\mathrm{Er}^{3+}$ e do $\mathrm{Yb}^{3+}$ e os respectivos comprimentos de onda para as amostras $\mathrm{T} 1$ dopadas e codopadas com $\mathrm{Er}_{2} \mathrm{O}_{3}$ e $\mathrm{Yb}_{2} \mathrm{O}_{3}$.

\begin{tabular}{|c|c|c|c|}
\hline \multicolumn{2}{|c|}{$\mathrm{T} 1$ codopada com $\mathrm{Er}_{2} \mathrm{O}_{3}$ e $\mathrm{Yb}_{2} \mathrm{O}_{3}$} & \multirow{2}{*}{$\frac{\text { T1 dopada com } \mathrm{Er}_{2} \mathrm{O}_{3}}{\text { Níveis do } \mathrm{Er}^{3+}}$} & \\
\hline Níveis do $\mathrm{Er}^{3+}$ & Níveis do $\mathrm{Yb}^{3+}$ & & $\begin{array}{c}\text { Comprimento de onda } \\
(\mathrm{nm})\end{array}$ \\
\hline $\begin{array}{l}{ }^{4} \mathrm{I}_{1 / 2} \\
{ }^{4} \mathrm{I}_{1 / 1 / 2} \\
{ }^{4} \mathrm{I}_{\mathrm{g} / 2} \\
{ }^{4} \mathrm{~F}_{9 / 2} \\
{ }^{4} \mathrm{~S}_{3 / 2} \\
{ }^{2} \mathrm{H}_{11 / 2} \\
{ }^{4} \mathrm{H}_{7 / 2} \\
{ }^{4} \mathrm{~F}_{5 / 2} \\
{ }^{4} \mathrm{~F}_{3 / 2} \\
{ }^{4} \mathrm{H}_{9 / 2} \\
{ }^{4} \mathrm{G}_{11 / 2}\end{array}$ & $\begin{array}{l}{ }^{2} \overline{F_{5 / 2}} \\
- \\
- \\
- \\
- \\
- \\
- \\
- \\
-\end{array}$ & $\begin{array}{l}{ }^{4} \mathrm{I}_{13 / 2} \\
{ }^{4} \mathrm{I}_{1 / 1 / 2} \\
{ }^{4} \mathrm{I}_{\mathrm{g} / 2} \\
{ }^{4} \mathrm{~F}_{9 / 2} \\
{ }^{4} \mathrm{~F}_{3 / 2} \\
{ }^{2} \mathrm{~S}_{3 / 1 / 2} \\
{ }^{2} \mathrm{H}_{11 / 2} \\
{ }^{4} \mathrm{~F}_{7 / 2} \\
{ }^{4} \mathrm{~F}_{3 / 2} \\
{ }^{4} \mathrm{~F}_{5 / 2} \\
{ }^{2} \mathrm{H}_{9 / 2} \\
{ }^{4} \mathrm{G}_{11 / 2}\end{array}$ & $\begin{array}{c}1534 \\
976 \\
801 \\
652 \\
544 \\
521 \\
488 \\
451 \\
443 \\
407 \\
379 \\
\end{array}$ \\
\hline
\end{tabular}

\subsubsection{Medida de Luminescência}

Na Figura 39 são apresentados os espectros de emissão das amostras T1 codopadas com $0,5 \% \mathrm{Er}_{2} \mathrm{O}_{3}$ e concentrações entre 1,0\% a 5,0\% de $\mathrm{Yb}_{2} \mathrm{O}_{3}$.

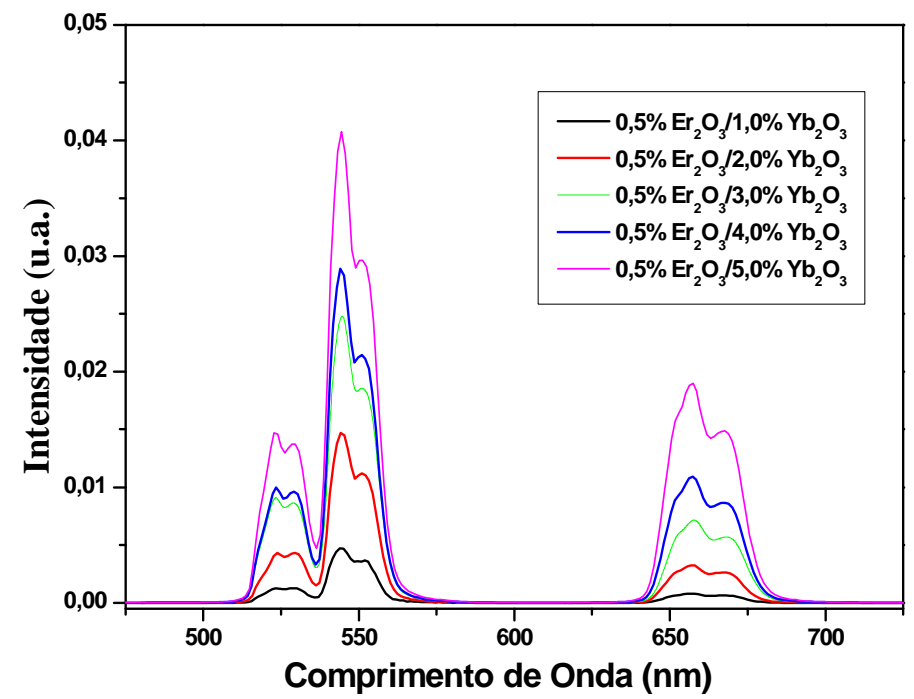

Figura 39 - Espectros de emissão no visível da amostra $\mathrm{T} 1$ codopada com $\mathrm{Er}_{2} \mathrm{O}_{3}$ e $\mathrm{Yb}_{2} \mathrm{O}_{3}$. 
No espectro anterior observamos claramente o aumento da emissão na região do visível em função do aumento da concentração de $\mathrm{Yb}_{2} \mathrm{O}_{3}$. A Figura 40 apresenta o comportamento das emissões em $530 \mathrm{~nm}, 550 \mathrm{~nm}$ e $660 \mathrm{~nm}$ das amostras $\mathrm{T} 1$ em função da concentração do $\mathrm{Yb}_{2} \mathrm{O}_{3}$.

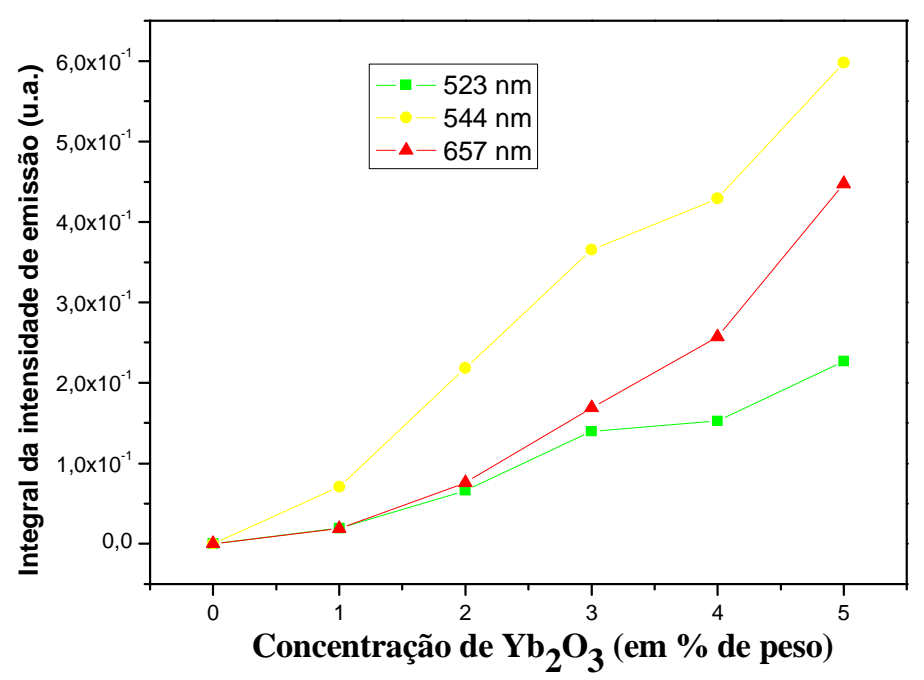

Figura 40 - Integral da intensidade de emissão em função da concentração de $\mathrm{Yb}_{2} \mathrm{O}_{3}$.

Conforme mostrado na figura anterior, o aumento da concentração de $\mathrm{Yb}_{2} \mathrm{O}_{3}$ favorece o aumento da luminescência na região do visível, pois ele é

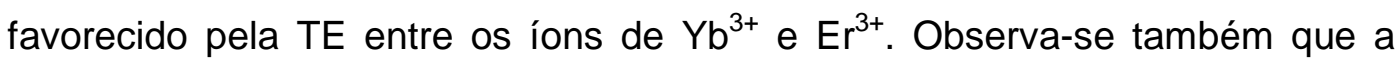
emissão em torno de $660 \mathrm{~nm}$ foi mais favorecida do que as outras (530 e 550 $\mathrm{nm}$ ) com o aumento da concentração de $\mathrm{Yb}^{3+}$.

$\mathrm{Na}$ Figura 41 são apresentados os resultados das emissões de conversão ascendente em $550 \mathrm{~nm}$ e $660 \mathrm{~nm}$ em função do aumento da potência do laser incidente, em escala logarítmica. Os coeficientes angulares das retas resultantes são indicados, pois representam os fótons que participam do processo de conversão ascendente.

Em todos os gráficos obteve-se um coeficiente angular com valor médio de 1,90. Pode-se afirmar que o mecanismo de conversão ascendente ocorreu pela absorção de dois fótons a partir do estado fundamental do íon, nas amostras $\mathrm{T} 1$, conforme a eq. 1. Neste caso nota-se que os valores são diferentes de 2,0, pois na conversão ascendente do érbio, pode ocorrer o mecanismo de relaxação cruzada (a partir de um estado intermediário de 
energia o íon pode perder uma parte da sua energia na forma fônons, decaindo para um nível de menor energia e em seguida absorver outro fóton que o promova para um nível maior de energia) ou pode, a partir de um nível de maior energia, sofrer um decaimento por fônons e ao decair para o nível fundamental e emitir um comprimento característico deste último, com uma energia menor que a de dois fótons.

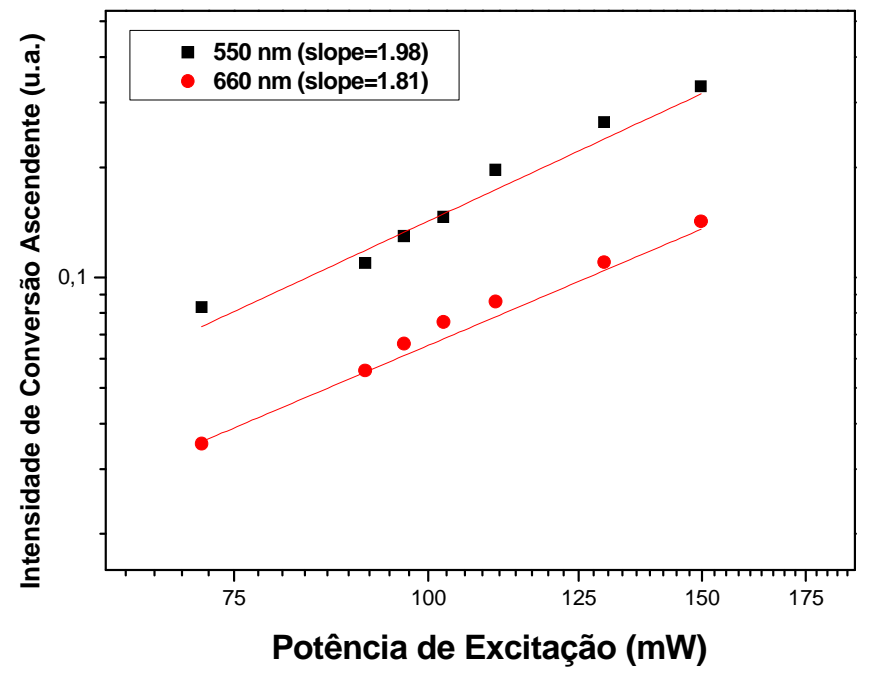

Figura 41 - Intensidade de conversão ascendente em função da potência de excitação da amostra preparada com $0,5 \% \mathrm{Er}_{2} \mathrm{O}_{3}-3,0 \% \mathrm{Yb}_{2} \mathrm{O}_{3}$.

As demais amostras com diferentes concentrações de $\mathrm{Yb}_{2} \mathrm{O}_{3}$ apresentam o mesmo comportamento e por isso não representamos esses resultados. 


\subsection{VIDROS CODOPADOS E CONTENDO NANOPARTÍCULAS}

Apresentamos os resultados das amostras codopadas com NPs metálicas. As medidas de absorção óptica foram feitas na IFUSP com o equipamento Cary Spectrom 500 e as medidas de luminescência foram feitas no Laboratório de Tecnologia em Materiais Fotônicos e Optoeletrônicos da FATEC-SP.

\subsubsection{Medida de Absorção Óptica}

Nas Figuras 42 a 44 são mostradas os espectros de absorção das amostras preparadas com $\mathrm{Er}_{2} \mathrm{O}_{3}$ e diferentes concentrações de $\mathrm{Yb}_{2} \mathrm{O}_{3}$ com NPs metálicas. As amostras foram preparadas com $\mathrm{Au}_{2} \mathrm{O}_{3}, \mathrm{AgNO}_{3}$ e $\mathrm{Ag}_{2} \mathrm{O}$ usando a mesma concentração - $1,0 \%$ em peso da matriz hospedeira.

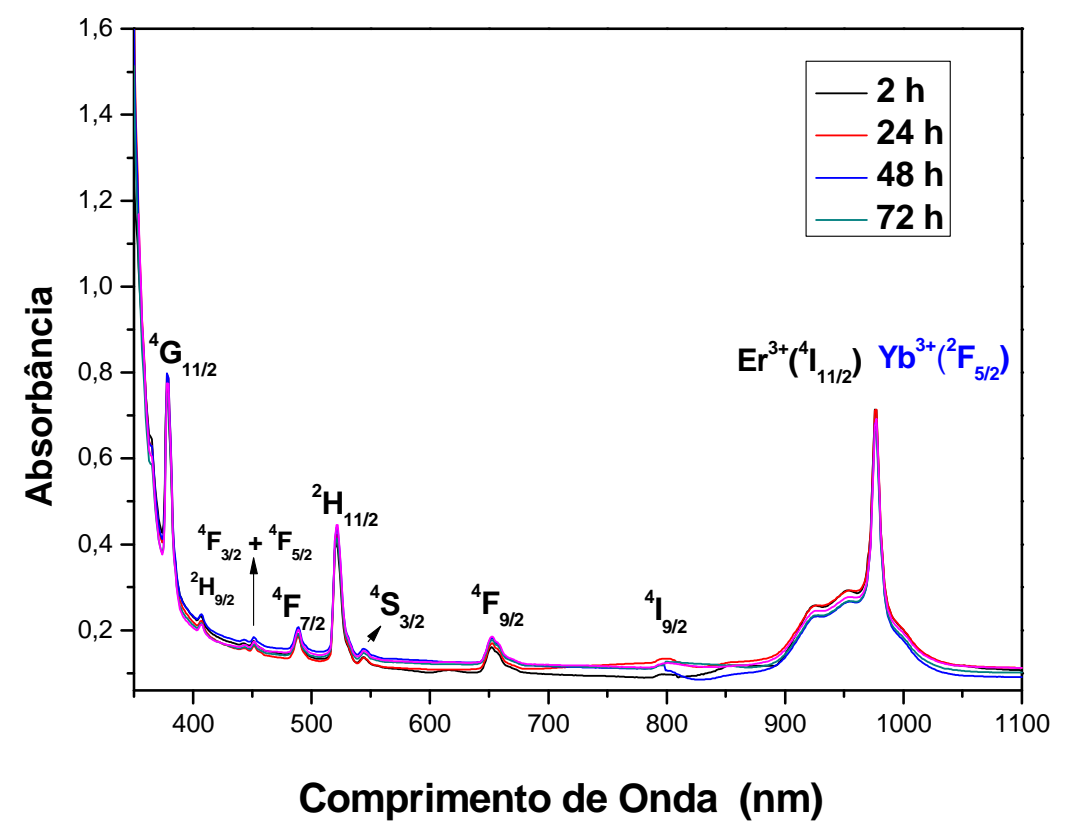

Figura 42 - Espectro de absorção óptica das amostras $\mathrm{T} 1$ codopadas com $0,5 \% \mathrm{Er}_{2} \mathrm{O}_{3}, 2,0 \%$ $\mathrm{Yb}_{2} \mathrm{O}_{3}$ e com 1,0\% $\mathrm{Au}_{2} \mathrm{O}_{3}$, para vários períodos de tratamento térmico. 


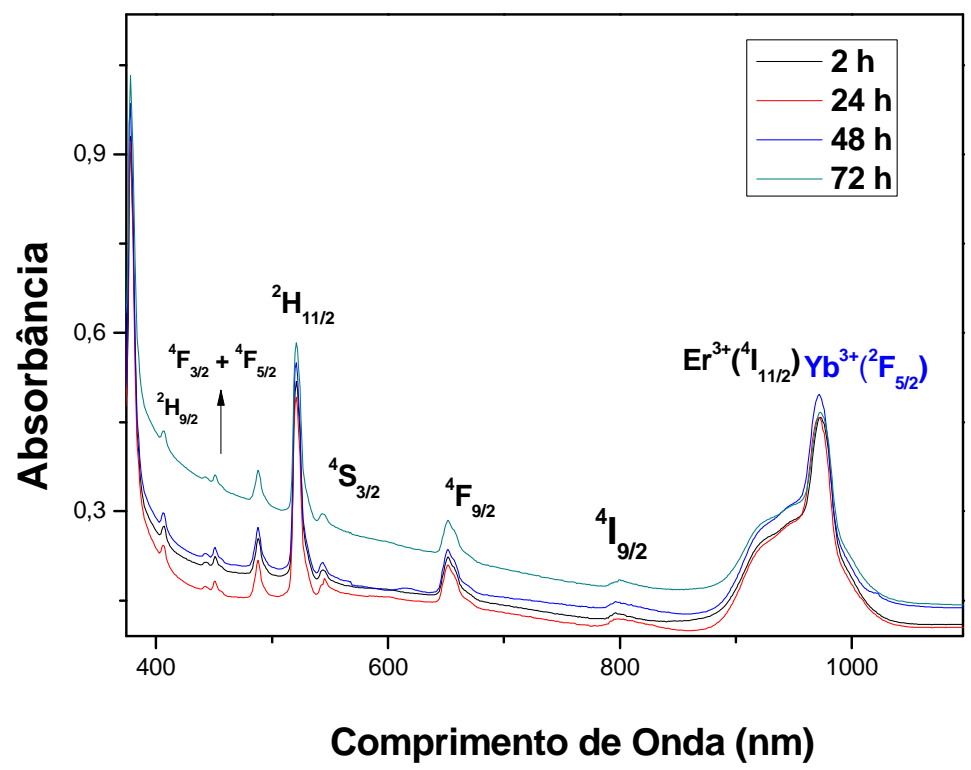

Figura 43 - Espectro de absorção óptica das amostras $\mathrm{T} 1$ codopadas com $0,5 \% \mathrm{Er}_{2} \mathrm{O}_{3}, 2,0 \%$ $\mathrm{Yb}_{2} \mathrm{O}_{3}$ e com $1,0 \% \mathrm{Ag}_{2} \mathrm{O}$, para vários períodos de tratamento térmico.

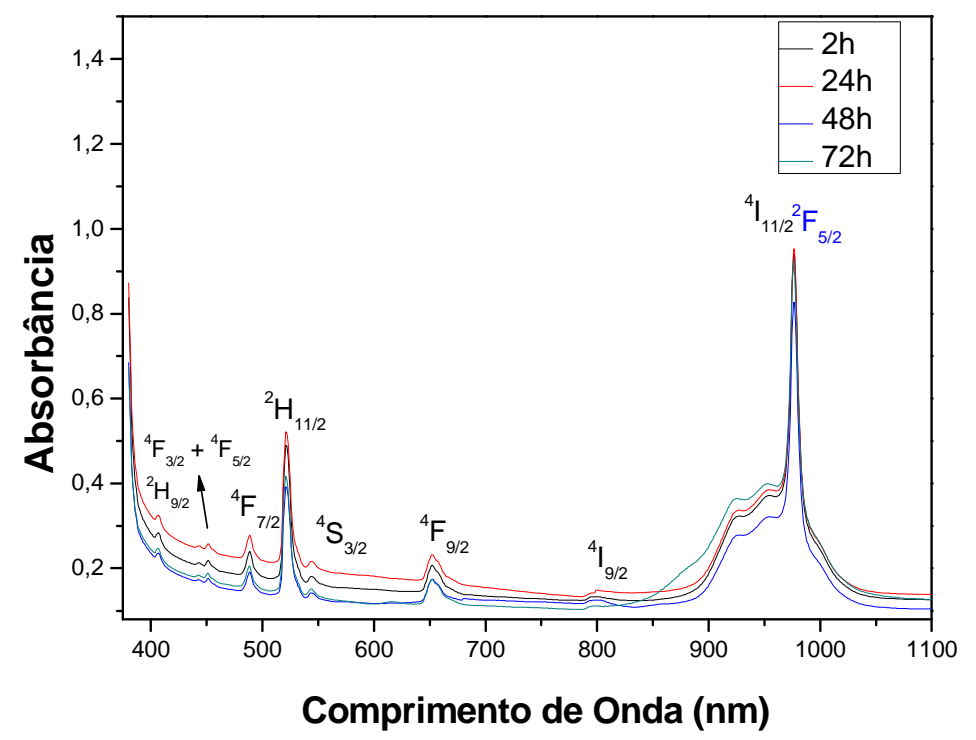

Figura 44 - Espectro de absorção óptica das amostras $\mathrm{T} 1$ codopadas com $0,5 \% \mathrm{Er}_{2} \mathrm{O}_{3}, 3,0 \%$ $\mathrm{Yb}_{2} \mathrm{O}_{3}$ e com $1,0 \% \mathrm{AgNO}_{3}$, para vários períodos de tratamento térmico.

Nas medidas de absorção são observadas as bandas associadas às transições do $\mathrm{Er}^{3+}$ e do $\mathrm{Yb}^{3+}$. Entretanto, não foi possível observar as bandas de plasmon, o que é decorrente da pequena concentração de NPs metálicas, conforme relatado em trabalhos anteriores do grupo [29]. 


\subsubsection{Medida de Luminescência}

Nas figuras a seguir são mostrados os espectros de emissão, no visível, de todas as amostras codopadas com NPs metálicas. Todas as medidas foram feitas no LTMFO da FATEC-SP.

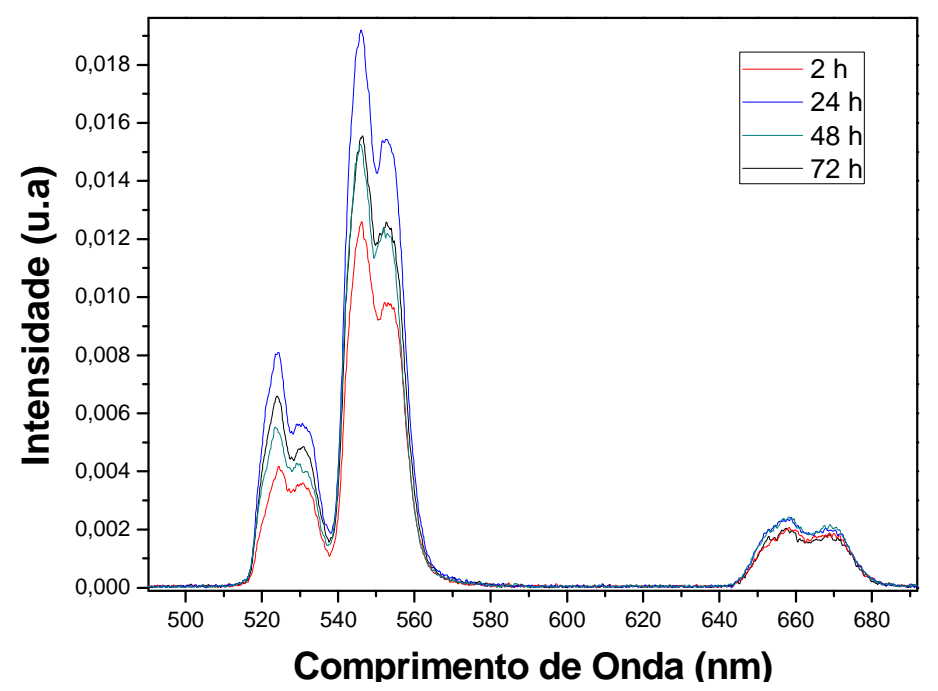

Figura 45 - Espectros de emissão no visível da amostra codopada com 0,5\% $\mathrm{Er}_{2} \mathrm{O}_{3}$ e 2,0\% $\mathrm{Yb}_{2} \mathrm{O}_{3}$ e $1,0 \% \mathrm{Ag}_{2} \mathrm{O}$.

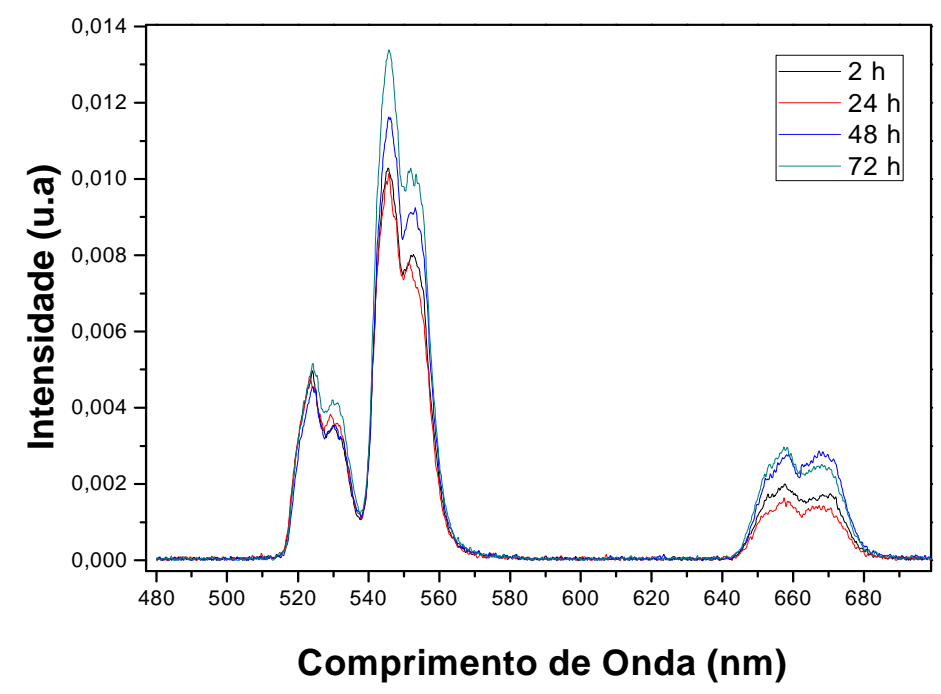

Figura 46 - Espectros de emissão no visível da amostra codopada com $05 \% \mathrm{Er}_{2} \mathrm{O}_{3}$ e 3,0\% $\mathrm{Yb}_{2} \mathrm{O}_{3}$ e $1,0 \% \mathrm{Ag}_{2} \mathrm{O}$.

Na Figura 45 observa-se a maior emissão na região do verde para o tempo de 24 horas de tratamento térmico; para a emissão no vermelho não se observa aumento. Para as amostras com 3,0\% de $\mathrm{Yb}_{2} \mathrm{O}_{3}$, Figura 46, observa- 
se o maior aumento da emissão, em 550 nm, para o período de 72 horas. Para a emissão do vemelho (em $660 \mathrm{~nm}$ ) o aumento da emissão é equivalente para tratamentos de 48 e 72 horas. A Figura 47 mostra os resultados para as medidas nas quais foram variadas a potência do laser.

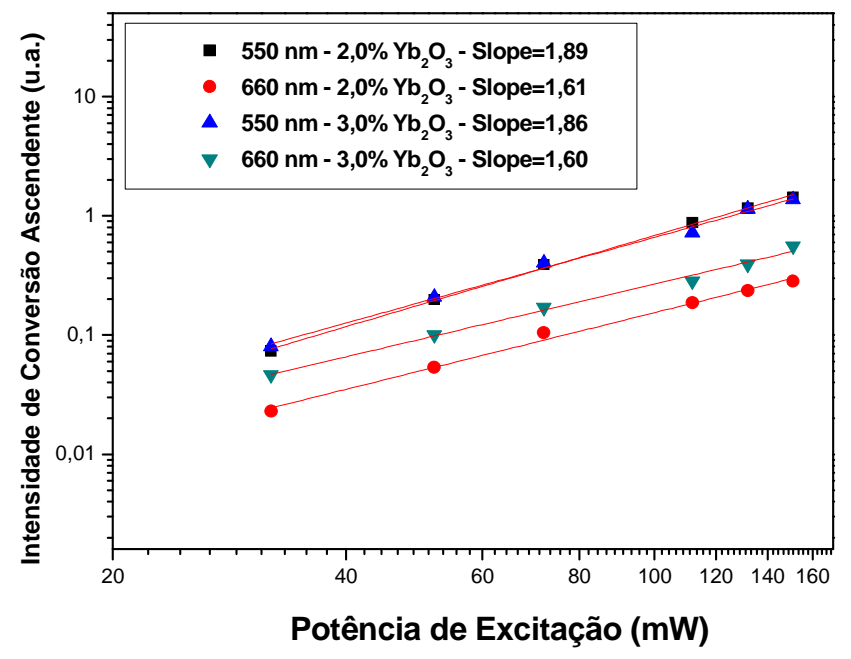

Figura 47 - Intensidade de conversão ascendente em função da potência de excitação para as amostras com $0,5 \% \mathrm{Er}_{2} \mathrm{O}_{3}$ e 2,0\% e 3,0\% $\mathrm{Yb}_{2} \mathrm{O}_{3}-1,0 \% \mathrm{Ag}_{2} \mathrm{O}$ de período de nucleação 72 horas.

Podemos observar a participação de 2 fótons no processo de conversão ascendente para as emissões em 550 e 660 nm de acordo com a eq. 1.

A seguir, são mostrados espectros de emissão das amostras preparadas com $0,5 \% \mathrm{Er}_{2} \mathrm{O}_{3}-2,0 \% \mathrm{Yb}_{2} \mathrm{O}_{3}-1,0 \% \mathrm{AgNO}_{3}$ e $0,5 \% \mathrm{Er}_{2} \mathrm{O}_{3}-3,0 \% \mathrm{Yb}_{2} \mathrm{O}_{3}-$ $1,0 \% \mathrm{AgNO}_{3}$.

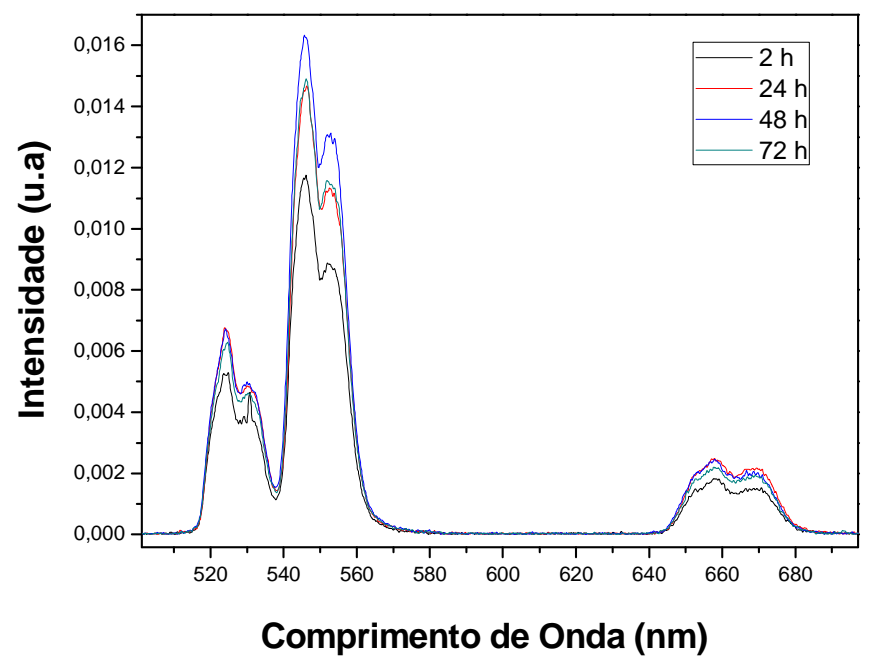

Figura 48 - Espectros de emissão no visível da amostra codopada com $05 \% \mathrm{Er}_{2} \mathrm{O}_{3}$ e 2,0\% $\mathrm{Yb}_{2} \mathrm{O}_{3}$ e $1,0 \% \mathrm{AgNO}_{3}$. 
Na Figura 49 observa-se o maior aumento da intensidade da emissão, em $550 \mathrm{~nm}$, para o período do tratamento térmico de 48 horas. Já para as outras emissões o aumento foi pequeno, principalmente, para a emissão em $680 \mathrm{~nm}$. Para os resultados mostrados na figura a seguir observa-se aumento mais significativo ( 50\%) para as emissões em 530 e $550 \mathrm{~nm}$, para tratamento térmico de 72 h. Para a emissão em 660 nm não é observado aumento da luminescência com o tratamento térmico.

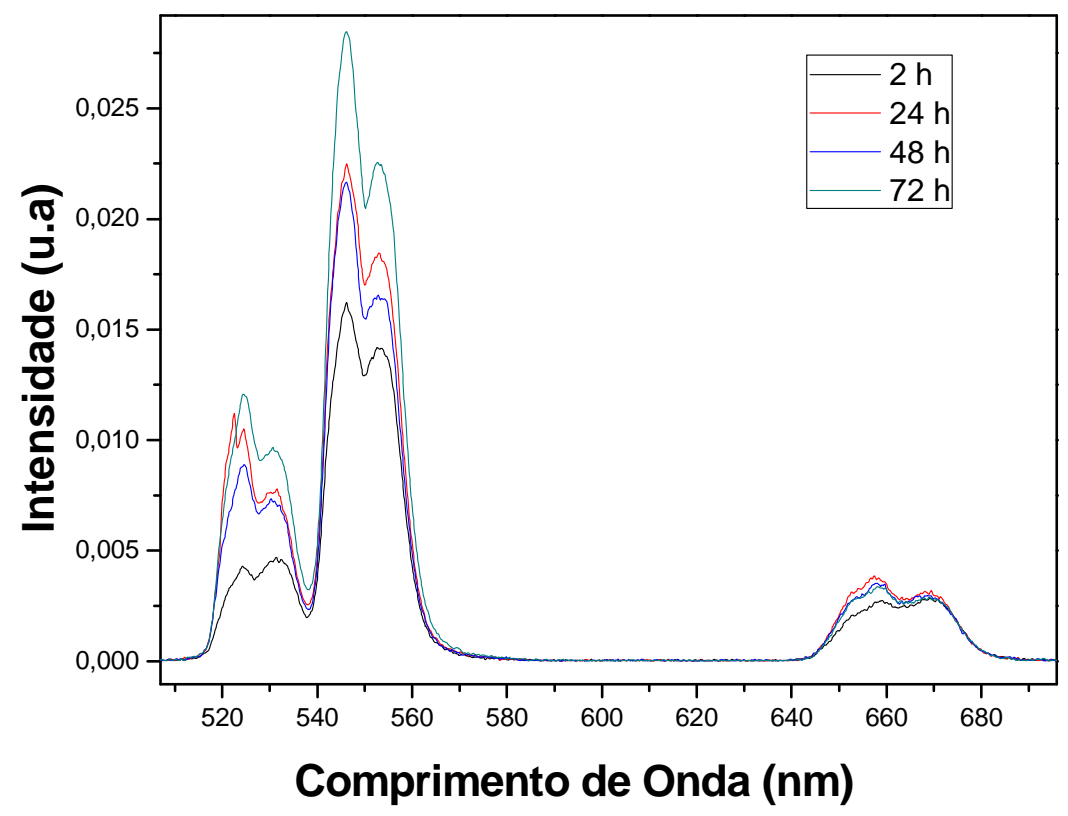

Figura 49 - Espectros de emissão no visível da amostra codopada com $05 \% \mathrm{Er}_{2} \mathrm{O}_{3}$ e 3,0\% $\mathrm{Yb}_{2} \mathrm{O}_{3}$ e $1,0 \% \mathrm{AgNO}_{3}$.

A Figura 50 mostra os resultados obtidos para as medidas com a variação de potência do laser incidente, onde observamos, novamente, a participação de 2 fótons em todos os processos de conversão ascendente. 


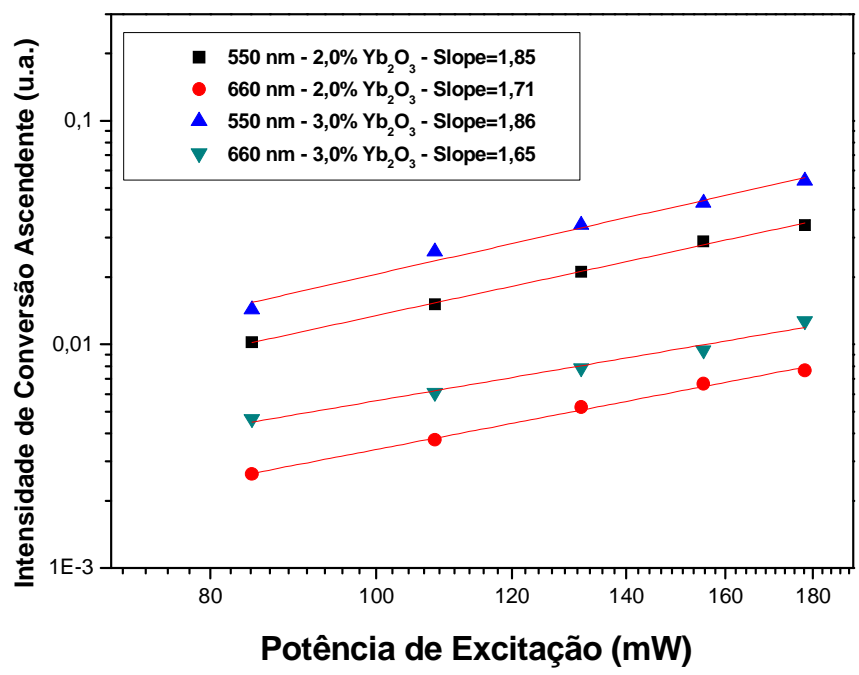

Figura 50 - Intensidade de conversão ascendente em função da potência de excitação para as amostras com $0,5 \% \mathrm{Er}_{2} \mathrm{O}_{3}$ e 2,0\% e 3,0\% $\mathrm{Yb}_{2} \mathrm{O}_{3}-1,0 \% \mathrm{AgNO}_{3}$ de período de nucleação 72 horas.

A figura a seguir mostra a cor emitida pela amostra $\mathrm{T} 1$ : $05 \% \mathrm{Er}_{2} \mathrm{O}_{3} \mathrm{e}$ $3,0 \% \mathrm{Yb}_{2} \mathrm{O}_{3}$ e $1,0 \% \mathrm{AgNO}_{3}$ para o período de nucleação de 72 horas.

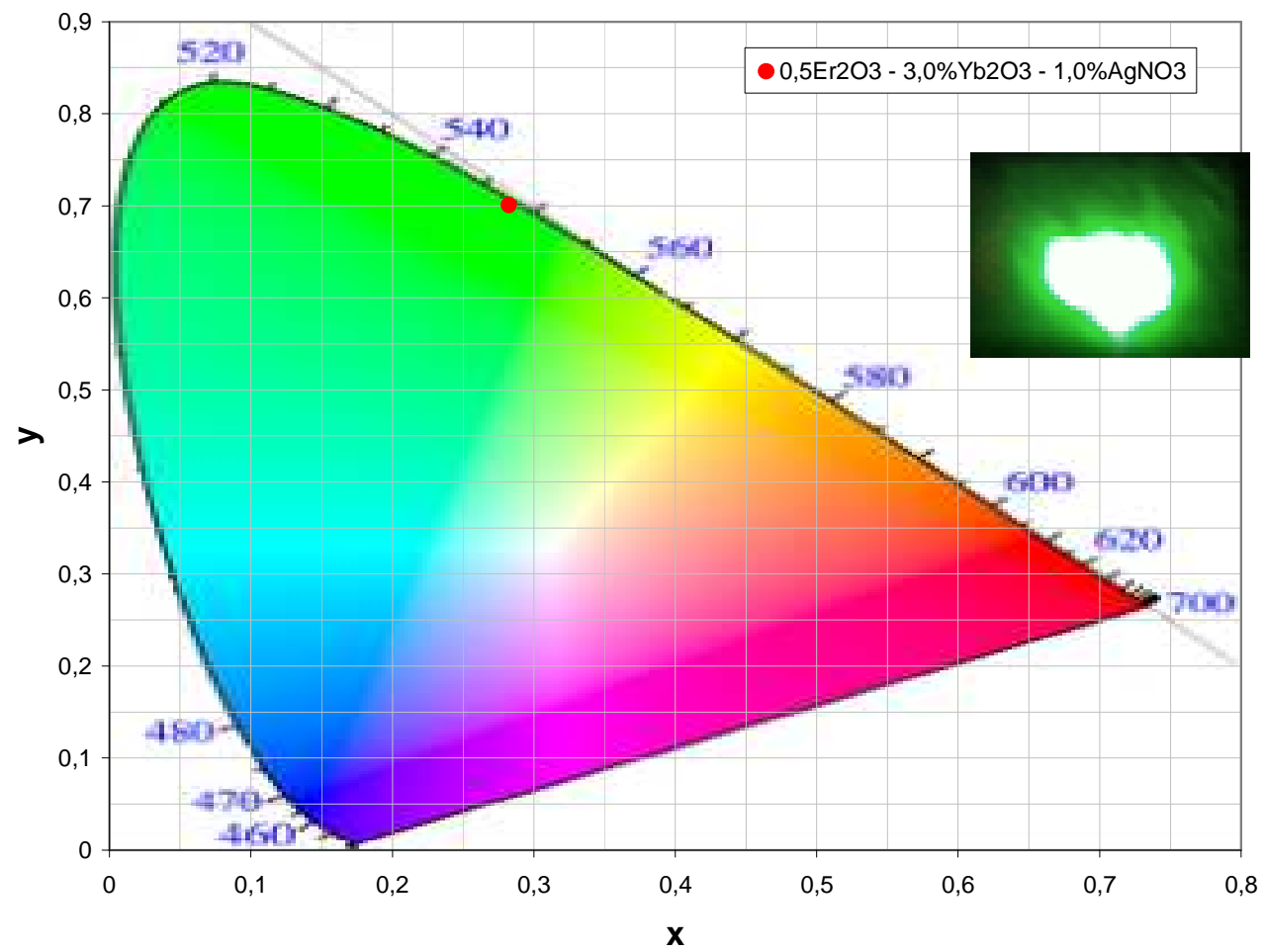

Figura 51 - Diagrama CIE e fotografia da amostra $\mathrm{T} 10,5 \% \mathrm{Er}_{2} \mathrm{O}_{3}-3,0 \% \mathrm{Yb}_{2} \mathrm{O}_{3}-1,0 \% \mathrm{AgNO}_{3}$ de período de nucleação 72 horas. 
Nas Figuras a seguir serão mostrados os espectros de emissão para as amostras preparadas com $1,0 \%$ de $\mathrm{Au}_{2} \mathrm{O}_{3}$.

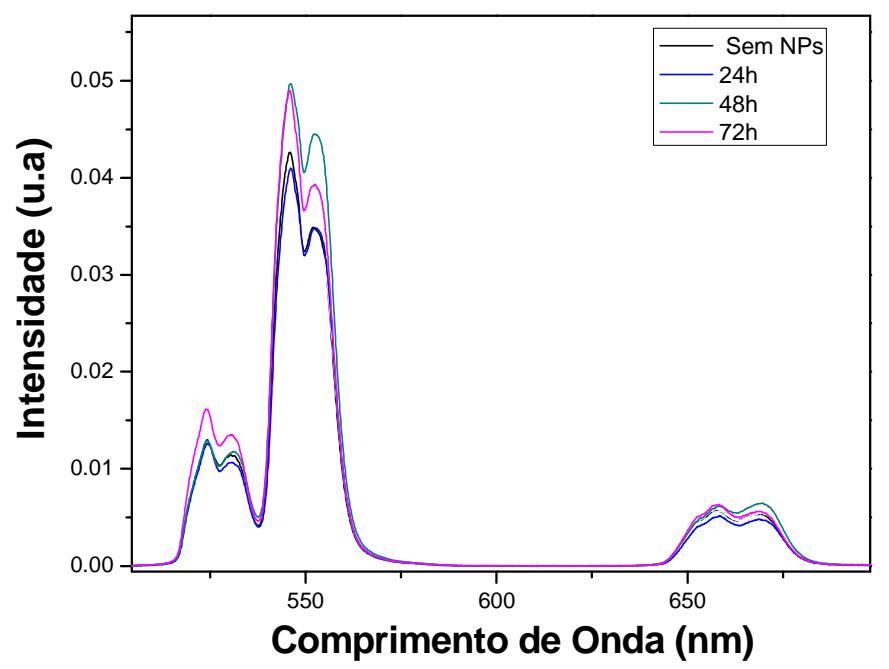

Figura 52 - Espectros de emissão no visível da amostra codopada com $05 \% \mathrm{Er}_{2} \mathrm{O}_{3}$ e 2,0\% $\mathrm{Yb}_{2} \mathrm{O}_{3}$ e $1,0 \% \mathrm{Au}_{2} \mathrm{O}_{3}$.

$\mathrm{Na}$ Figura 52, observa-se um pequeno aumento da intensidade de emissão do érbio para o tempo de tratamento térmico de 48 horas.

Figura 53 mostra as emissões obtidas das amostras dopadas com 0,5\% $\mathrm{Er}_{2} \mathrm{O}_{3}-3,0 \% \mathrm{Yb}_{2} \mathrm{O}_{3}-1,0 \% \mathrm{Au}_{2} \mathrm{O}_{3}$ para os períodos de 2, 24, 48 e 72 horas.

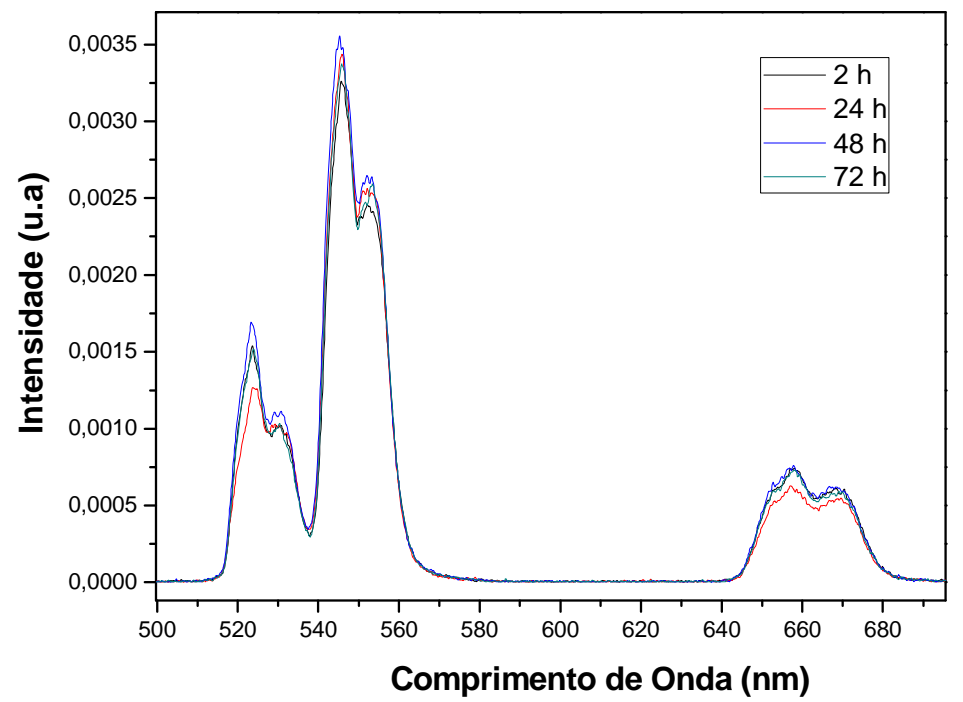

Figura 53 - Espectros de emissão no visível da amostra codopada com $05 \% \mathrm{Er}_{2} \mathrm{O}_{3}$ e 3,0\% $\mathrm{Yb}_{2} \mathrm{O}_{3}$ e $1,0 \% \mathrm{Au}_{2} \mathrm{O}_{3}$. 
A Figura 54 mostra que a intensidade de emissão não muda com o aumento do tempo de tratamento térmico. Da mesma forma que nos caso anteriores notamos a participação de 2 fótons nas emissões de 550 e 660 nm, conforme explicado no item 3.1.

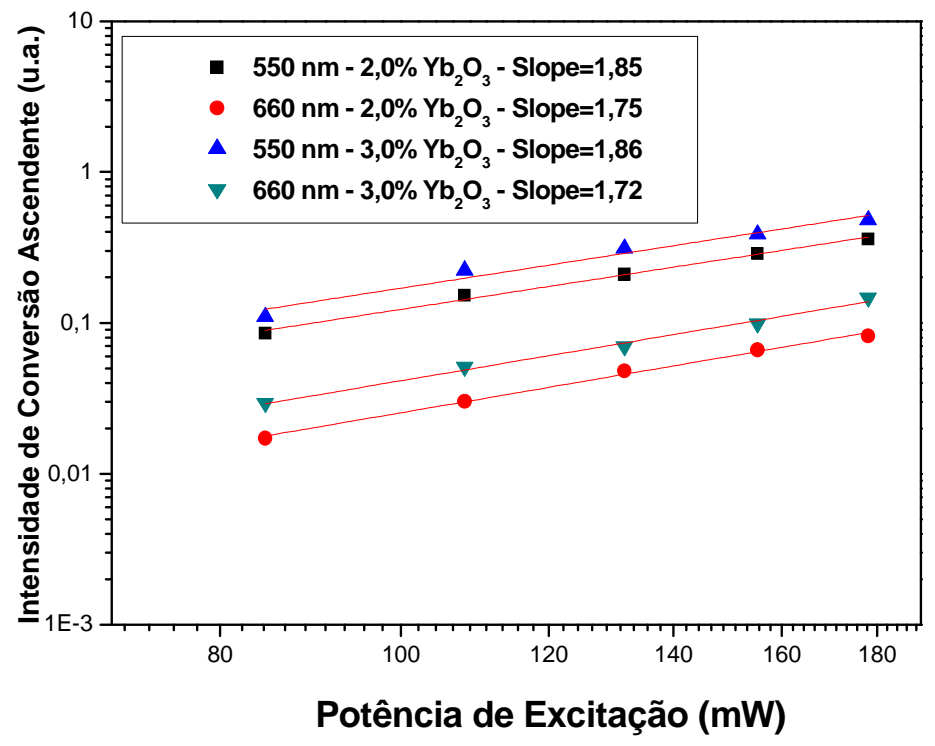

Figura 54 - Intensidade de conversão ascendente em função da potência de excitação para as amostras com $0,5 \% \mathrm{Er}_{2} \mathrm{O}_{3}$ e 2,0\% e 3,0\% $\mathrm{Yb}_{2} \mathrm{O}_{3}-1,0 \% \mathrm{Au}_{2} \mathrm{O}_{3}$ de período de nucleação 72 horas.

Dentre os resultados obtidos destacamos a amostras com $0,5 \% \mathrm{Er}_{2} \mathrm{O}_{3^{-}}$ $3,0 \% \mathrm{Yb}_{2} \mathrm{O}_{3}-1,0 \% \mathrm{AgNO}_{3}$ para qual foi observado o maior aumento de emissão em 530 e 550 nm. ( 50\%)

Cabe acrescentar que maior concentração de reagente poderia permitir a observação de banda de absorção de plasmon decorrente de uma nucleação mais eficiente o que poderia causar maior aumento da luminescência. Nota-se que as amostras com NPs de prata apresentam maior aumento da luminescência do que as amostras com NPs de ouro. Observa-se ainda em todos os casos que a presença de NPs não altera o número de fótons que participam do processo de conversão ascendente do $\mathrm{Er}^{3+}$.

As emissões em $660 \mathrm{~nm}$ não são alteradas pela presença de NPs metálicas conferindo o que já foi observado em estudos anteriores nos quais foram constatados que as emissões mais afetadas pelas NPs metálicas são as que têm comprimento de onda mais próximos aos comprimentos de onda de 
absorção dos plasmons das NPs metálicas (em torno de $600 \mathrm{~nm}$ para a NPs de prata e de $500 \mathrm{~nm}$ para o ouro) [71].

\subsubsection{Microscopia Eletrônica de Transmissão}

As medidas de microscopia eletrônica de transmissão foram feitas nas amostras 0,5\% $\mathrm{Er}_{2} \mathrm{O}_{3}-2,0 \% \mathrm{Yb}_{2} \mathrm{O}_{3}-1,0 \% \mathrm{Au}_{2} \mathrm{O}_{3}$ e $0,5 \% \mathrm{Er}_{2} \mathrm{O}_{3}-3,0 \% \mathrm{Yb}_{2} \mathrm{O}_{3}-$ $1,0 \% \mathrm{AgNO}_{3}$ para tratamento de 72 horas. Nas análises, foram constatadas a presença de fases cristalinas de $\mathrm{Au}$ e $\mathrm{Ag}$, apresentando tamanho médio aproximado de $10 \mathrm{~nm}$ para a NPs de ouro e NPs de prata com tamanho médio entre 5 a $30 \mathrm{~nm}$.
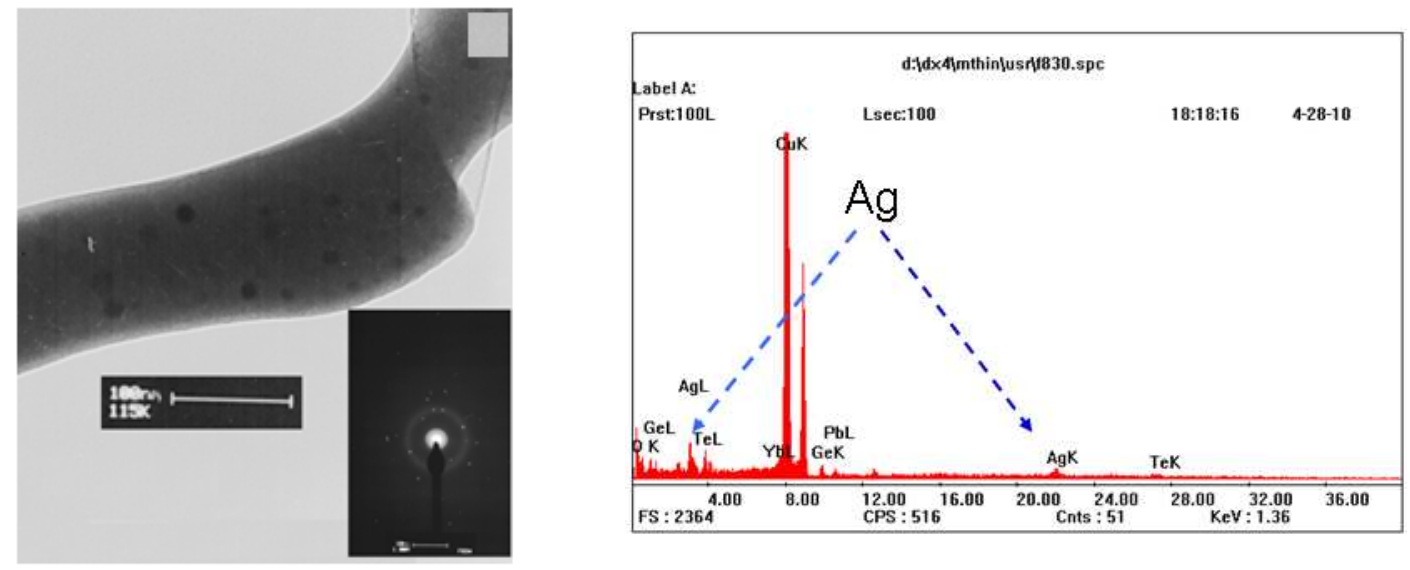

Figura 55 - Micrografia e EDX das amostras $\mathrm{T} 1$ com $0,5 \% \mathrm{Er}_{2} \mathrm{O}_{3}-3,0 \% \mathrm{Yb}_{2} \mathrm{O}_{3}-1,0 \% \mathrm{AgNO}_{3}$ para período de nucleação de 72 horas..
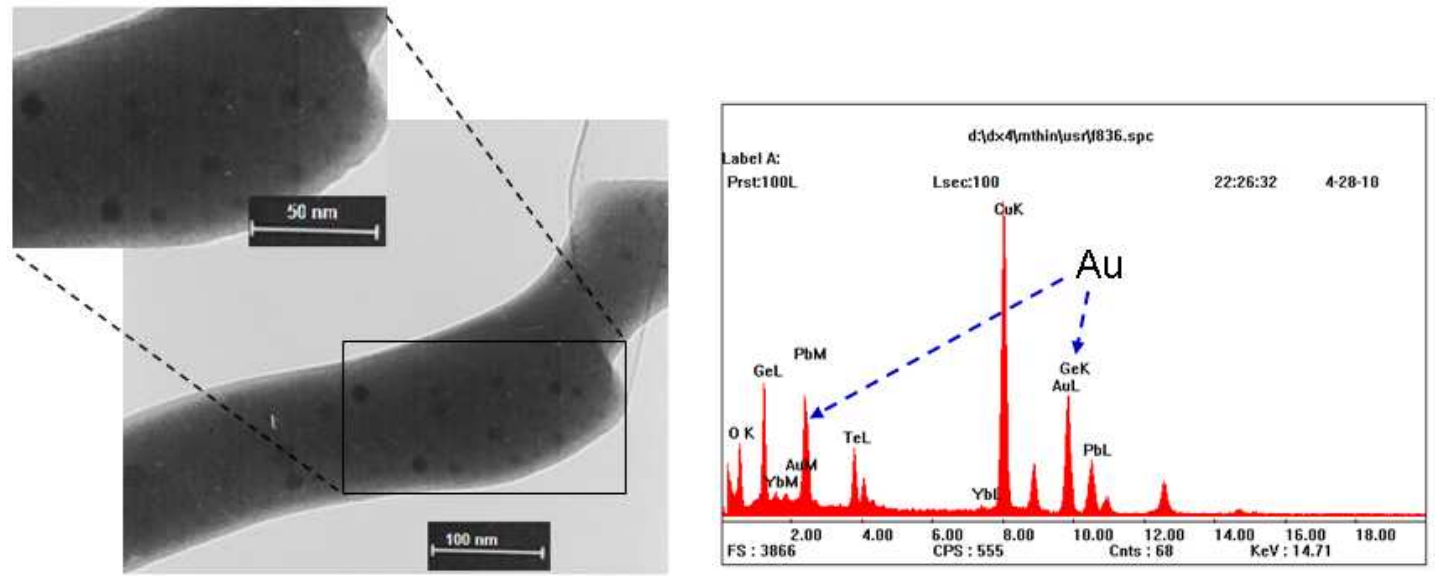

Figura 56 - Micrografia e EDX das amostras T1 com 0,5\% $\mathrm{Er}_{2} \mathrm{O}_{3}-2,0 \% \mathrm{Yb}_{2} \mathrm{O}_{3}-1,0 \% \mathrm{Au}_{2} \mathrm{O}_{3}$ para período de nucleação de 72 horas. 


\subsection{VIDROS TRIDOPADOS}

Os resultados da amostras tridopadas são apresentados a seguir.

\subsubsection{Medida de Absorção Óptica}

Nas Figura 57 a 58 são apresentados alguns espectros de absorção das amostras tridopadas e as respectivas transições eletrônicas das amostras preparadas com $\mathrm{Er}_{2} \mathrm{O}_{3}, \mathrm{Tm}_{2} \mathrm{O}_{3}$ e $\mathrm{Yb}_{2} \mathrm{O}_{3}$.

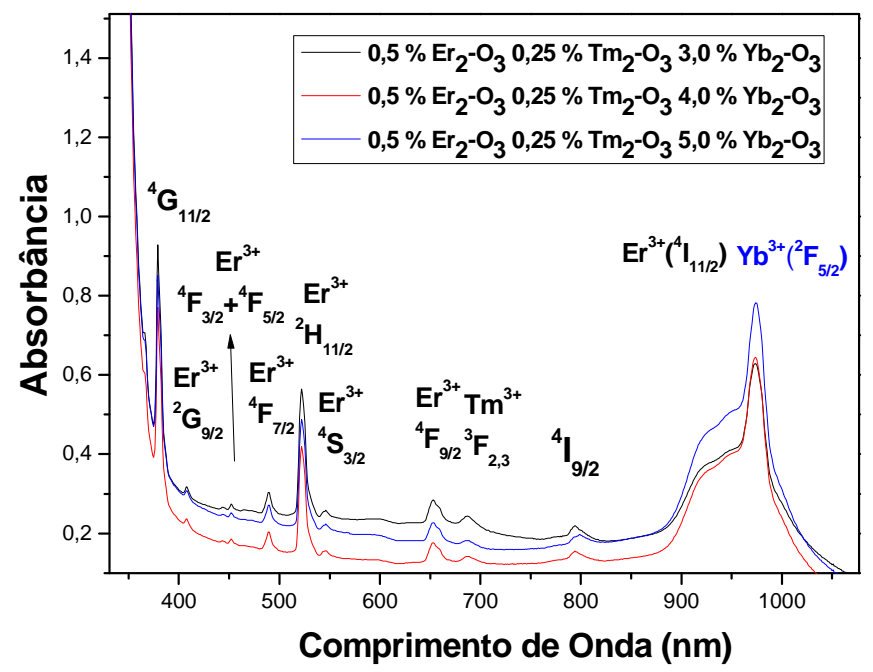

Figura 57 - Espectro de absorção óptica das amostras $\mathrm{T} 1$ tridopadas com $\mathrm{Er}_{2} \mathrm{O}_{3}, \mathrm{Tm}_{2} \mathrm{O}_{3} \mathrm{e}$ $\mathrm{Yb}_{2} \mathrm{O}_{3}$.

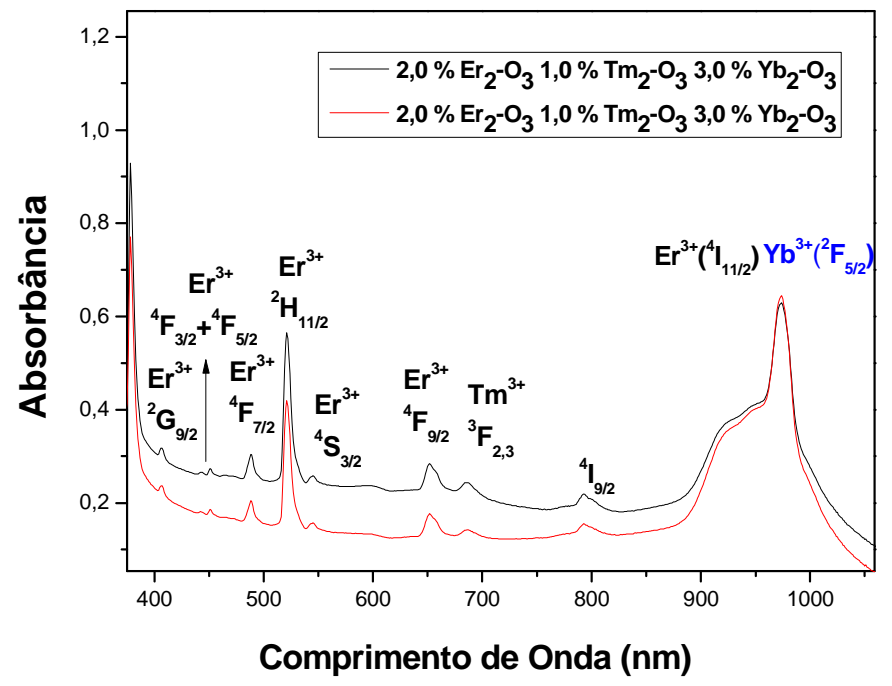

Figura 58 - Espectro de absorção óptica das amostras $\mathrm{T} 1$ tridopadas com $\mathrm{Er}_{2} \mathrm{O}_{3}, \mathrm{Tm}_{2} \mathrm{O}_{3} \mathrm{e}$ $\mathrm{Yb}_{2} \mathrm{O}_{3}$. 
Nas figuras anteriores, foram apresentados os espectros de absorção, de $350 \mathrm{~nm}$ a $1100 \mathrm{~nm}$ onde podemos observar as transições referentes aos íons de $\mathrm{Er}^{3+}, \mathrm{Tm}^{3+} \mathrm{e} \mathrm{Yb}^{3+}$. Assim, podemos concluir que houve a incorporação dos três óxidos de terras raras na forma trivalente. 


\subsubsection{Medida de Luminescência}

As medidas de emissão foram feitas na região do visível (400 nm a 700 $\mathrm{nm}$ ) e foram observadas as intensidades de emissão, referentes às emissões do túlio, em torno de $480 \mathrm{~nm}$, as do érbio em torno $530 \mathrm{~nm}, 550 \mathrm{~nm}$ e $680 \mathrm{~nm}$. As concentrações do $\mathrm{Er}_{2} \mathrm{O}_{3}, \mathrm{Tm}_{2} \mathrm{O}_{3}$ e do $\mathrm{Yb}_{2} \mathrm{O}_{3}$ e as potências de excitação do laser foram variadas com o propósito de se obter emissões mais próximas possíveis da luz branca.

$\mathrm{Na}$ Figura 59 são mostrado espectros de emissão das amostras tridopadas (grupo A) com potência de excitação de 181,6 mW e para diferentes concentrações de $\mathrm{Tm}_{2} \mathrm{O}_{3}$ e de $\mathrm{Yb}_{2} \mathrm{O}_{3}$ (grupo A).

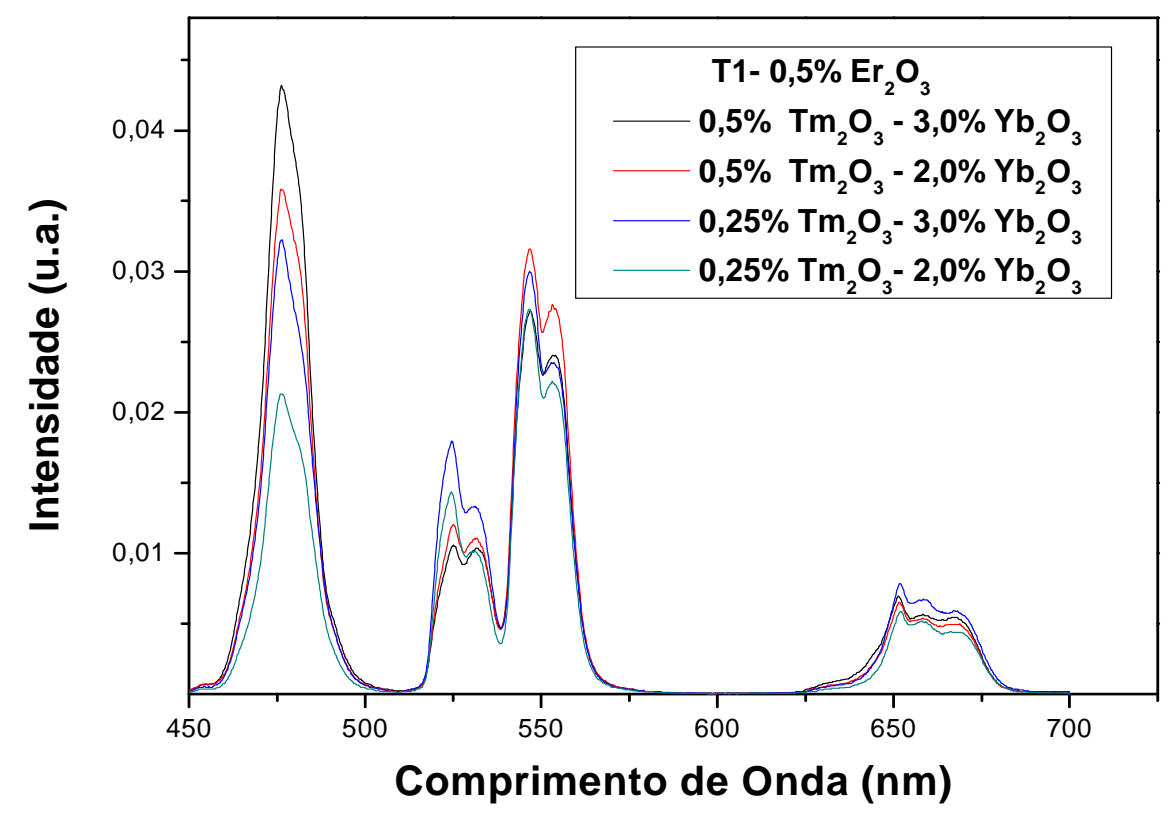

Figura 59 - Espectros de emissão no visível da amostra T1 tridopada do Grupo A sobre potência de excitação de $181,6 \mathrm{~mW}$.

$\mathrm{Na}$ figura acima, observa-se que ocorreu um aumento da emissão azul do $\mathrm{Tm}^{3+}$ (em $480 \mathrm{~nm}$ ) em decorrência do aumento da concentração de $\mathrm{Yb}_{2} \mathrm{O}_{3}$. Isto supõe, conforme resultados anteriores, que a transferência de energia do íon de itérbio para os íons de érbio e túlio é predominante em relação ao 
fenômeno conversão ascendente do estado excitado.. Observa-se também a diminuição das emissões do $\mathrm{Er}^{3+}$, principalmente nas emissões do verde em torno de $530 \mathrm{~nm}$ e $550 \mathrm{~nm}$, o que nos leva a concluir que a transferência de energia do itérbio para o túlio é mais eficiente do que do itérbio para o érbio. Esta ultima eficiência so é aumentada para concentrações para Yb2O3 superiores a 3,0\%, conforme será mostrado. Já as emissões do vermelho do $\mathrm{Er}^{3+}$ sofreram pequenas variações com as diferentes concentrações de $\mathrm{Tm}_{2} \mathrm{O}_{3}$ e $\mathrm{Yb}_{2} \mathrm{O}_{3}$. Na figura abaixo são analisadas as cores emitidas das amostras produzidas de acordo com o diagrama de cromaticidade.
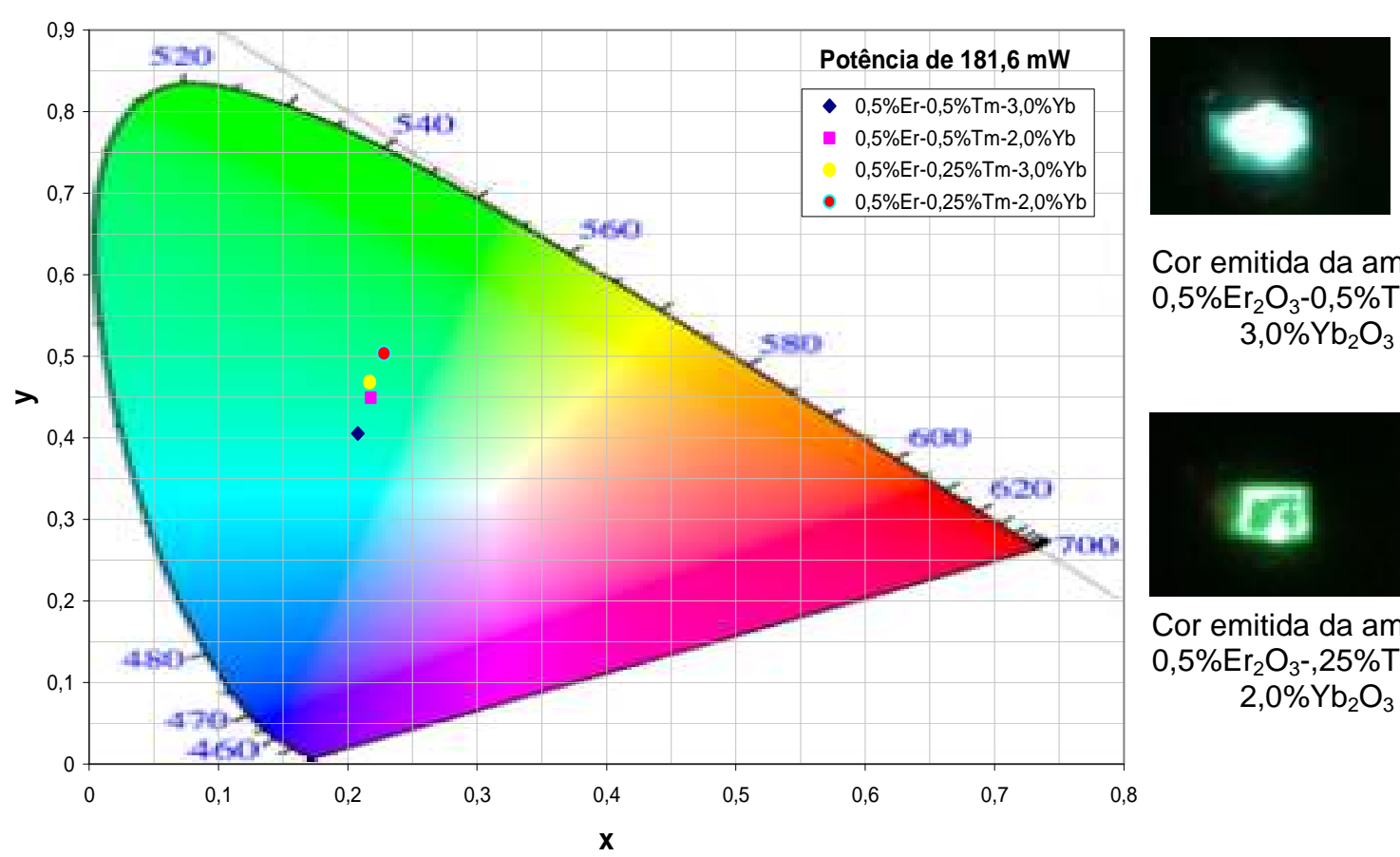

Cor emitida da amostra: $0,5 \% \mathrm{Er}_{2} \mathrm{O}_{3}-0,5 \% \mathrm{Tm}_{2} \mathrm{O}_{3}$ $3,0 \% \mathrm{Yb}_{2} \mathrm{O}_{3}$

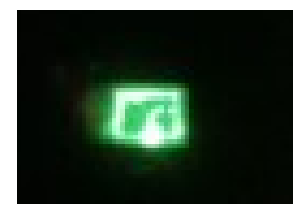

Cor emitida da amostra:

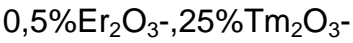
$2,0 \% \mathrm{Yb}_{2} \mathrm{O}_{3}$

Figura 60 - Diagrama CIE das T1 tridopada do Grupo A sobre potência de excitação de 181,6 $\mathrm{mW}$ e fotografia da amostra $0,5 \% \mathrm{Er}_{2} \mathrm{O}_{3}-0,5 \% \mathrm{Tm}_{2} \mathrm{O}_{3}-3,0 \% \mathrm{Yb}_{2} \mathrm{O}_{3}$ e $0,5 \% \mathrm{Er}_{2} \mathrm{O}_{3}-0,25 \% \mathrm{Tm}_{2} \mathrm{O}_{3}$ $2,0 \% \mathrm{Yb}_{2} \mathrm{O}_{3}$.

A Figura 60 apresenta as cores das emissões provenientes das amostras produzidas, onde a amostra $\mathrm{T} 1 \mathrm{com} 0,5 \% \mathrm{Er}_{2} \mathrm{O}_{3}-0,5 \% \mathrm{Tm}_{2} \mathrm{O}_{3}$ $3,0 \% \mathrm{Yb}_{2} \mathrm{O}_{3}$ apresentou-se mais próxima da região que caracteriza a luz branca no diagrama CIE. Já a amostra que apresentou mais afastada foi a com $0,5 \% \mathrm{Er}_{2} \mathrm{O}_{3}-0,25 \% \mathrm{Tm}_{2} \mathrm{O}_{3}-2,0 \% \mathrm{Yb}_{2} \mathrm{O}_{3}$. Observa-se que as cores emitidas pelas amostras com menor concentração de $\mathrm{Tm}_{2} \mathrm{O}_{3}$ apresentaram-se, predominantemente, com maiores valores das coordenadas $\mathrm{x} e \mathrm{y}$. 
Nas figuras abaixo são observadas a influência da variação da potência de excitação no espectro de emissão e na cor emitida pela amostra com $0,5 \% \mathrm{Er}_{2} \mathrm{O}_{3}-0,5 \% \mathrm{Tm}-3,0 \% \mathrm{Yb}$. Observa-se que o aumento da potência favorece o aumento da relação das emissões da luz azul (em $480 \mathrm{~nm}$ ) com as outras emissões da luz verde e vermelha, conforme a eq. 01.

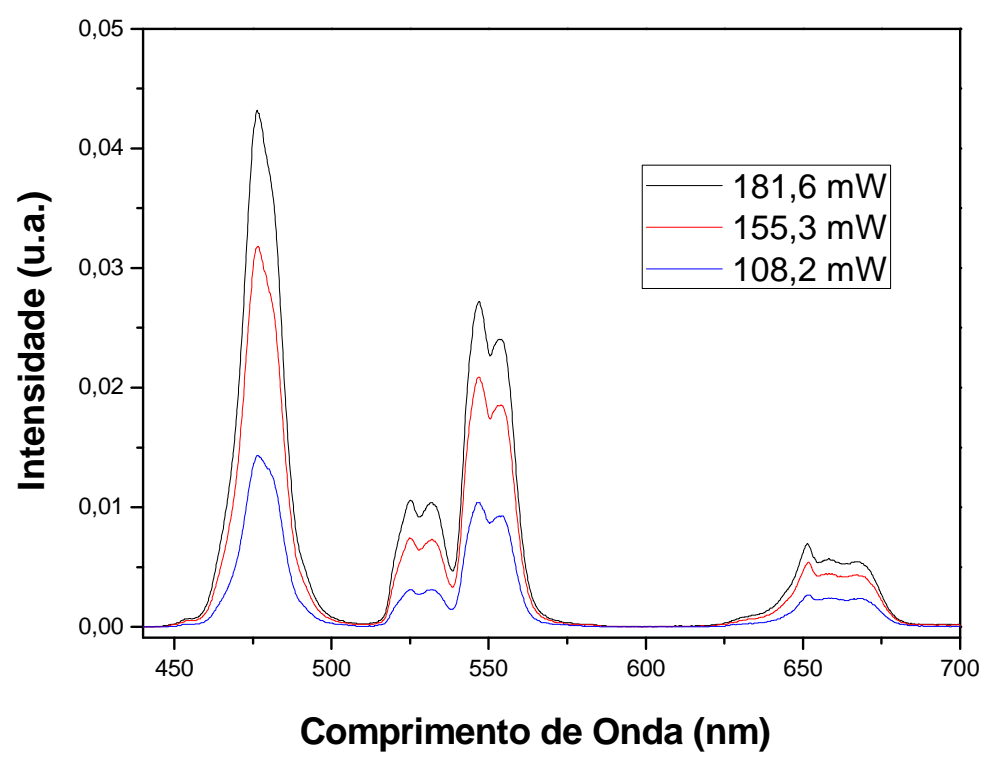

Figura 61 - Espectros de emissão no visível da amostra $\mathrm{T} 1$ - 0,5\% $\mathrm{Er}_{2} \mathrm{O}_{3}-0,5 \% \mathrm{Tm}_{2} \mathrm{O}_{3}-3,0 \%$ $\mathrm{Yb}_{2} \mathrm{O}_{3}$, com diferente potência de excitação.

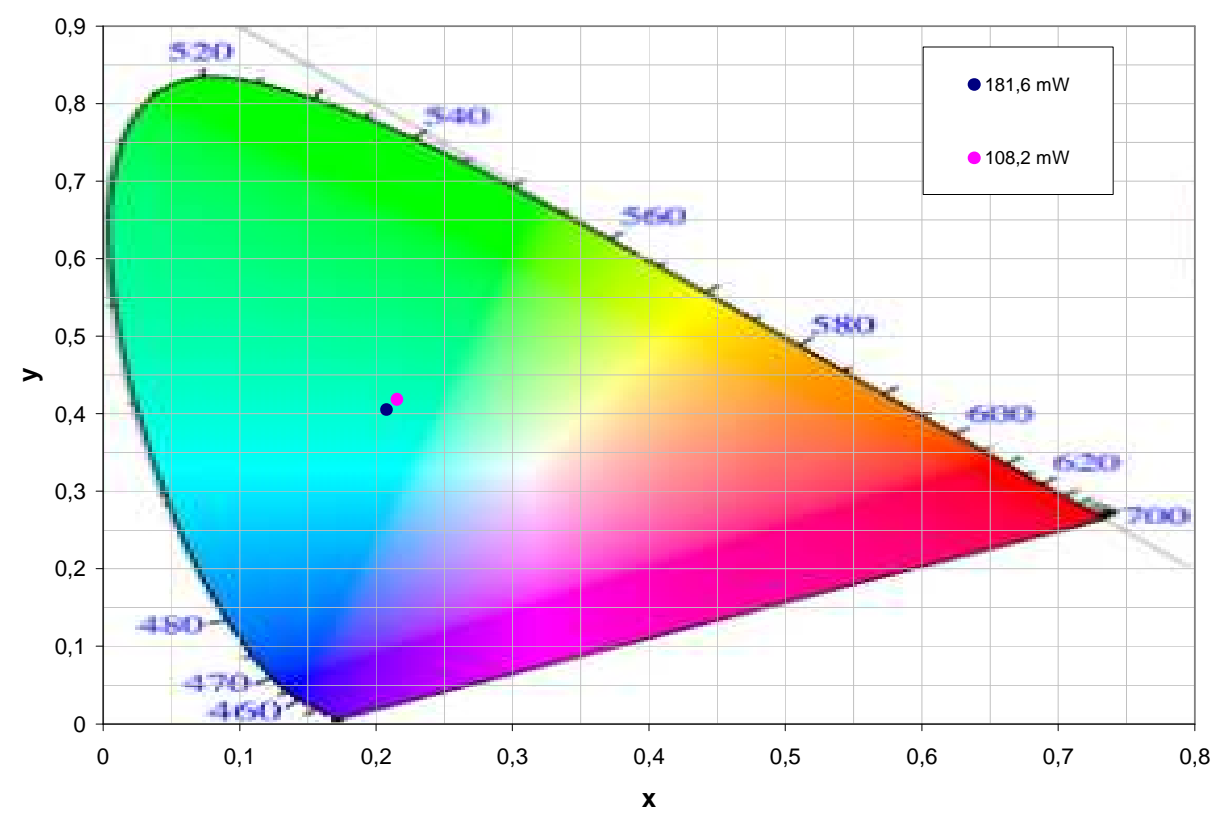

Figura 62 - Diagrama de cromaticidade das $\mathrm{T} 1$ - 0,5\% $\mathrm{Er}_{2} \mathrm{O}_{3}-0,5 \% \mathrm{Tm}_{2} \mathrm{O}_{3}-3,0 \% \mathrm{Yb}_{2} \mathrm{O}_{3}, \mathrm{com}$ diferente potência de excitação. 
Os resultados anteriores mostram pequena influência da potência na cor emitida resultante.

$\mathrm{Na}$ figura a seguir apresentamos os resultados decorrentes da variação da potência do laser de excitação para amostras com $0,5 \mathrm{Er}_{2} \mathrm{O}_{3}-0,5 \% \mathrm{Tm}_{2} \mathrm{O}_{3}$ $3,0 \% \mathrm{Yb}_{2} \mathrm{O}_{3}$.

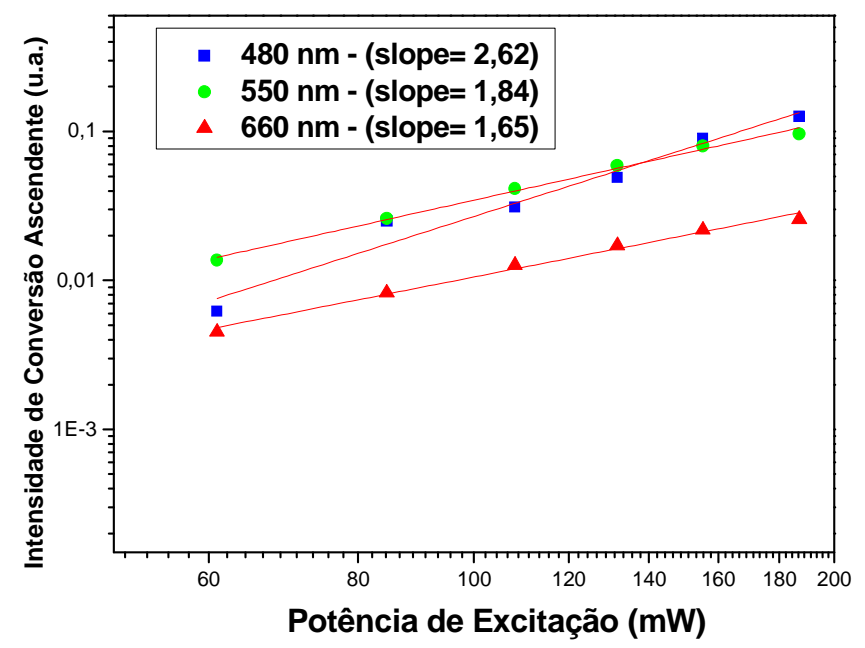

Figura 63 - Intensidade de conversão ascendente em função da potência de excitação da amostra $0,5 \% \mathrm{Er}_{2} \mathrm{O}_{3}-0,5 \% \mathrm{Tm}_{2} \mathrm{O}_{3}-3,0 \% \mathrm{Yb}_{2} \mathrm{O}_{3}$.

Os resultados anteriores mostram que para as emissões em 480 nm há participação de 3 fótons e para as emissões em 550 e 660 nm, 2 fótons no processo de conversão ascendente.

As figuras a seguir mostram os resultados das amostras pertencentes ao Grupo B, com a variação da concentração de $\mathrm{Yb}_{2} \mathrm{O}_{3}(2,0 \%$ a 5,0\% em peso) para a amostra com $0,5 \% \mathrm{Er}_{2} \mathrm{O}_{3}-0,25 \% \mathrm{Tm}_{2} \mathrm{O}_{3}$. Conforme mencionado anteriormente a transferência do itérbio para o érbio é mais eficiente para a conversão ascendente do érbio para concentrações de $\mathrm{YB}_{2} \mathrm{O}_{3}$ superiores a $3,0 \%$. Para a conversão ascendente do túlio notamos o que foi observado anteriormente, isto é, que transferência de energia do íon de itérbio para os íons de érbio e túlio é predominante em relação ao fenômeno conversão ascendente do estado excitado. 


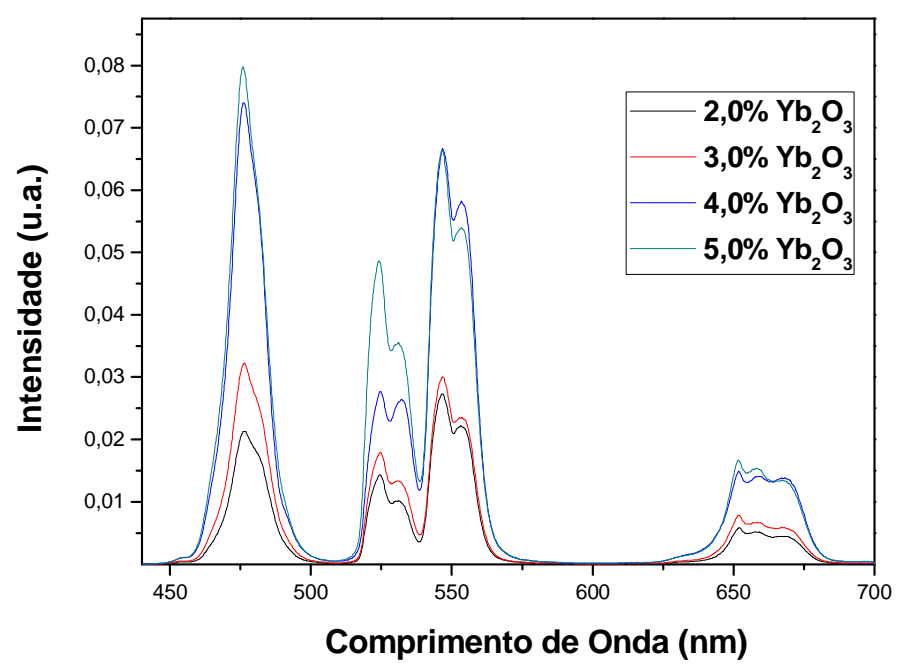

Figura 64 - Espectros de emissão no visível da amostra do Grupo B com potência de excitação de $181,6 \mathrm{~mW}$.

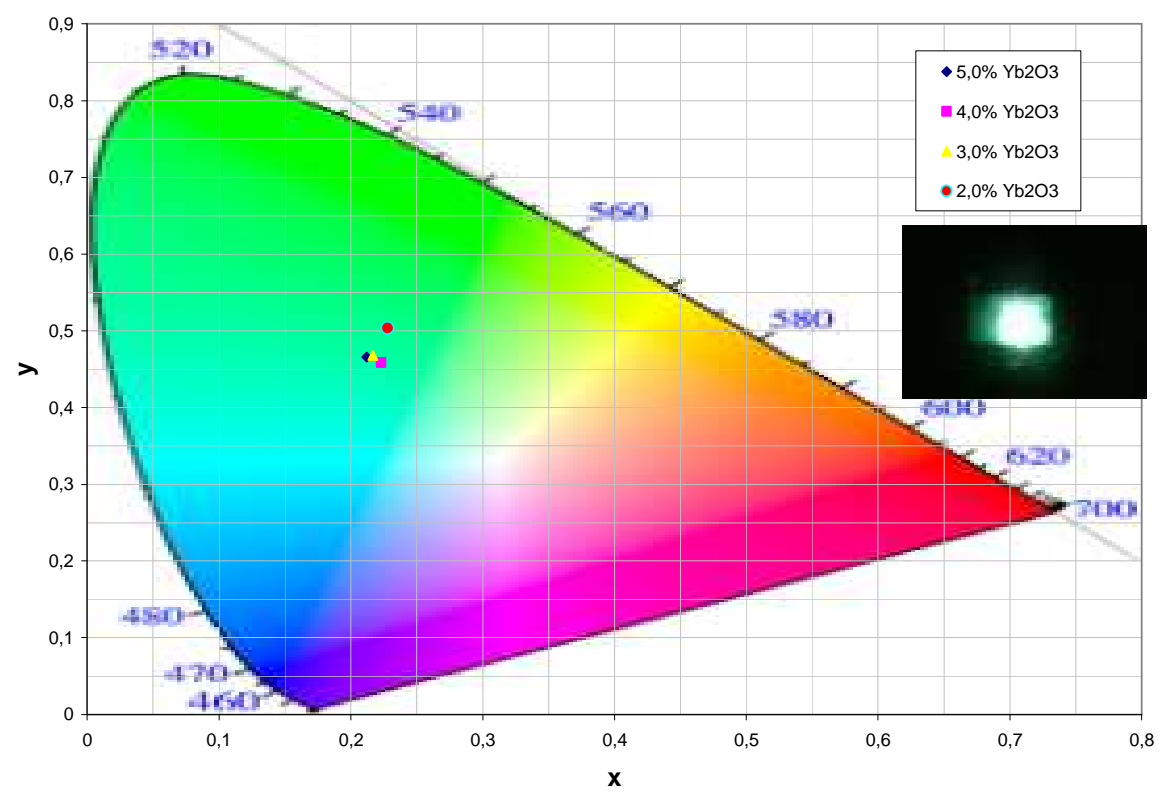

Figura 65 - Diagrama de CIE e fotografia das amostras do Grupo B com potência de excitação de $181,6 \mathrm{~mW}$.

Os resultados do estudo da emissão em função da concentração de $\mathrm{Yb}_{2} \mathrm{O}_{3}$ para emissões do $\mathrm{Er}^{3+}$ e $\mathrm{Tm}^{3+}$ são mostrados a seguir. 


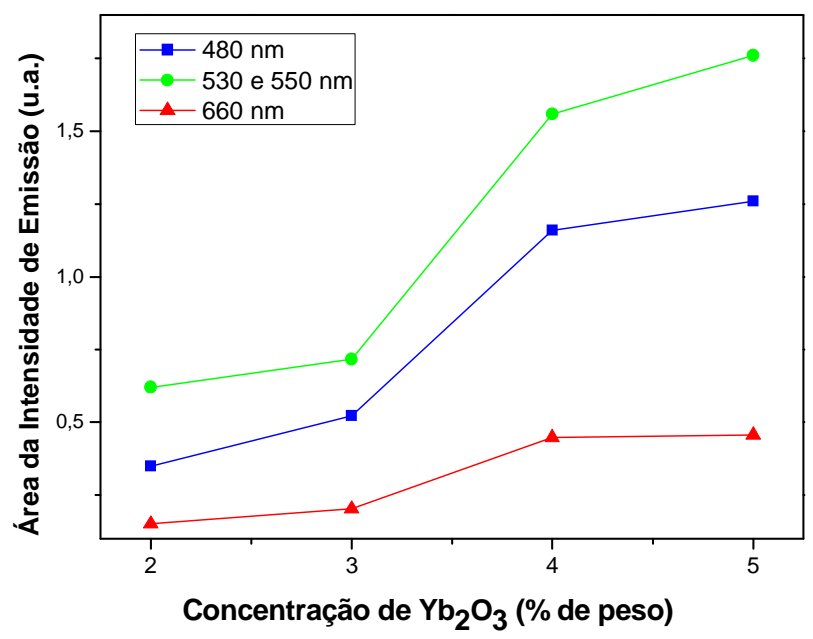

Figura 66 - Integral da intensidade de emissão em função da concentração de $\mathrm{Yb}_{2} \mathrm{O}_{3}$ das amostras do Grupo B

Nas figuras acima, observa-se o aumento das emissões dos íons de $\mathrm{Er}^{3+}$ e $\mathrm{Tm}^{3+}$ com o aumento da concentração de $\mathrm{Yb}_{2} \mathrm{O}_{3}$, conforme foi também observado para as amostras codopadas mostradas anteriormente. No diagrama de cromaticidade $\mathrm{CIE}$ observa-se que a amostra com 4,0\% de $\mathrm{Yb}_{2} \mathrm{O}_{3}$ apresentou emissão com intensidade mais próxima da cor branca do que a amostra com 2,0\% de $\mathrm{Yb}_{2} \mathrm{O}_{3}$. Acrescenta-se o fato de que para excitação em $980 \mathrm{~nm}, 0 \mathrm{Tm}^{3+}$ necessita de um doador $\left(\mathrm{Yb}^{3+}\right)$ de energia, sendo que a emissão do azul $(480 \mathrm{~nm})$ é dependente da concentração de $\mathrm{Yb}^{3+}$ nas amostras.

A seguir, são analisadas emissões das amostras do Grupo C, para potência de excitação de 181,6 mW.

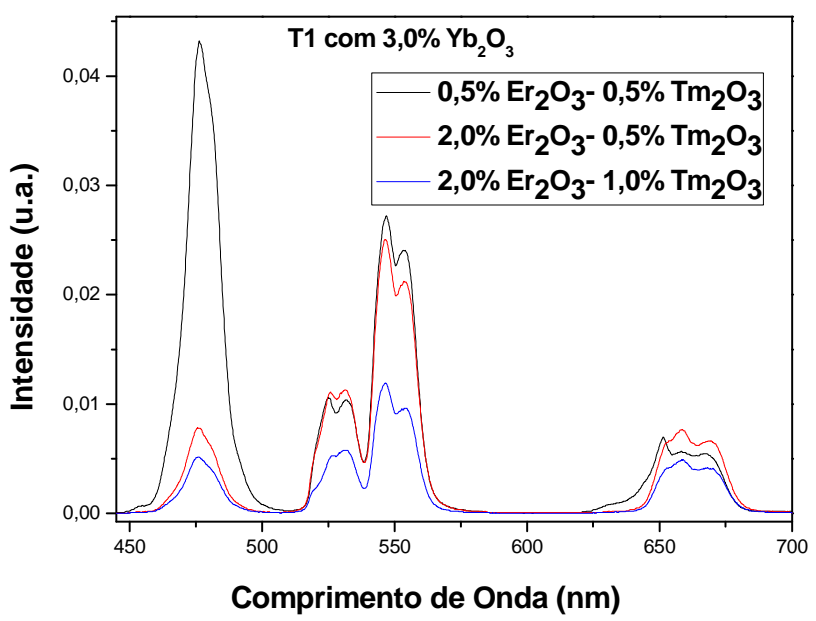

Figura 67 - Espectros de emissão no visível da amostra tridopadas do (Grupo C) com potência de excitação $181,6 \mathrm{~mW}$. 


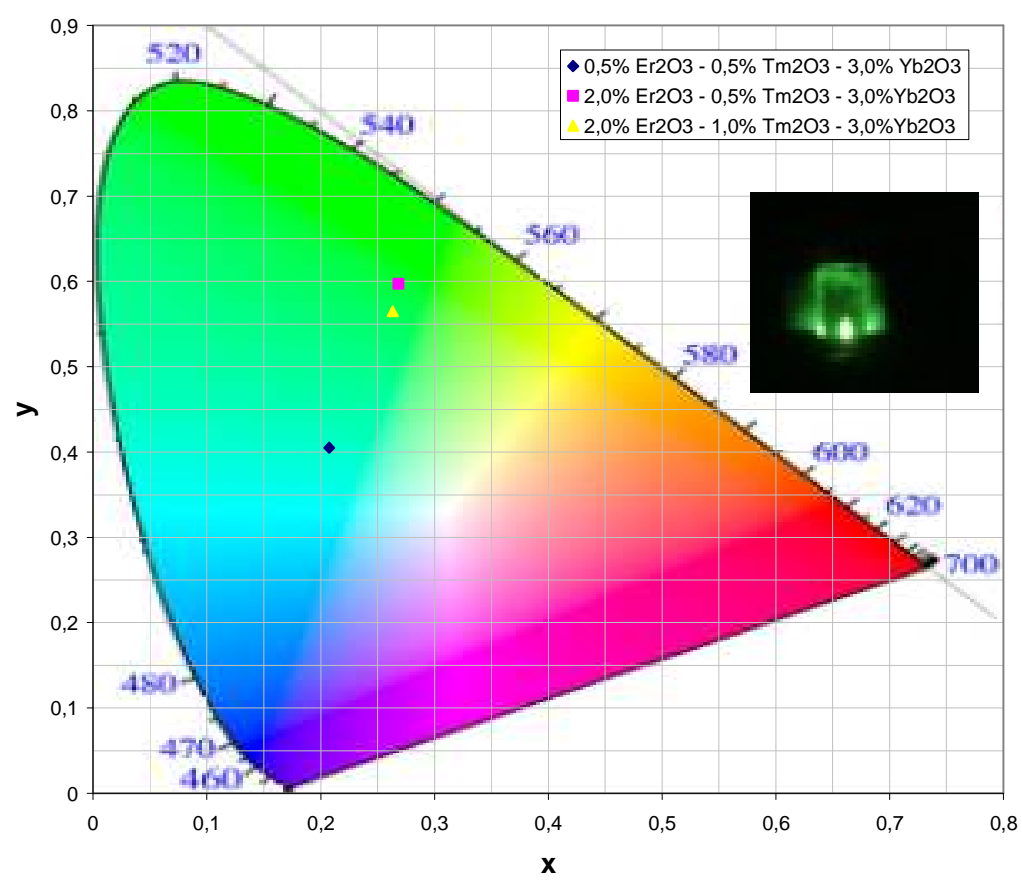

Figura 68 - Diagrama de CIE das amostras do Grupo C com potência de excitação de 181,6 $\mathrm{mW}$ e fotografia da amostra $2,0 \% \mathrm{Er}_{2} \mathrm{O}_{3}-1,0 \% \mathrm{Tm}_{2} \mathrm{O}_{3}-3,0 \% \mathrm{Yb}_{2} \mathrm{O}_{3}$.

Nas figuras acima, observa-se que a emissão das amostras com $0,5 \% \mathrm{Er}_{2} \mathrm{O}_{3}-0,5 \% \mathrm{Tm}_{2} \mathrm{O}_{3}-3,0 \% \mathrm{Yb}_{2} \mathrm{O}_{3}$ é a que apresenta maior aumento da emissão da luz azul em relação às outras emissões, mesmo com concentração de $0,5 \%$ de $\mathrm{Tm}_{2} \mathrm{O}_{3}$, evidenciando que o aumento da concentração de $\mathrm{Er}^{3+}$ diminui a emissão em 530 e $550 \mathrm{~nm}$ e também em $480 \mathrm{~nm}$, pois foi verificado ocorre quenching de concentração (diminuição da intensidade de emissão).

Nas figuras abaixo são apresentas as emissão e cores emitidas das respectivas amostras do Grupo $\mathrm{C}$ as, $2,0 \% \mathrm{Er}_{2} \mathrm{O}_{3}-0,5 \% \mathrm{Tm}_{2} \mathrm{O}_{3}-3,0 \% \mathrm{Yb}_{2} \mathrm{O}_{3}$ e $2,0 \% \mathrm{Er}_{2} \mathrm{O}_{3}-1,0 \% \mathrm{Tm}_{2} \mathrm{O}_{3}-3,0 \% \mathrm{Yb}_{2} \mathrm{O}_{3}$ para diferentes potências de excitação $(108,2$ e $181,6 \mathrm{~mW})$ 


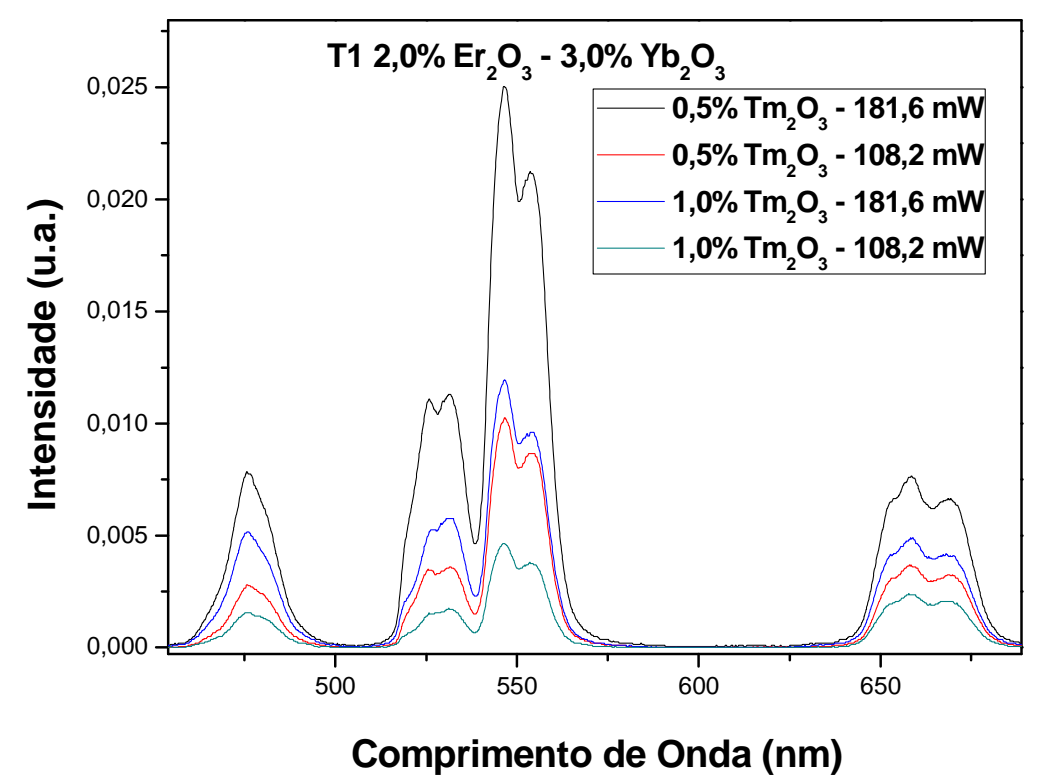

Figura 69 - Espectros de emissão no visível da amostra T1 tridopada com 2,0\% $\mathrm{Er}_{2} \mathrm{O}_{3}$ $3,0 \% \mathrm{Yb}_{2} \mathrm{O}_{3}$ com diferentes concentrações de $\mathrm{Tm}_{2} \mathrm{O}_{3}$ e potência de excitação.

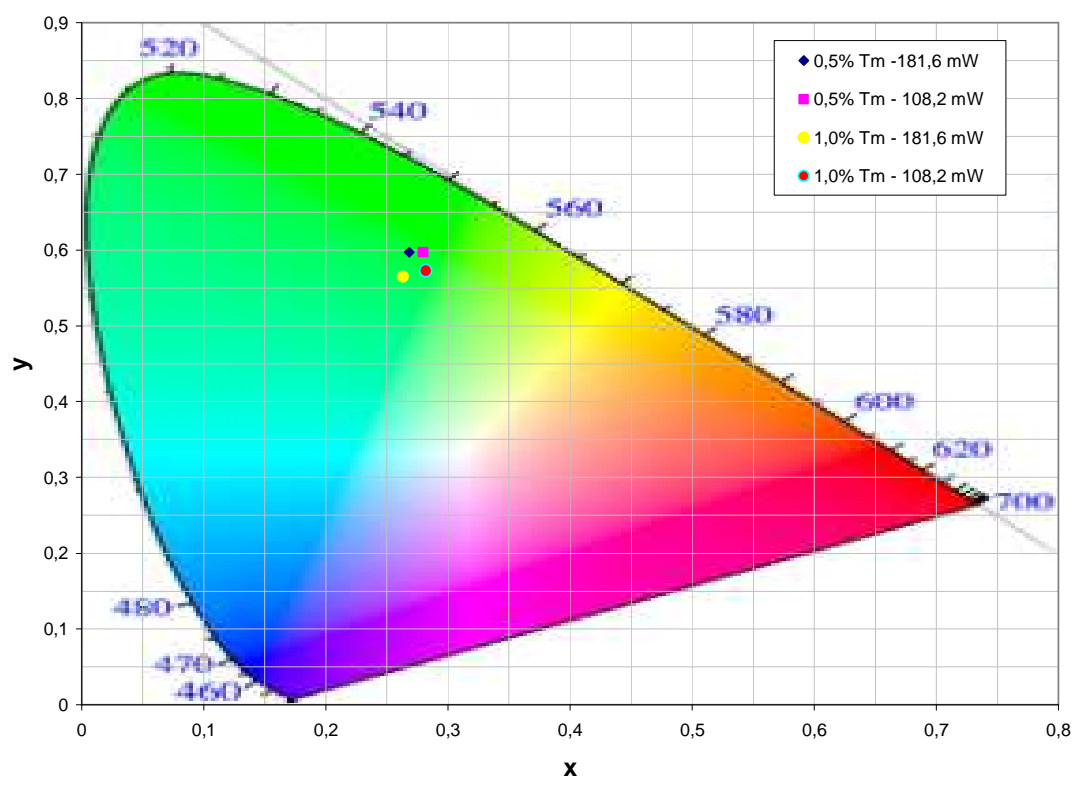

Figura 70 - Diagrama de cromaticidade da amostra T1 tridopada com 2,0\% $\mathrm{Er}_{2} \mathrm{O}_{3}-3,0 \% \mathrm{Yb}_{2} \mathrm{O}_{3}$ com diferentes concentrações de $\mathrm{Tm}_{2} \mathrm{O}_{3}$ e potências de excitação.

Podemos observar em todos os casos aumento das emissões em 530 e $550 \mathrm{~nm}$ quando comparadas com outros resultados o que decorre do aumento da concentração de $\mathrm{Er}_{2} \mathrm{O}_{3}$. Tal fato pode também ser observado no gráfico de 
cromaticidade no qual todos resultados de emissão afastam-se da cor branca. Notamos ainda que a diminuição da concentração de $\mathrm{Tm}_{2} \mathrm{O}_{3}$ causa emissão da luz azul, verde e vermelha com maior intensidade. Na Figura 70 notamos o deslocamento da coordenada x para a direita à medida que a potência é diminuída. Isto significa que a intensidade da luz verde é diminuída ocasionando, assim a predominância da luz vermelha.

Apresentamos os resultados das medidas feitas com a variação de potência do laser de excitação, onde notamos a participação de 3 fótons para a conversão ascendente do $\mathrm{Tm}^{3+}$ e de 2 fótons para a do $\mathrm{Er}^{3+}$. Estas medidas foram feitas somente para a amostra com 2,0\% $\mathrm{Er}_{2} \mathrm{O}_{3}-1,0 \% \mathrm{Tm}_{2} \mathrm{O}_{3}-3,0 \% \mathrm{Yb}_{2} \mathrm{O}_{3}$ de forma a comprovar os resultados da literatura.

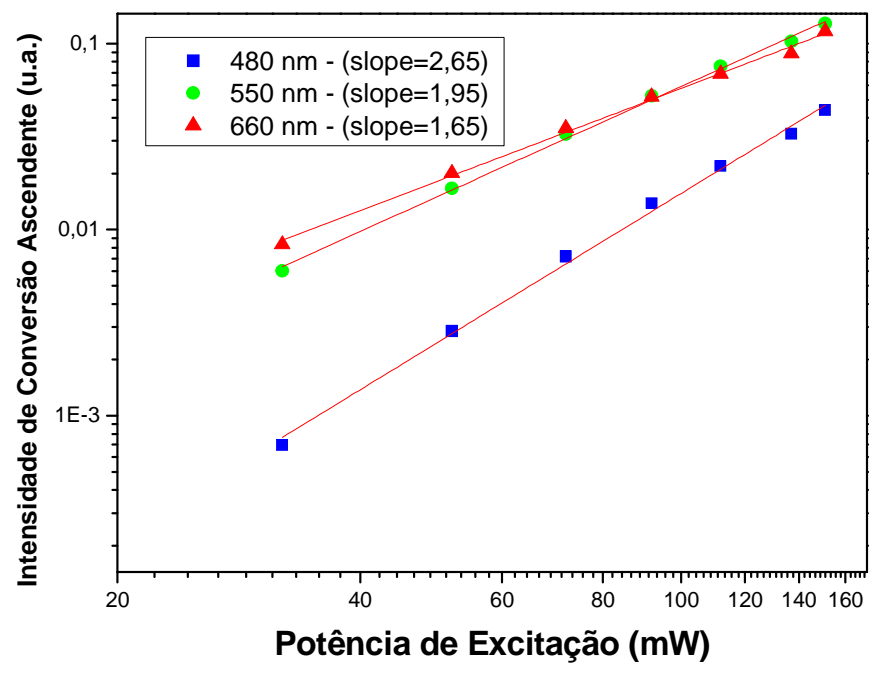

Figura 71 - Intensidade de conversão ascendente em função da potência de excitação da amostra com 2,0\% $\mathrm{Er}_{2} \mathrm{O}_{3}-1,0 \% \mathrm{Tm}_{2} \mathrm{O}_{3}-3,0 \% \mathrm{Yb}_{2} \mathrm{O}_{3}$.

De forma em geral podemos concluir que as amostras tridopadas com $\mathrm{Er}_{2} \mathrm{O}_{3}, \mathrm{Tm}_{2} \mathrm{O}_{3}$ e $\mathrm{Yb}_{2} \mathrm{O}_{3}$ têm aplicações em displays coloridos. Ressalta-se a amostra com 0,5\% $\mathrm{Er}_{2} \mathrm{O}_{3}-0,5 \% \mathrm{Tm}_{2} \mathrm{O}_{3}-3,0 \% \quad \mathrm{Yb}_{2} \mathrm{O}_{3}$ que apresentou a emissão da luz azul esverdeada com coordenadas x e y mais próximas da luz branca dentre todas as amostras estudadas.

$\mathrm{Na}$ figura abaixo é mostrado o espectro de emissão da amostra tridopada com 0,5\% $\mathrm{Er}_{2} \mathrm{O}_{3}-0,15 \% \quad \mathrm{Tm}_{2} \mathrm{O}_{3}-3,0 \% \quad \mathrm{Yb}_{2} \mathrm{O}_{3}$, sendo esta a primeira amostra tridodopada produzida. 


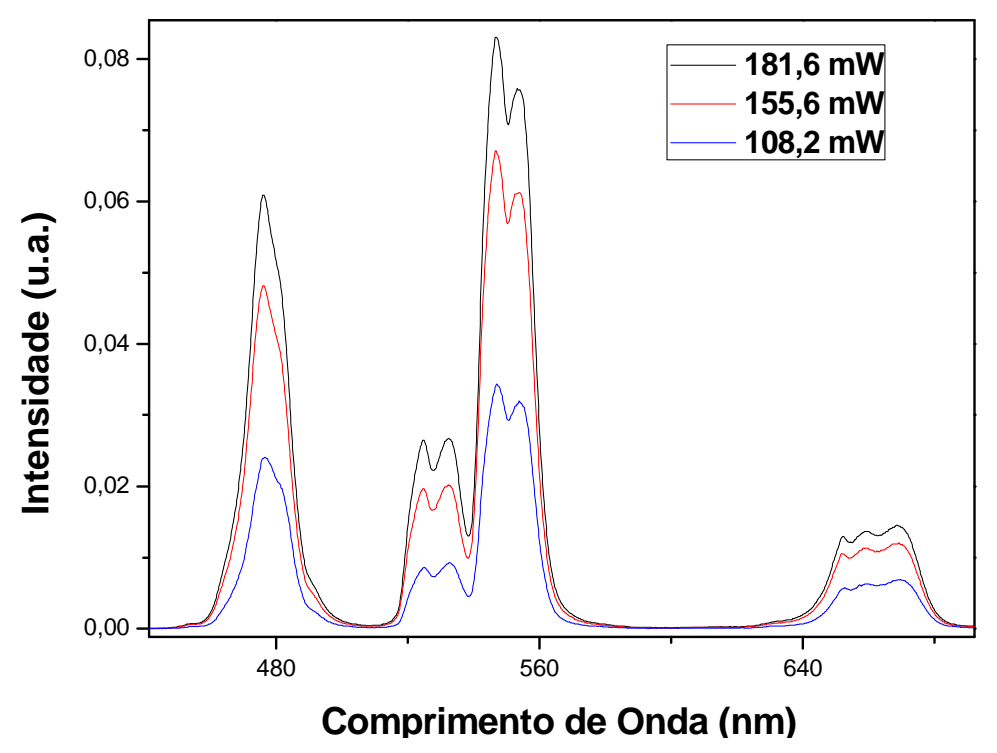

Figura 72 - Espectros de emissão no visível da amostra $\mathrm{T} 1$ tridopada com $0,5 \% \mathrm{Er}_{2} \mathrm{O}_{3}-0,15 \%$ $\mathrm{Tm}_{2} \mathrm{O}_{3}-3,0 \% \mathrm{Yb}_{2} \mathrm{O}_{3}$ com diferentes potências de excitação.

Na figura abaixo é mostrada a gama de cores obtida com a amostra $0,5 \% \mathrm{Er}_{2} \mathrm{O}_{3}-0,5 \% \mathrm{Tm}_{2} \mathrm{O}_{3}-3,0 \% \mathrm{Yb}_{2} \mathrm{O}_{3}$, utilizando um filtro ideal, e sua comparação com o modelo de cromaticidade NTSC obtida na literatura [73].

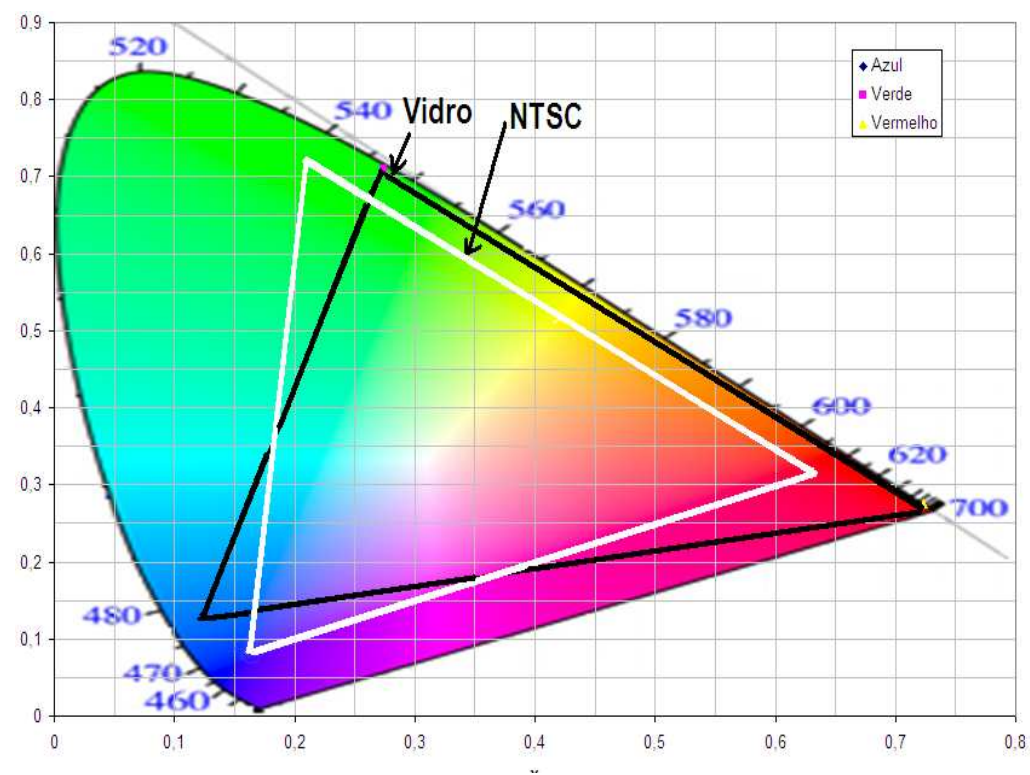

Figura 73 - Diagrama de CIE com o padrões de cromaticidade NTSC e a gama obtida de cores obtida para a amostra $0,5 \% \mathrm{Er}_{2} \mathrm{O}_{3}-0,25 \% \mathrm{Tm}_{2} \mathrm{O}_{3}-3,0 \% \mathrm{Yb}_{2} \mathrm{O}_{3}$, designada como vidro na figura. 
$\mathrm{Na}$ figura acima, observa-se que a gama de cores possível para a amostra $0,5 \% \mathrm{Er}_{2} \mathrm{O}_{3}-0,25 \% \mathrm{Tm}_{2} \mathrm{O}_{3}-3,0 \% \mathrm{Yb}_{2} \mathrm{O}_{3}$, obtida supondo a presença de filtro ideal, está próxima próxima do padrão NTSC. Cabe acrescentar que para todas as amostras tridopadas produzidas neste trabalho, a área de cores obtida é a mesma, pois o que diferencia a emissão de cores são os elementos luminescentes utilizados (íons de terras raras) e a matriz hospedeira, que não foram alteradas. Por este motivo não estão sendo apresentadas.

No padrão NTSC usado para comparação, cada vértice do triângulo, apresenta uma coordenada fixa para as cores vermelha, verde e azul. Caso seja usado para construção de um dispositivo, teremos que obrigatoriamente fazê-lo de forma atender as referidas coordenadas. 


\subsection{VIDROS TRIDOPADOS COM NANOPARTÍCULAS}

As medidas a seguir mostram os resultados das amostras tridopadas preparadas com NPs de prata, onde verificamos a influencia no processo de conversão ascendente. Não foram preparadas amostras com $\mathrm{Au}_{2} \mathrm{O}_{3}$ em decorrência dos resultados menos eficientes obtidos com as amostras codopadas.

\subsubsection{Medida de Absorção Óptica}

Nas figuras a seguir serão mostradas os espectros de absorção das amostras tridopadas com $0,5 \% \mathrm{Er}_{2} \mathrm{O}_{3}-0,25 \% \mathrm{Tm}_{2} \mathrm{O}_{3}-3,0 \% \mathrm{Yb}_{2} \mathrm{O}_{3}-3,0 \% \mathrm{AgNO}_{3}$ e com presença de NPs de prata, para os tempos de nucleação de 2, 24, 48 e 72 horas.

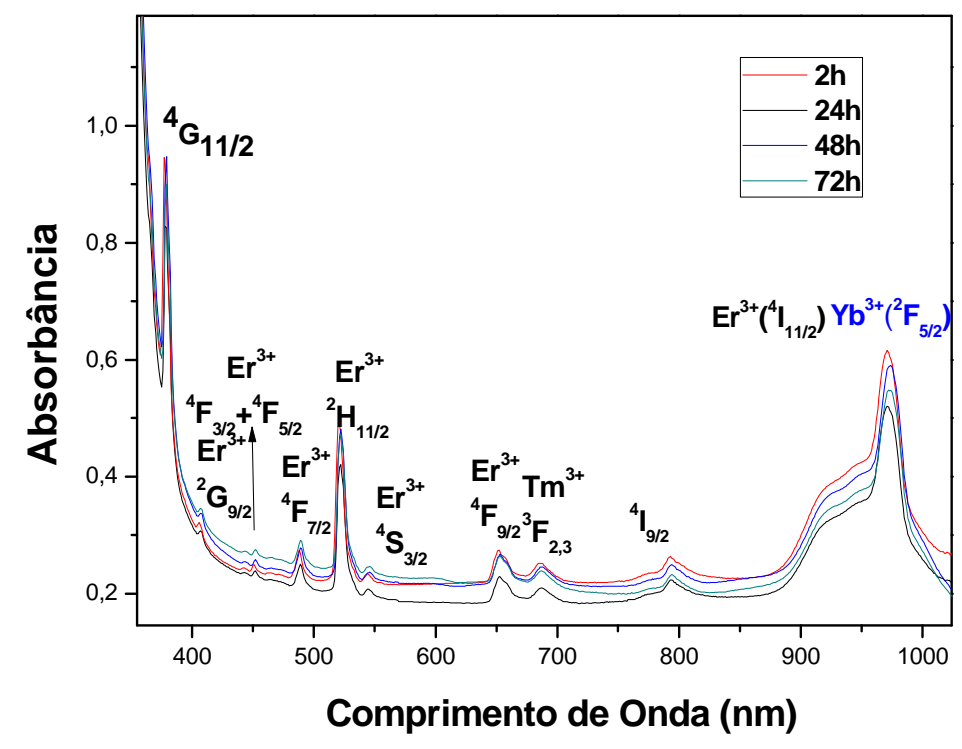

Figura 74 - Espectro de absorção óptica das amostras $\mathrm{T} 1$ tridopadas com $0,5 \% \mathrm{Er}_{2} \mathrm{O}_{3}$ $0,25 \% \mathrm{Tm}_{2} \mathrm{O}_{3}-3,0 \% \mathrm{Yb}_{2} \mathrm{O}_{3}-3,0 \% \mathrm{AgNO}_{3}$ para vários períodos de tratamento térmico.

$\mathrm{Na}$ figura acima não se observa a absorção provocadas por banda de plasmon em nenhum dos períodos de tratamento térmico. 


\subsubsection{Medida de Luminescência}

Nos espectros abaixo são apresentadas as emissões da amostra T1 $0,5 \% \mathrm{Er}_{2} \mathrm{O}_{3}-0,25 \% \mathrm{Tm}_{2} \mathrm{O}_{3}-3,0 \% \mathrm{Yb}_{2} \mathrm{O}_{3}-3,0 \% \mathrm{AgNO}_{3}$ para os tempos de nucleação de 2, 24, 48, 72 e potencias de 108,6 e 181,2 mW

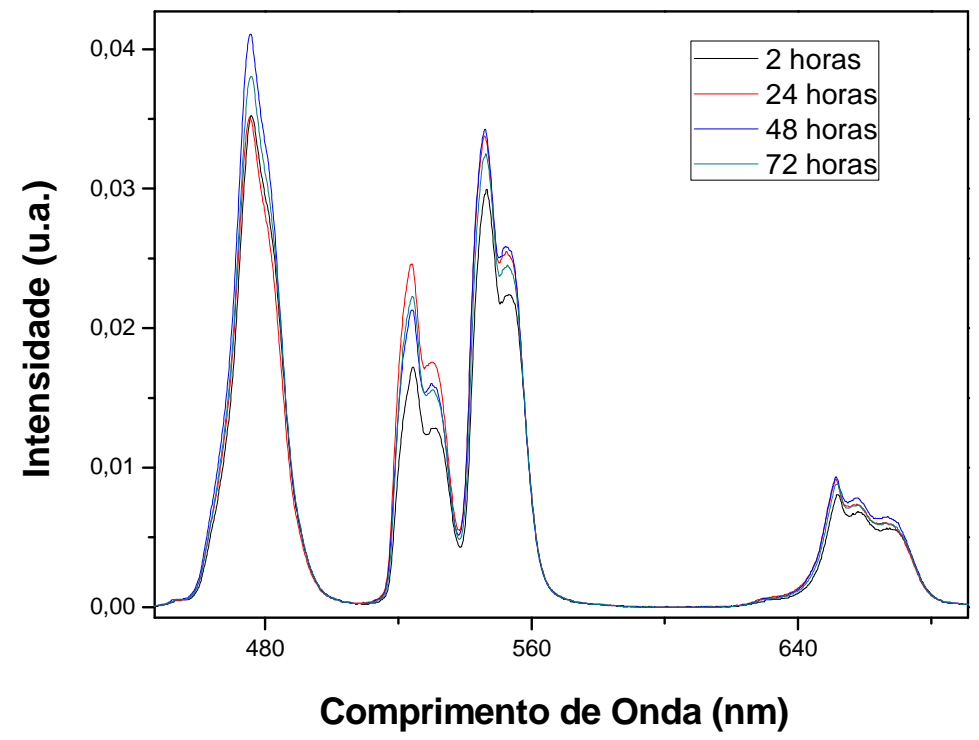

Figura 75 - Espectros de emissão no visível da amostra $\mathrm{T} 1$ com $0,5 \% \mathrm{Er}_{2} \mathrm{O}_{3}-0,25 \% \mathrm{Tm}_{2} \mathrm{O}_{3}$ $3,0 \% \mathrm{Yb}_{2} \mathrm{O}_{3}-3,0 \% \mathrm{AgNO}_{3}$ para potencia de $181,6 \mathrm{~mW}$.

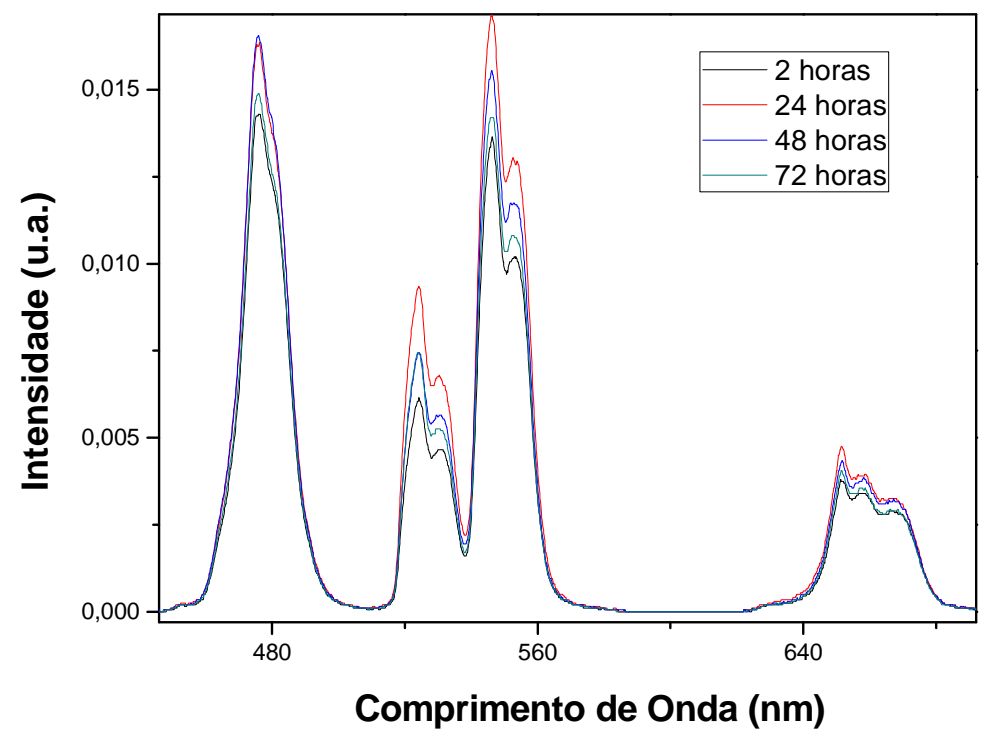

Figura 76 - Espectros de emissão no visível da amostra $\mathrm{T} 1$ com $0,5 \% \mathrm{Er}_{2} \mathrm{O}_{3}-0,25 \% \mathrm{Tm}_{2} \mathrm{O}_{3}$ $3,0 \% \mathrm{Yb}_{2} \mathrm{O}_{3}-3,0 \% \mathrm{AgNO}_{3}$ para potencia de $108,2 \mathrm{~mW}$. 
Comparando os resultados anteriores notamos que a emissão da luz verde do $\mathrm{Er}^{3+}$ foi mais afetada para a potência de 108,6 mW. As demais emissões foram igualmente afetadas quando comparados os resultados provenientes das diferentes potências do laser utilizadas

Observamos que ocorreu aumento na luminescência para as duas potências de excitação analisadas, sendo mais expressiva para os tempos de nucleação de 24 horas e 48 horas.

Pelo digrama de cromaticidade e as fotografias da Figura 77 observamos pequenas alterações nas cores emitidas pelas amostras com a variação do tempo de nucleação.

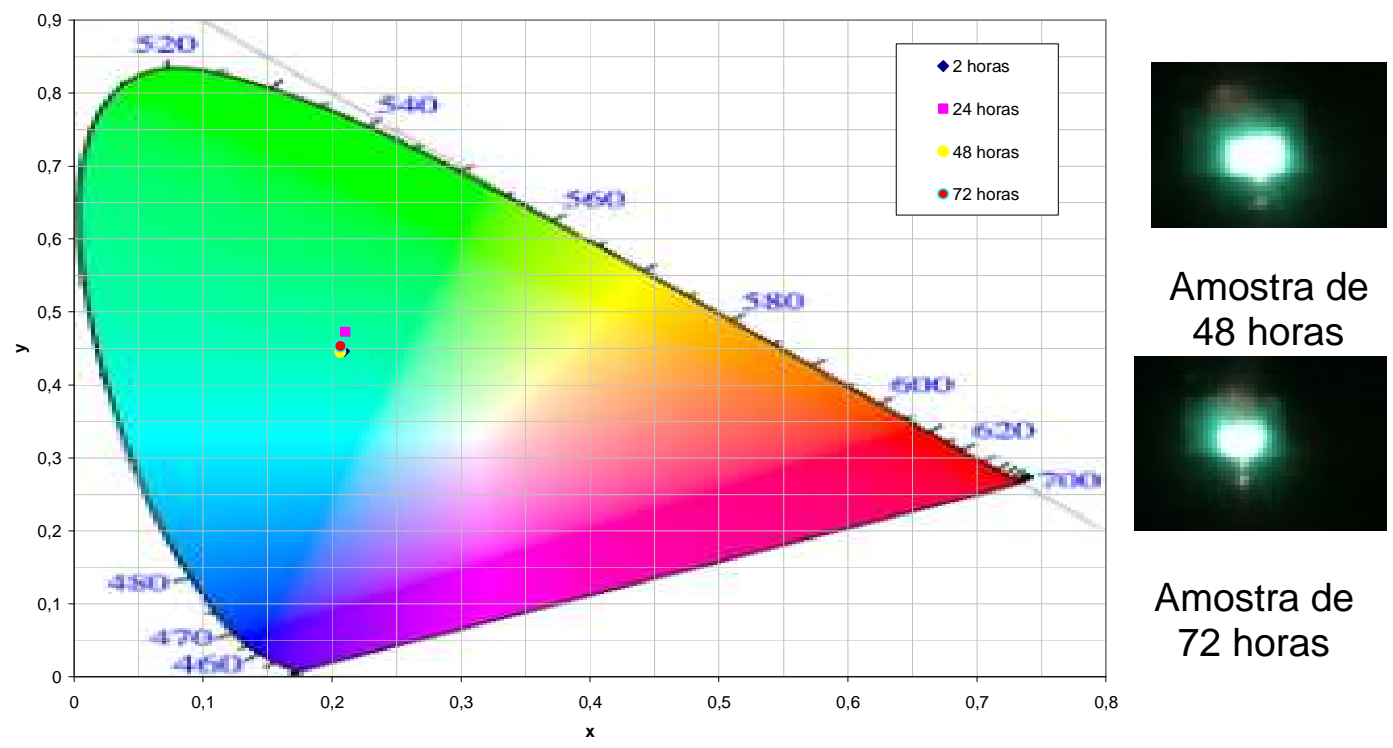

Figura 77 - Diagrama de cromaticidade e fotografia da amostra T1 tridopada com $0,5 \% \mathrm{Er}_{2} \mathrm{O}_{3}$ $0,25 \% \mathrm{Tm}_{2} \mathrm{O}_{3}-3,0 \% \mathrm{Yb}_{2} \mathrm{O}_{3}-3,0 \% \mathrm{AgNO}_{3}$ para potência de excitação de $181,6 \mathrm{~mW}$ e para diferentes períodos de nucleação.

Os resultados obtidos com a variação da potência do laser de excitação mostram o mesmo fenômeno observado anteriormente com a participação de 3 fótons para a conversão ascendente do $\mathrm{Tm}^{3+}$ e 2 fotons para o $\mathrm{Er}^{3+}$. 


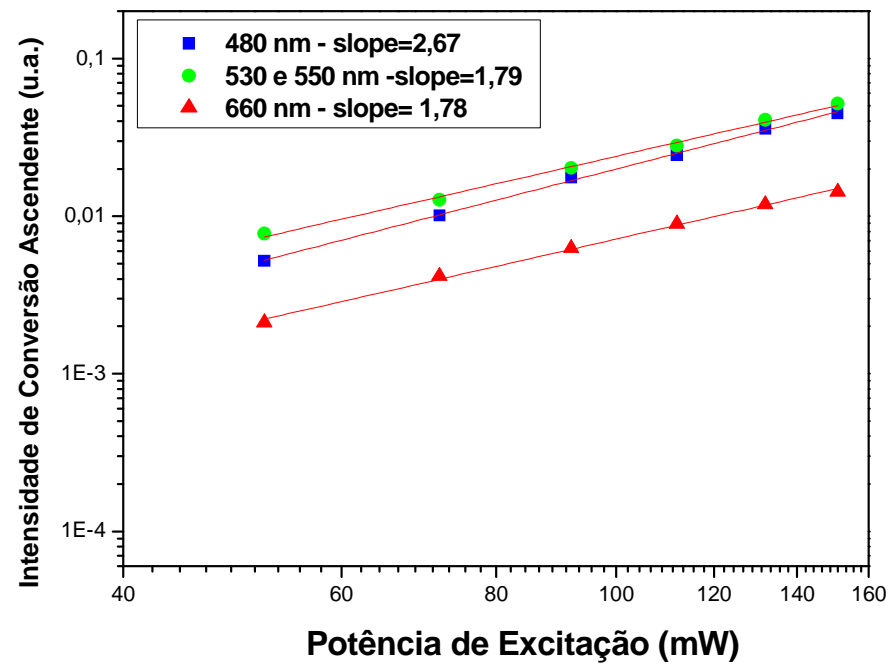

Figura 78 - Intensidade de conversão ascendente em função da potência de excitação da amostra $0,5 \% \mathrm{Er}_{2} \mathrm{O}_{3}-0,25 \% \mathrm{Tm}_{2} \mathrm{O}_{3}-3,0 \% \mathrm{Yb}_{2} \mathrm{O}_{3}-3,0 \% \mathrm{AgNO}_{3}$ para período de nucleação de 72 horas.

Na figura abaixo é mostrada a distribuição e formas das possíveis fases cristalinas de prata formadas na amostra $0,5 \% \mathrm{Er}_{2} \mathrm{O}_{3}-0,25 \% \mathrm{Tm}_{2} \mathrm{O}_{3}-3,0 \% \mathrm{Yb}_{2} \mathrm{O}_{3}-$ $3,0 \% \mathrm{AgNO}_{3}$. $\mathrm{O}$ tamanho médio das esferas formadas apresentou diâmetro médio de $8 \mathrm{~nm}$.

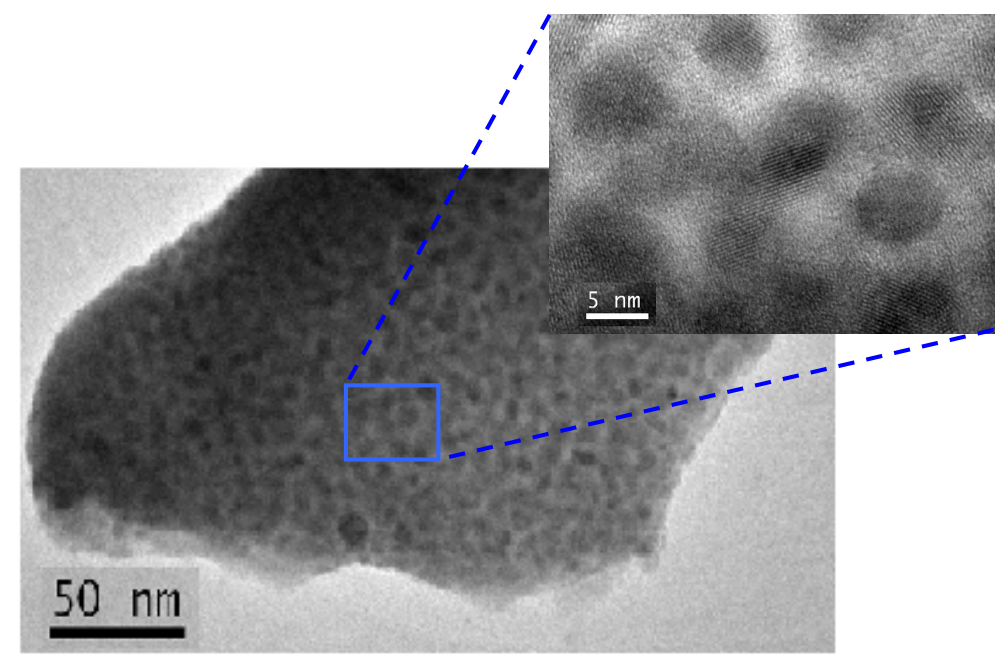

Figura 79 - Micrografia das amostras $\mathrm{T} 1 \mathrm{com} 0,5 \% \mathrm{Er}_{2} \mathrm{O}_{3}-0,25 \% \mathrm{Tm}_{2} \mathrm{O}_{3}-3,0 \% \mathrm{Yb}_{2} \mathrm{O}_{3}-3,0 \% \mathrm{AgNO} 3$ para período de nucleação de 72 horas. 
$\mathrm{Na}$ figura abaixo são mostrados os resultados da amostra 2,0\% $\mathrm{Er}_{2} \mathrm{O}_{3^{-}}$ $0,25 \% \mathrm{Tm}_{2} \mathrm{O}_{3}-3,0 \% \mathrm{Yb}_{2} \mathrm{O}_{3}-3,0 \% \mathrm{AgNO}_{3}$ para diferentes períodos de nucleação. Podemos observar que o aumento da concentração de $\mathrm{Er}_{2} \mathrm{O}_{3}$ causou aumento significativo da emissão do $\mathrm{Er}^{3+}$. Observamos ainda que o aumento do tratamento térmico só causa influência na emissão da luz verde.

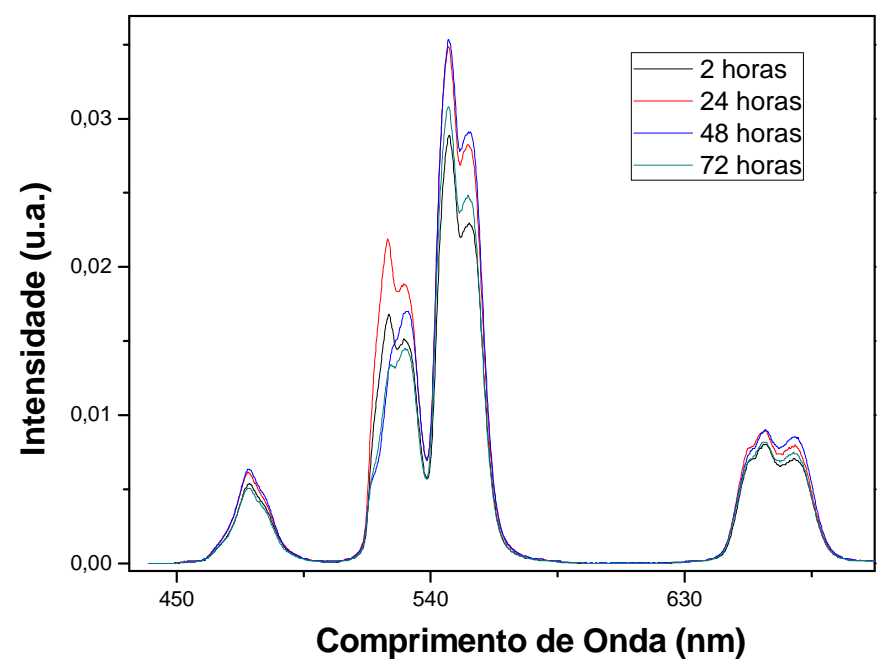

Figura 80 - Espectros de emissão no visível da amostra $\mathrm{T} 1$ com 2,0\% $\mathrm{Er}_{2} \mathrm{O}_{3}-0,25 \% \mathrm{Tm}_{2} \mathrm{O}_{3}$ $3,0 \% \mathrm{Yb}_{2} \mathrm{O}_{3}-3,0 \% \mathrm{AgNO}_{3}$ para potência de $108,2 \mathrm{~mW}$.

A cor da luz emitida neste caso, o verde, não é alterada quando comparado com o tratamento térmico de 2 horas com o de 72 horas.

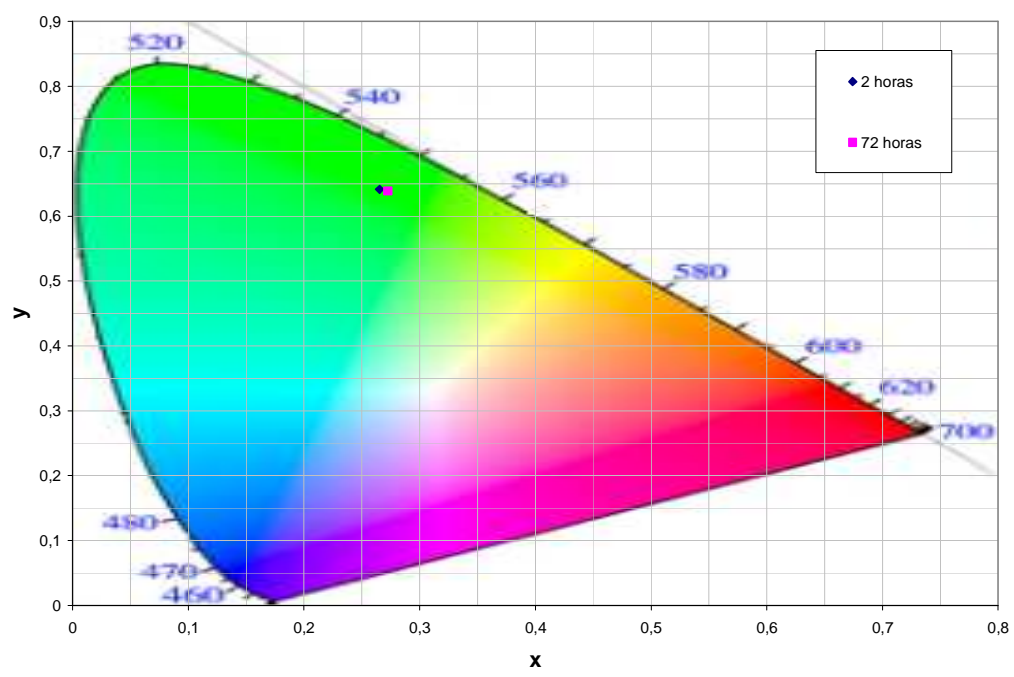

Figura 81 - Diagrama de cromaticidade da amostra $\mathrm{T} 1$ com 2,0\% $\mathrm{Er}_{2} \mathrm{O}_{3}-0,25 \% \mathrm{Tm}_{2} \mathrm{O}_{3}$ $3,0 \% \mathrm{Yb}_{2} \mathrm{O}_{3}-3,0 \% \mathrm{AgNO}_{3}$ para potência de excitação de $181,6 \mathrm{~mW}$ e para diferentes períodos de nucleação. 
Na figura abaixo é mostrada a distribuição e tamanho da fase cristalina de prata formada na amostra com 2,0\% $\mathrm{Er}_{2} \mathrm{O}_{3}-0,25 \% \mathrm{Tm}_{2} \mathrm{O}_{3}-3,0 \% \mathrm{Yb}_{2} \mathrm{O}_{3}$ $3,0 \% \mathrm{AgNO}_{3}$ com 72 de tratamento térmico; as possíveis NPs de prata formadas apresentaram tamanho médio de $8 \mathrm{~nm}$.

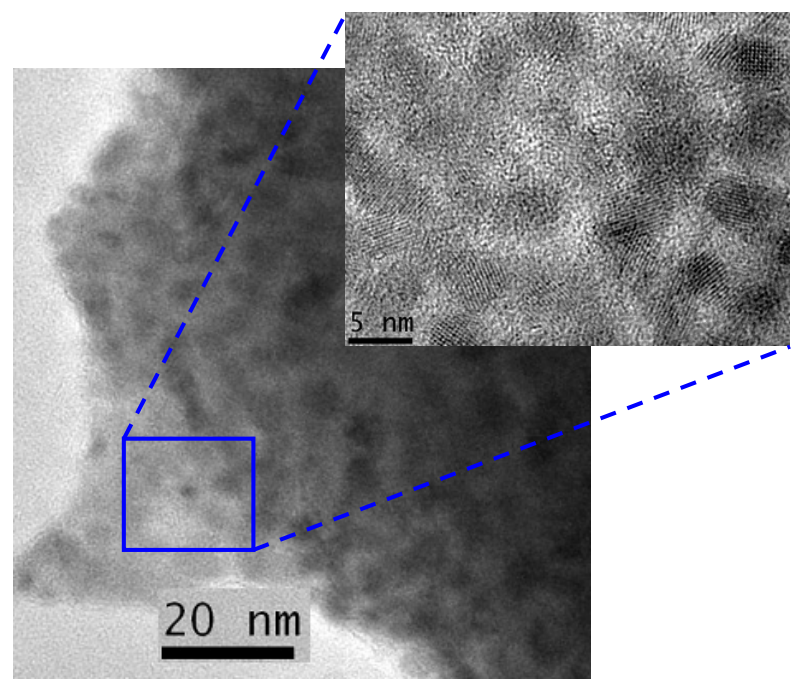

Figura 82 - Micrografia das amostras $\mathrm{T} 1 \mathrm{com} 2,0 \% \mathrm{Er}_{2} \mathrm{O}_{3}-0,25 \% \mathrm{Tm}_{2} \mathrm{O}_{3}-3,0 \% \mathrm{Yb}_{2} \mathrm{O}_{3}-3,0 \% \mathrm{AgNO}_{3}$ para período de nucleação de 72 horas.

De forma geral a amostra com 2,0\% $\mathrm{Er}_{2} \mathrm{O}_{3}-0,25 \% \mathrm{Tm}_{2} \mathrm{O}_{3}-3,0 \% \mathrm{Yb}_{2} \mathrm{O}_{3}-$ $3,0 \% \mathrm{AgNO}_{3}$ não apresentou alteração significativa na presença de NPs de prata. 


\section{CONCLUSÕES}

Os resultados obtidos mostram que o sistema vítreo estudado apresenta propriedades e características interessantes para as aplicações sugeridas.

O estudo realizado permitiu analisar o fenômeno da luminescência proveniente da incorporação dos íons de terras raras (érbio, túlio e itérbio) em diversas concentrações bem como a interferência de NPs metálicas nos processos de emissão de luz.

$\mathrm{O}$ aumento da concentração de $\mathrm{Yb}^{3+}$ nos vidros com $\mathrm{Er}^{3+}$ e $\mathrm{Yb}^{3+}$ favoreceu o aumento da luminescência na região do visível. O processo de conversão ascendente se deu por meio da absorção de dois fótons para as emissões de luz verde e vermelha.

Nas amostras codopadas com NPs metálicas, observou-se a interferência das NPs metálicas, sobretudo para as que foram produzidas com prata nas quais houve aumento de $\sim 50 \%$ para as emissões de 530 e $550 \mathrm{~nm}$. Ressalta-se ainda que em todos os casos a presença de NPs não alterou o número de fótons (2) que participou do processo de conversão ascendente do $\mathrm{Er}^{3+}$ e que as emissões em $660 \mathrm{~nm}$ não foram afetadas pela presença das NPs metálicas, por estarem afastadas dos comprimentos de onda de absorção dos plamons das NPs. Para as tridopadas preparadas com NPs metálicas não houve nenhuma interferência do tratamento térmico que mereça destaque.

Nas amostras tridopadas com $\mathrm{Er}_{2} \mathrm{O}_{3}, \mathrm{Tm}_{2} \mathrm{O}_{3}$ e $\mathrm{Yb}_{2} \mathrm{O}_{3}$ e sem NPs metálicas observou-se a dependência da concentração dos dopantes e da potência de excitação nas emissões das cores obtidas, sendo esses parâmetros indispensáveis para análise das emissões das cores.

Destaca-se a amostra produzida com $0,5 \% \mathrm{Er}_{2} \mathrm{O}_{3}-0,5 \% \mathrm{Tm}_{2} \mathrm{O}_{3^{-}}$ $3,0 \% \mathrm{Yb}_{2} \mathrm{O}_{3}$ com aplicações para display de luz azul esverdeada que apresentou-se mais próxima da região que caracteriza a luz branca no diagrama CIE dentre todas as amostras produzidas. Nestas amostras tridopadas a emissão de luz se dá por meio de processo de conversão ascendente com a participação de 3 fótons para a luz emitida pelo $\mathrm{Tm}^{3+}$ e de fótons para a luz emitida pelo $\mathrm{Er}^{3+}$. Ressalta-se ainda que em todas as amostras tridopadas o aumento da potência de excitação favorece o aumento 
da emissão da luz azul e a diminuição da emissão da luz verde e vermelha. Cabe acrescentar que como foi possível obter as cores primárias por meio das amostras tridopadas é possível construir, através de filtros ópticos, displays coloridos e para obtenção da luz branca, a amostra promissora para este fim é a $0,5 \% \mathrm{Er}_{2} \mathrm{O}_{3}-0,5 \% \mathrm{Tm}_{2} \mathrm{O}_{3}-3,0 \% \mathrm{Yb}_{2} \mathrm{O}_{3}$.

Concluímos que o sistema $\mathrm{T} 1$ preparado com $\mathrm{Er}_{2} \mathrm{O}_{3}, \mathrm{Tm}_{2} \mathrm{O}_{3}$ e $\mathrm{Yb}_{2} \mathrm{O}_{3}$ pode ser empregado na fabricação de displays coloridos, a partir do principio de conversão ascendente. 


\section{CONTINUIDADE DO TRABALHO}

Sugere-se o preparo de amostras tridopadas com outras concentrações de íons de terras-raras de forma a tentar obter a emissão da luz branca.

Sugere-se ainda a produção de filmes finos de telureto tridopados com íons de terras-raras depositados sobre LED de emissão no infravermelho e sobre substratos de vidros transparentes para construção de displays coloridos.

\section{PUBLICAÇÕES EM PERIÓDICOS}

L. R. P. Kassab, M. E. Camilo, C. T. Amâncio, D. M. da Silva, J. R. Martinelli. Effects of Gold Nanoparticles in the Green and Red Emissions of $\mathrm{TeO}_{2}-\mathrm{PbO}-$ $\mathrm{GeO}_{2}$ Glasses Doped with $\mathrm{Er}^{3+}-\mathrm{Yb}^{3+}$ - Aprovado para publicação: Optical Materials em março de 2011.

Amâncio C. T., Assumpção T.A. A., Kassab L. R. P. "Three Color Upconversion Luminescence of $\mathrm{Er}^{3+} / \mathrm{Yb}^{3+} / \mathrm{Tm}^{3+}$ Doped Tellurite Glass for Applications with Displays" Journal of the Electrochemical Society, 2010.

J. Jakutis, L. Gomes, C.T. Amancio, L.R.P. Kassab, J.R. Martinelli, N.U. Wetter "Increased $\mathrm{Er}^{3+}$ upconversion in tellurite fibers and glasses by co-doping with Yb茾" Optical Materials 33 (2010) 107-111.

\section{PARTICIPAÇÃO EM CONGRESSOS}

Amâncio C. T., Assumpção T.A. A., Kassab L. R. P. "Three Color Upconversion Luminescence of $\mathrm{Er}^{3+/} \mathrm{Yb}^{3+/} \mathrm{Tm}^{3+}$ Doped Tellurite Glass for Applications with Displays" Chip in Sampa - SBMicro 2010, São Paulo- SP, setembro de 2010. 
Amâncio,C. T., da Silva D. M., Kassab L. R. P., Jakutis Neto J., Wetter N. U., de Araújo C. B. "Green and Red Emissions in Tellurite Glasses Doped with $\mathrm{Er}^{3+} / \mathrm{Yb}^{3+}$ and the influence of Metallic Nanoparticicles" International Congress on Glass 2010, Salvador-BA, setembro de 2010. 


\section{REFERÊNCIAS BIBLIOGRÁFICAS}

[1] Ronda, C. R. Luminescence - From Theory To Applications. Wiley-Vch. 2008;

[2] Krasnov, A. N. Displays 24, 73-79 (2003);

[3] Ronda C. R.; Srivastava A. Luminescence Science and Display Materials The Electrochemical Society Interface - Spring 2006. acessado em http://www.electrochem.org/dl/interface/spr/spr06/spr06_p55-57.pdf - 02/2011;

[4] Idalgo, E.; Araújo, E. B. Propriedades estruturais e térmicas de vidros teluretos $20 \mathrm{Li}_{2} \mathrm{O}-80 \mathrm{TeO}_{2}$. Cerâmica, 53, 325 (2007);

[5] Snitzer, E.; Wang, J.; Vogel, E. M. Tellurite glass and fiber amplifier. Bell Communications Research, Inc. (Livingston, NJ) 5251062 - 1993;

[6] Yasutake O. et al. "Tellurite glass, optical amplifier, and light source" Nippon Telegraph and Telephone Corporation (Shinjuku-ku, JP) 6266181 Tokyo, 2001;

[7] Aitken, B. G.; Ellison A. J. G. Tellurite glasses and optical components. Corning Incorporated (Corning, NY) 6352950, 2002;

[8] Pollack, S. A. Full color upconversion display - United States Hughes Aircraft Company (Los Angeles, CA) 5003179 - 1991;

[9] Mcfarlane, R. A. (Thousand Oaks, CA) "Infrared-to-visible upconversion display system and method operable at room temperature" Hughes Aircraft Company (Los Angeles, CA) 5245623 - 1993;

[10] Downing, E. A. (Palo Alto, CA). Method and system for threedimensional display of information based on two-photon upconversion 3D Technology Laboratories, Inc. (Mountain, CA) 5914807 - 1999;

[11] Kobayashi, R. A. Produção de Vidro de Telureto Dopados com Itérbio para Aplicação na Região do Infravermelho, Trabalho de conclusão de curso FATEC-SP. (2005);

[12] de Araújo C., et al. J. Appl. Phys. 99, (2006) 123522 ;

[13] Almeida, R. P., et al. Optics Communications. 281 (2008) 108;

[14] Lui, G. ; et al. J. Colloid Interface Sci. 278 (2004) 133

[15] Hirai, T. ; et al. J. Colloid Interface Sci. 253 (2002) 62;

[16] Kassab, L. R. P. et al. J. Phys. D, Appl. Phys. 102 (2007) 103515; 
[17] Kaminskii, A. A. Laser Crystals, 2nd ed. Springer, (1990) Berlin;

[18] Malinowski, M. ; et al., Phys. Status Solidi A 140 (1993) K49;

[19] de Araújo, L.E.E., et al. Phys. Ver. B, 50, (1994) 16219;

[20] Kassab, L. R. P. et al. J. Phys. D, Appl. Phys. 40 (2007) 4073-4077;

[21] Lima, S. M, et al. J. Non-Cryst. Solids. 284 (2001) 274-281;

[22] Inoue, S. et al. J. Non-Cryst. Solids. 324 (2003)133;

[23] Pilla, V. et al. J. Non-Cryst.Solids. 352 (2006) 3598;

[24] Kassab, L.R.P. et al. Optics Communications. 20 (2008) 01-05;

[25] N.Perelomova, M. Taguieva. Problemas de Cristalofísica. Ed. Mir, (1975). Moscou. Rússia;

[26] Kassab L.R.P. et al., Opt. Commun. 269 (2007) 148;

[27] Zhang H. et al., Optics Express. 14 (2006) 4826;

[28] Liu, J. et all, Optics Communications. 253 (2005) 315;

[29] Assumpção, T. A. A, Desenvolvimento de técnica para nucleação de nanopartículas metálicas em vidros de germanato dopados com íons de Túlio para aplicações em dispositivos fotônicos. Dissertação de Mestrado. Escola Politécnica da Universidade de São Paulo. São Paulo, 2010;

[30] Kilk, P. G., Brongersma, M. L., A. Polman, Strong exciton-erbium coupling in Si nanocrystal-doped SiO2, Appl. Phys. Lett., 76, 17, 2000;

[31] Shiqing, X.; Wei A.; Degang D.; et al. Journal of Rare Earths, 26, (2008) 895;

[32] Maia, S. B. O vidro e sua fabricação. Interciências, Rio de Janeiro, 2003;

[33] Cacho, V. D. Caracterização de materiais vítreos de germanato dopados com itérbio para o uso em circuitos optoeletrônicos. Dissertação de Mestrado Escola Politécnica da Universidade de São Paulo. São Paulo, 2005;

[34] Akerman, M.. Natureza, Estrutura e Propriedades do Vidro. CETEVSaint Gobain-VidrosBrasil em www.saint-gobain-etev.com.br/ovidro/vidro.pdf acessado em 01/2008;

[35] Gonzalez, R. E. R. Guias de onda por troca iônica em vidros de teluritos dopados com érbio. Dissertação de Mestrado, Unicamp, Campinas - 2003;

[36] Bendow, B.; Chen S. Y.; Stanford P. Y. Physical Review B, 8, 1679 (1973). 
[37] Immanuil, L.; Fabelinkii, L. Molecular Scattering of Light, Plenum Press, New York (1968).

[38] Yano, T.; Fukomoto, A.; Watanabe, A. Tellurite glass: A new acoustooptic material, J. Appl. Phys. 42, 3674 (1971).

[39] Reisfeld, R.; Eckestein, Y. Solid State Commun, 13, 741 (1973);

[40] Heckroodt, R.O.; Res, M. A. Erbium tellurite glasses. Phys. Chem. of Glasses, 17, 217 (1976);

[41] Sakida, S.; Hayakawa, S.; Yoko, T. Journal of Non-Crystalline Solids, 243, (1999), pp. 1-25.

[42] Neov, S.; Kozhukharov, V.; Gerasimova, I.; Krezhov, E.et all. J. Phys. C: Sol. Stat. Phys., 12, 2475 (1979).

[43] Chillce, E. F. Fibras ópticas de vidro de teluritos de tungstênio para amplificação de grande largura de banda. Tese de Doutorado - Unicamp, Campinas, 2005.

[44] QU, S.; Zhao, C.; Jiang, X.; Fang, G.; et al., Chem. Phys. Letters, 352 (2003).

[45] Idalgo, E.; Araújo, E. B. Propriedades estruturais e térmicas de vidros teluretos $20 \mathrm{Li}_{2} \mathrm{O}-80 \mathrm{TeO}_{2}$, Cerâmica, 53, 325 (2007).

[46] Cassanjes, F. C. Vidros à base de telúrio para dispositivos fotônicos, Dissertação de doutorado - Instituto de Química de Araraquara, UNESP, Araraquara, 2003.

[47] Shen, X.; et al. Physics B, 381, 219 (2006).

[48] Krakau, K. A. Opticomechanical Industry, URSS, 4, 15 (1939).

[49] Polukhin, V. N. Proceeding Tech.Cong., Vavilov State Optical Institute, 120, (1936).

[50] Poluklin, V. N. ; Modestov O. V. Inorg. Mat., 10, 757 (1974);

[51] Nunes, J. J. Vidros. CENATEC SENAI "Mario Amato", Núcleo de Técnico em Cerâmica, 1998;

[52] Weber, M. J. Handbook on laser science and technology. Boca Raton: CRC Press, 1982;

[53] Oliveira, S. L. Investigação espectroscópicas de sistemas vítreos dopados com $\mathrm{Tm}^{3+}, \mathrm{Ho}^{3+}$, e $\mathrm{Nd}^{3+}$ - Dissertação de mestrado - instituto de Física de São Carlos. São Carlos, 2004. 
[54] Jagosich, F. H. Estudo espectroscópico para desenvolvimento dos meios laser ativos do $\mathrm{Ho}^{3+}$ no YLF que operam na região de 3 microns - Dissertação de mestrado - Instituto de Pesquisa Energéticas e Nucleares. São Paulo, 2000. [55] Koechner, W. Solid State Engeneering, Spring-Verlag, Berlim, 1996;

[56] Araújo, C. B. ; et al, Appl. Phys. Lett., 68, 602, 1996.

[57] Emsley, J. Nature's building blocks: an A-Z guide to the elements (Oxford University Press, Nova York, 2001).

[58] Rapaport, A. ; et al., Optics Express, 12 (2004) 5215.

[59] Dulick, M.; et al., Journal of Luminescence, 48 (1991) 517.

[60] Matos, P. S. F.; Wetter, N. U. Investigação de Lasers de Fluoreto dopados com túlio e bombeados por diodolaser. Tese de doutorado. Instituto de Pesquisas Energéticas e Nucleares, Universidade de São Paulo. São Paulo, 2006.

[61] Fukumoto, M. E. Caracterização espectroscópica de vidros de óxidos de metais pesados dopados com terras raras visando aplicações em circuitos optoeletrônicos, Dissertação de Mestrado - EPUSP, São Paulo, 2003.

[62] Feng, L. ; et al. Optical properties of $\mathrm{Er}^{3+-}$ singly doped and $\mathrm{Er}^{3+} / \mathrm{Yb}^{3+}$ codoped novel oxyfluoride glasses, Journal of Non-Crytalline Solids, 352, 2090, 2006.

[63] Liua, K.; Punb, E. Y. B. Comparative studies of spectroscopic properties in $\mathrm{Er}^{3+}-\mathrm{Yb}^{3+}$ codoped phosphate glasses, Journal of Alloys and Compounds, 2008.

[64] Shiqing, X.; Hongping, M.; Dawei, F.; et al. Mat. Lett. 59 (2005) 3066.

[65] Bomfim Jr, F. A. Produção e Caracterização de Vidros de Óxidos de Metais Pesados Dopados com Terras-Raras e Nanopartículas Metálicas. Dissertação de Mestrado - IPEN-SP, São Paulo, 2008.

[66] Silva, D. M., Kassab, L. R. P.;Luthi S. R. ; Araújo C. B. ; et al, Appl. Phys. Lett. 90, 081913 (2007).

[67] Jain, P.K.; Hang, X.; El-Saved, I. H.; et al. Plasmonics 2:107-118, 2007.

[68] Pitarke, J. M.; Silkin V. M.; Chulkov, E. V.; Echenique, P. M. Rep. Prog. Phys. 70, (2007) 1-87.

[69] Link, S.; El-Sayed, M. A. Annu. Rev. Phys. Chem. (2003). 54:331-66.

[70] Hutter, E.; Fendler, J. H. Adv. Matter, 16, 1685, 2004. 
[71] Silva, D. M. Produção e Caracterização de Materiais Vítreos de Germanato com Nanopartículas Metálicas e Íons de Érbio para Aplicações em Fotônica. Dissertação de Mestrado. Escola Politécnica da Universidade de São Paulo. São Paulo, 2007.

[72] http://scienceblogs.com.br/100nexos/2009/02/magenta-e-todas-asoutras-cores-da-massa-cinzenta.php - acessado em 02/2011.

[73] http://webinsider.uol.com.br/2009/06/03/gama-de-cores-nos-displaysmodernos - Acessado em 02/2011.

[74] Veenis, W. Bril. A. Vacuum ultraviolet excitation and quantum efficiencies of luminescence powders, mainly rare-earth activated borates. Philips J. Res. 33, 124, 1978.

[75] Rack. P.D. Naman, A. Holloway, P.H.,Sun- S.S., Tuenge, R.T. Materials used in electroluminescent display. MRS Bull, 21, 49, 1996.

[76] Amâncio, C. T., Produção e Caracterização de Amostras Vítreas e Fibras Ópticas de Telureto Codopadas com ĺons de Terras Raras. Trabalho de conclusão de curso - MPCE - FATEC-SP, São Paulo, 2008. 